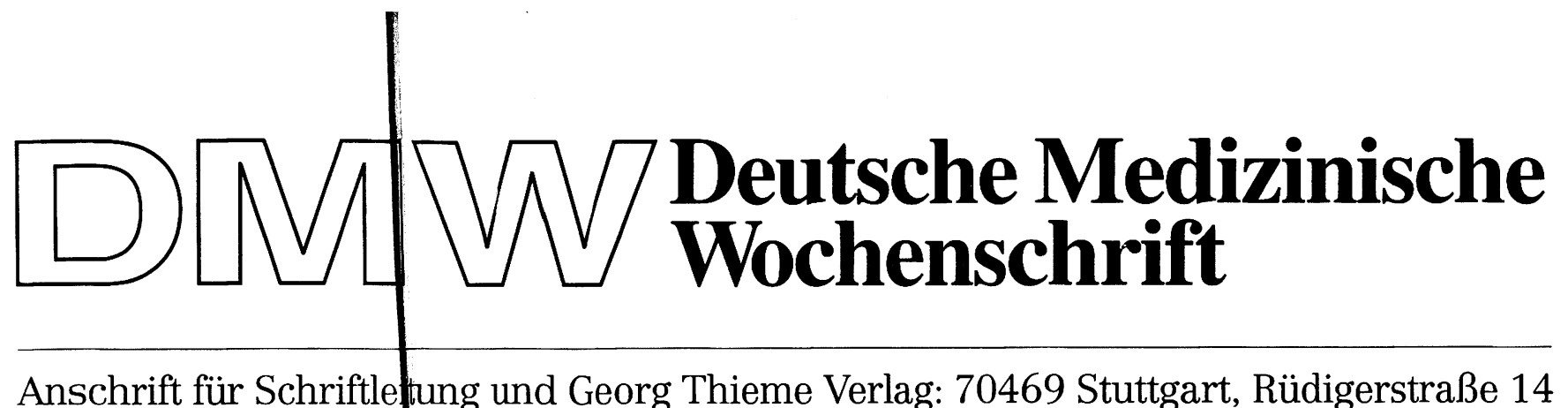

Anschrift für Schriftlefung und Georg Thieme Verlag: 70469 Stuttgart, Rüdigerstraße 14

$$
\begin{gathered}
4 \text { aled } 6 z^{2} 92 \\
119 \\
1954 \\
943-1808
\end{gathered}
$$

Schriftleitung:

Dr. med. habil. R. Apgustin stuttgart Prof. Dr. J. F. Riemann Ludwigshafen Prof. Dr. M. Rothmund Marburg Prof. Dr. P. C. Scriba München
Prof. Dr. W. Siegenthaler zürich Prof. Dr. J. R. Siewert München Prof. Dr. A. Sturm Herne/Bochum

Register fürden 119. Jahrgang

2. Halbjahr 1994 Hefte 27-51/52

Georg Thiem Verlag Stuttgart $\cdot$ New York 


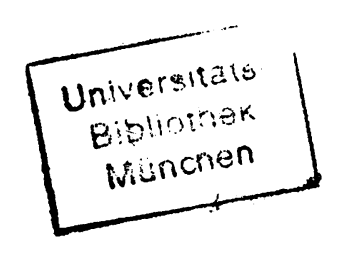

Diejenigen Bezeichnungen, die zugleich eingetragene Warenzeichen sind, wurden nicht besonders kenntlich gemacht. l:s kann also aus der Bezeichnung einer Ware mit dem für diese eingetragenen Warenzeichen nicht geschlossen werden, daß die Bezeichnung ein freier Warenname ist. Ebensowenig ist zu entnehmen, ob Patente oder Gebrauchsmuster vorliegen.

Alle Rechte, insbesondere das Recht der Vervielfältigung und Verbreitung sowie der Übersetzung, vorbehalten. Kein Teil des Werkes darf in irgendeiner Form (durch Photokopie, Mikrofilm oder ein anderes Verfahren) ohne schriftliche Genehmigung des Verlages reproduziert uder unter Verwendung elektronischer Systeme verarbeitet, vervielfältigt oder verbreitet werden.

Some of the product names, patents and registered designs referred to are in fact registered trademarks or proprietary names even though specific reference to this fact is not always made in the text. Therefore, the appearance of a name without designation as proprietary is not to be cinstrued as a representation by the publisher that it is in the public domain.

All rights, including the rights of publication, distribution and sales, as well as the right to translation, are reserved. No part of this work covered by the copyrights hereon may be reproduced or copied in any form or by any means - graphic, electronic or mechanical including plistocopying, recording, taping, or information and retrieval systems - without written permission of the publisher. 


\section{A}

Aborte; rezidivierende

Autoimmune Progesterondermatitis

\section{Abszeß}

Amöbenabszeß der Leber mit hepatobronchialer Fistel

Lumbale Spondylodiszitis durch Salmonella enteritidis

Primär kutane Nocardia-farci- 1276 kas nica-Infektion nach Herztransplantation

Primär kutane Nocardia-farcinica-Infektion nach Herztransplantation (Berichtigung)

\section{Acetylcholin}

Gesteigerte vaskuläre Sensitivität auf Nitroglycerin bei Patienten mit Hypercholesterinämie und peripherer Endotheldysfunktion

\section{Aciclovir}

Wirksamkeit von Aciclovir und Glucocorticoiden in der Behandlung des Herpes zoster und postzosterischer Neuralgien

\section{Acidose}

Aktuelle Möglichkeiten des kontinenten Harnblasenersatzes

Ventilatorische Insuffizienz und hyperkapnische Kompensation infolge chronisch belasteter »Atempumpe«. Physiologie, Pathophysiologie und Therapie

\section{Adaptation}

Pathophysiologie der Myokarddurchblutung. Teil I Adaptation an Myokardischämie (»hibernating «Myokard)

\section{Adenom}

Farbdopplersonographisch gesteuerte perkutane Alkoholinstillation zur Therapie der funktionellen Schilddrüsenautonomie Kanalikuläres Adenom

1258 fr

1383 kas

$1623 \mathrm{mq}$

\section{Adenosintriphosphat}

Adenosintriphosphat (ATP) bei supraventrikulären Tachykardien im Neugeborenen- und Säuglingsalter

\section{Adipositas}

1034 kas Elterliche Vernachlässigung in der Kindheit und Adipositas im frühen Erwachsenenalter

Adnexitis

Aktuelle Epidemiologie, Diagnostik und Therapie der Urogenitaltuberkulose

$1568 \quad$ AFP

(siehe Alpha-1-Fetoprotein)

Afterloading-Bestrahlung

Diagnostik und Therapie des Analkarzinoms

1065 or Agranulozytose

Therapie einer Clozapin-induzierten Agranulozytose mit granulozytenkolonie-stimulierendem Faktor

\section{Ajmalin-Test}

$1526 \mathrm{~km}$ Klinische Bedeutung des Ajmalin-Tests in der nichtinvasiven Diagnostik bei Wolff-Parkinson-WhiteSyndrom

\section{Albendazol}

1327 üb Gnathostomiasis nach Aufenthalt in Thailand

1209 üb

\section{Aldosteron-System}

Renin-Angiotensin-System und Blutdruckregulation

Alkohol

Geschäftsfähigkeit bei hohem Blutalkoholspiegel

\section{Alkoholinstillation}

Farbdopplersonographisch gesteuerte perkutane Alkoholinstillation zur Therapie der funktionellen Schilddrüsenautonomie

\section{Allergie; gegen}

\section{Hymenopterengift}

1607 or Besteht bei einer InsektengiftAllergie immer die Indikation für eine Hyposensibilisierung?

\section{Alloimmunthrombozyto-} penie; neonatale

Neonatale Alloimmunthrombozytopenie

$1351 \mathrm{kas}$

\section{Allopurinol}

Allopurinol

1045

as

All-trans-Retinsäure

Komplette Remission bei aku-

1143 or ter Promyelozytenleukämie. Vorteile von alltrans-Retinsäure im Vergleich mit konventioneller Chemotherapie

\section{Alpha-1-Fetoprotein}

Indikation zur Amniozentese

1121 adt bei über 35jährigen Schwangeren aufgrund von Serummarkern

\section{1-alpha-Hydroxylase}

Vitamin D und Osteoporose. Pathogenese - Therapie

1479 üb

1701 adt Amenorrhoe; primäre

Diagnose eines UllrichTurner-Syndroms im Rentengutachten

\section{7 kas Amniozentese}

Indikation zur Amniozentese bei über 35jährigen Schwangeren aufgrund von Serummarkern

985 or

\section{Amöbiasis}

Amöbenabszeß der Leber mit hepatobronchialer Fistel

\section{ANA}

1618 kas

(siehe Antikörper; Antinukleäre)

\section{Analkarzinom}

965 pp Diagnostik und Therapie des Analkarzinoms

\section{Anämie}

1602 fr Autoimmunprozesse als paraneoplastische Manifestationen bei familiärem Mammakarzinom

1607 or

Eisenmangelanämie

Hämolytische Krise mit Leberversagen als Erstmanifestation eines Morbus Wilson

Schwere Panzytopenie im hohen Lebensalter nach

1093 la zwölfmonatiger ACE-Hemmer-Therapie

Ancylostoma brasiliense

Larva migrans cutanea (»creeping eruption«)

\footnotetext{
* Adjektive, die gegen die Schreibregel mit großen Anfangsbuchstaben geschrieben wurden, sind Bestandteil von Abkürzungen oder Akronymen.
}

\section{Rubrikenschlüssel}

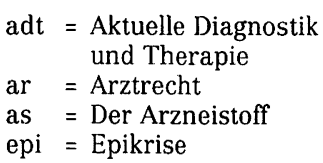

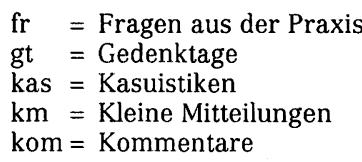

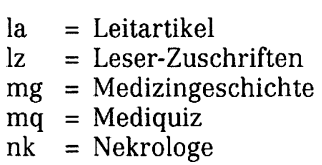

\author{
or $\quad=$ Originalien \\ pp = Prinzip \& Perspektive \\ stp $=$ Standpunkte \\ üb = Übersichten
}




\section{Aneurysma}

Aneurysmen beider Arteriae iliacae communes

Klinische Bedeutung und echokardiographischer Nachweis von Aneurysmen des Vorhofseptums

Subarachnoidalblutung

Zerebraler ischämischer Insult. Wertigkeit der transösophagealen Echokardiographie in der Diagnostik kardialer Emboliequellen

\section{Angiitis}

(siehe Vaskulitis)

Angina abdominalis

Chronische mesenteriale Ischämie

\section{Angina pectoris}

Angina pectoris und normales Koronarangiogramm bei arterieller Hypertonie und linksventrikulärer Hypertrophie

Die klinische Bedeutung der Konzentrationsbestimmung der Troponine

Zentralnervöse Vermittlung der Angina pectoris

\section{Angiodysplasie}

Endoskopische intraoperative Diagnostik einer blutenden Angiodysplasie im Jejunum beim Heyde-Syndrom

\section{Angiokeratoma corporis \\ diffusum}

Angiokeratoma corporis diffusum

\section{Angiologie}

Pathologie der Pulmonalarterien bei Lungentumoren

\section{Angioplastie}

Akuter Koronargefäßverschluß nach elektiver perkutaner transluminaler Koronarangioplastie. Inzidenz und Therapie bei 5000 konsekutiven Patienten

Retrograde Katheter-Rekanalisation langstreckiger Verschlüsse der Arteria femoralis superficialis

Wiedereröffnung chronischer Koronararterienverschlüsse: Welche Faktoren beeinflussen den Erfolg?

\section{Angiotensin-Converting-}

\section{Enzym-Hemmer}

Angiotensin-ConvertingEnzym-Hemmer bei der Behandlung der diabetischen Nephropathie

Angiotensin-ConvertingEnzym-Hemmer nach Herzinfarkt

GISSI III: Wirkung von Lisinopril und transdermaler Applikation von Nitroglycerin nach akutem Herzinfarkt
Schwere Panzytopenie im hohen Lebensalter nach zwölfmonatiger ACE-Hemmer-Therapie

1205 adt

Angst

Erfassung von Angst und Depressivität in der medizi-

$1322 \mathrm{mq}$

1585 adt nischen Routineversorgung

\section{Anosmie}

Kallmann-Syndrom. Pathophysiologie und Klinik

\section{Antacida}

Therapic der gastroösophagealen Refluxkrankheit

\section{Anthelmintika}

979 or Gnathostomiasis nach Aufenthalt in Thailand

\section{Antiarrhythmika}

1175 üb Adenosintriphosphat (ATP) bei supraventrikulären Tachykardien im Neugeborenen-und Säuglingsalter Sotalol

1013 la Antibasalmembran-Antikörper

$1604 \mathrm{~km}$

Einseitige diffuse Lungenbeteiligung bei Vaskulitis mit Anti-Neutrophilen-Zytoplasma-Antikörpern sowie Antikörpern gegen glomerulär: Basalmembranen

\section{Anticholinergika}

Enzephalopathie nach Intoxikation mit einem Anticholinergikum

$1281 \mathrm{mq}$

Antigen; Prostataspezifisches

Prostatakarzinom

\section{Antikoagulation}

1415

Einsal: von niedermolekularem lleparin zur Antikoagulation in der Schwangerschaft

1023 or Ist die »International Normalized Ratio (INR) « in der klinischen Praxis unentbehrlich?

Operationsindikation bei asymptomatischer hoch-

948 or gradiger Aortenklappenstenose

Orale Kontrazeption bei Protein-C-Mangel

1766 or Rupturgefahr bei Nierenzysten

Zerebraler ischämischer Insult. Wertigkeit der transösophagealen Echokardiographie in der Diagnostik kardialer Emboliequellen

\section{8 km Antikörper; Antinukleäre}

Diagnostik und Bedeutung von antinukleären Antikör-

1448 fr pern

\section{Antimonpräparate}

Therapie kutaner und mukokutaner Leishmaniosen
1029 kas Anti-Neutrophilen-Zytoplasma-Antikörper

Churg-Strauss-Syndrom oder chronische eosinophile Pneumonie?

1283 adt Einseitige diffuse Lungenbeteiligung bei Vaskulitis mit Anti-Neutrophilen-Zytoplasma-Antikörpern sowie Antikörpern gegen glome-

1436 üb ruläre Basalmembranen

\section{Antioxidantien}

$1473 \mathrm{adt}$

Antioxidantien

\section{Antiöstrogen}

Östrogenantagonisten und Thromboseprophylaxe

1618 kas

\section{Antistreptolysin}

Persistierende Antistreptolysin-Titer

1351 kas Antituberkulotika

Aktuelle Epidemiologie, Diagnostik und Therapie der Urogenitaltuberkulose

1477 as Unverträglichkeit der Tuberkulosetherapie bei AIDS

1071 kas Aortendissektion

Akute Aortendissektion. Diagnose durch transthorakale Echokardiographie

\section{Aortenisthmusstenose}

Postduktale Aortenisthmusstenose (Coarctatio aortae)

$1803 \mathrm{lz}$ Aortenklappenstenose Operationsindikation bei asymptomatischer hochgradiger Aortenklappenstenose

1054 lz APC

(siehe Protein C; aktiviertes)

1497 kas APC-Resistenz

Resistenz gegenüber aktivier- $1680 \mathrm{~km}$ tem Protein C

1529 la Apnoe-Index

Morbidität und Letalität bei Schlafapnoe und nächtlichen Bradyarrhythmien

1630 üb Appendizitis

Operation bei Verdacht auf Appendizitis und Perforation

\section{0 fr Arbeitsmedizin}

1486 fr Akzidentelle Nadelstichverlet- 1563 fr

zung bei medizinischem Pflegepersonal

\section{$1585 \mathrm{adt}$ Arcus lipoides corneae}

Fischaugenkrankheit

\section{Areflexie}

Intensivtherapie des Guillain- 1248 üb Barré-Syndroms

\section{$1137 \quad \mathrm{lz}$ Arginin}

Gesteigerte vaskuläre Sensitivität auf Nitroglycerin bei Patienten mit Hypercholesterinämie und peripherer Endotheldysfunktion
1393 kas

1071 kas

$1135 \mathrm{fr}$

1182 fr

1099 fr

1121 adt

1728 kas

$1297 \quad$ lz

$1548 \mathrm{mq}$

1630 üb

1187 or

$1059 \mathrm{~km}$
$1565 \mathrm{lz}$

1065 or 


\section{Arteria femoralis super-} ficialis

Retrograde Katheter-Rekanalisation langstreckiger Verschlüsse der Arteria femoralis superficialis

\section{Arteriitis}

Takayasu-Arteriitis

\section{Arteriosklerose}

Aneurysmen beider Arteriae iliacae communes

Antioxidantien

Carotiswandveränderungen bei jungen Typ-I-Diabetikern. Ultraschalldiagnostik der frühen Arteriosklerose

Chronische mesenteriale Ischämie

Gesteigerte vaskuläre Sensitivität auf Nitroglycerin bei Patienten mit Hypercholesterinämie und peripherer Endotheldysfunktion

Retrograde Katheter-Rekanalisation langstreckiger Verschlüsse der Arteria femoralis superficialis

\section{Arthroskopie}

Baker-Zyste bei osteoartikulärer Tuberkulose des Kniegelenks

Baker-Zyste bei osteoartikulärer Tuberkulose des Kniegelenks (Berichtigung)

\section{Arztrecht}

Beschwerden gegenüber der Kassenärztlichen Vereinigung wegen unberechtigter Krankschreibung. Urteil des OLG Frankfurt a.M. vom 16.12. 1993

Durchführung von Routineoperationen ohne Beteiligung eines Facharztes. Urteil des OLG Düsseldorf vom 7.10.1993

Führen der Zusätze "Schmerztherapie « und "Schmerzsprechstunde« auf dem Praxisschild. Beschluß des Bundesverfassungsgerichtes vom 15.12.1993

Liquidationsrecht des Chefarztes bei vorhersehbarer Verhinderung an der Leistungserbringung. Urteil des OLG Hamm vom 4.5.1994

Rechtsprobleme bei der Forschung in Notfall-und Intensivmedizin

Zu den Sorgfaltspflichten des auf Überweisung tätigen Arztes. Urteil des Bundesgerichtshofs vom 5.10.1993

\section{Asbest}

948 or $\begin{aligned} & \text { Asbest-induzierte Erkrankun } \\ & \text { gen der Lunge und Pleura }\end{aligned}$

Ascorbinsäure

(siehe Vitamin C)

\section{Aspergillose; pulmonale}

1801 fr Pulmonale Aspergillose

Asterixis

$1082 \mathrm{mq}$ Medikamentös ausgelöste Asterixis

1135 fr Asthma bronchiale

1225 or Asthma bronchiale

Churg-Strauss-Syndrom oder chronische eosinophile Pneumonie?

979 or Regelmäßige Asthma-Therapie mit B-Sympathikomime-

1065 or tika

\section{Asystolie}

Therapie bradykarder und tachykarder Rhythmusstö-

948 or rungen durch transösophageale Elektrostimulation des Herzens

\section{Aszites}

Diagnostik des Aszites

Therapie des Aszites bei Lebererkrankungen

1806

\section{Ateminsuffizienz}

»Bronchiolitis obliterans organizing pneumonia « mit akuter respiratorischer Insuffizienz

1712 ar Syringomyelie als seltene Ursache einer beatmungspflichtigen respiratorischen Insuffizienz

Ventilatorische Insuffizienz und hyperkapnische Kom-

1255 ar pensation infolge chronisch belasteter »Atempumpe«. Physiologie, Pathophysiologie und Therapie

1561 ar Atmungsstörungen; schlafbezogene

Morbidität und Letalität bei Schlafapnoe und nächtlichen Bradyarrhythmien

\section{ATP}

1522 ar (siehe Adenosintriphosphat)

\section{Augenspiegel}

Hermann von Helmholtz (1821-1894) - Militärarzt, Sinnesphysiologe und »Reichskanzler der deut1796 ar schen Physik«. Zum 100. Todestag des universalen Arztes und Naturforschers
Autoaggression

1603 lz Akutes myoglobinurisches Nierenversagen als Folge von autoaggressivem Verhalten bei Oligophrenie

Autoimmunkrankheiten

Autoimmune Progesterondermatitis

1716

Autoimmunprozesse als paraneoplastische Manifestationen bei familiärem Mammakarzinom

Fibromyalgie-Syndrom

974 fr

$1565 \quad \mathrm{lz}$

Intensivtherapie des GuillainBarré-Syndroms

Sekundäre Neoplasien nach Immunsuppression

$1020 \mathrm{~km}$ Automutilation

(siehe Selbstverstümmelung)

Autonomie; disseminierte

1405 üb (siehe Hyperthyreose)

\section{Autonomie; fokale}

Farbdopplersonographisch gesteuerte perkutane Alkoholinstillation zur Therapie der funktionellen

1509 adt Schilddrüsenautonomie

1549 adt

1312 kas

\section{Autoperfusionskatheter}

Langzeitdilatation bei erfolgloser perkutaner transluminaler Koronarangioplastie

\section{AZT}

(siehe Zidovudin)

1771 kas

\section{Azzopardi-Phänomen}

Das extrapulmonale kleinzellige Karzinom - eine Rarität?

\section{9 üb Äquivalenz}

Problematik des Äquivalenzbegriffes bei der Therapie mit Glucocorticoiden. Ein Vergleich der klinischen Pharmakokinetik und Pharmakodynamik von Prednisolon und Methylprednisolon

\section{7 or}

\section{B}

\section{Bactec-System}

Aktuelle Epidemiologie, Diagnostik und Therapie der

$1215 \mathrm{mg}$ Urogenitaltuberkulose

\section{Baker-Zysten}

Baker-Zyste

Baker-Zyste bei osteoartikulä- 1579 kas rer Tuberkulose des Kniegelenks

Baker-Zyste bei osteoartikulä- 1806 rer Tuberkulose des Kniegelenks (Berichtigung)
$1040 \mathrm{mq}$

994 kas

1258 fr

1194 kas

1639 lz

1248 üb

1747 üb

1607 or

1591 üb

1671 üb

1121 adt

\section{Rubrikenschlüssel}

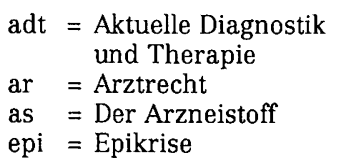

$\begin{array}{lll}\mathrm{fr} & =\text { Fragen aus der Praxis } & \mathrm{la}=\text { Leitartikel } \\ \mathrm{gt}=\text { Gedenktage } & \mathrm{lz}=\text { Leser-Zuschriften } \\ \mathrm{kas}=\text { Kasuistiken } & \mathrm{mg}=\text { Medizingeschichte } \\ \mathrm{km}=\text { Kleine Mitteilungen } & \mathrm{mq}=\text { Mediquiz } \\ \mathrm{km}=\text { Kommentare } & \mathrm{nk}=\text { Nekrologe }\end{array}$

or $=$ Originalien

pp $=$ Prinzip \& Perspektive

stp = Standpunkte

$\ddot{\mathrm{u} b}=$ Übersichten 
BAL

(siehe Lavage; bronchoalveoläre)

\section{Balkenmangel}

Agenesie des Corpus callosum (Balkenmangel)

\section{Ballondilatation;} von Gefäßen

(siehe Angioplastie)

\section{Ballondilatation; von Darm-} stenosen

Endoskopische Ballondilatation symptomatischer Strikturen bei Morbus Crohn

Ballonkatheter; perfundierbarer

Langzeitdilatation bei erfolgloser perkutaner transluminaler Koronarangioplastie

\section{Batten-Krankheit}

Leere Vakuolen im Zytoplasma der Lymphozyten bei juveniler neuronaler Ceroidlipofuscinose (Spielmeyer-Vogt-Krankheit, Batten-Krankheit)

\section{Beatmung; künstliche}

Ventilatorische Insuffizienz und hyperkapnische Kompensation infolge chronisch belasteter »Atempumpe«. Physiologie, Pathophysiologie und Therapie

\section{Belastungs-Elektrokardio-} graphie

Klinische und koronarangiographische Befunde bei Frauen mit Thoraxschmerzen

\section{Berichtigungen}

Baker-Zyste bei osteoartikulärer Tuberkulose des Kniegelenks

Hypocalcämische Kardiomyopathie als Ursache einer schweren Linksherzinsuffizienz

Primär kutane Nocardia-farcinica-Infektion nach Herztransplantation

\section{Bernstein-Test}

Diagnostik der gastroösophagealen Refluxkrankheit

\section{Berufskrankheiten}

(siehe Arbeitsmedizin)

\section{Beta-HCG}

(siehe Choriongonadotropin; humanes)

\section{Beta-Rezeptorenblocker}

Beta-Rezeptorenblocker bei dilatativer Kardiomyopathie

Beta-Rezeptorenblocker als Notfallmaßnahme bei akutem Herzinfarkt?

Sicca-Symptomatik unter systemischer Therapie mit Beta-Rezeptorenblockern
Sotalol

Beta-Sympathikomimetika

Regelmäßige Asthma-Therapie mit B-Sympathikomime$1738 \mathrm{mq}$ tika

\section{Bilharziose}

Schistosomiasis und Siegelringzellkarzinom der Ileozökalklappe

\section{Bioprothesen}

(siehe Herzklappenprothesen)

1377 or Biopsie-Urease-Test

Modifizierter ${ }^{13} \mathrm{C}$-Atemtest in der Diagnostik der Helicobacter-pylori-Besiedlung der gastralen Mucosa

1458 or Björk-Shiley-Klappe (siehe Herzklappenprothesen)

\section{Bleivergiftung}

Bleiintoxikation durch Mennige in Paprikapulver

\section{Blutdruckkrisen}

Blutdruckregulation

Renin-Angiotensin-System und Blutdruckregulation

1209 üb Blutentnahme; Techniken

Hautdesinfektion vor der Blutentnahme

\section{Blutprodukte}

Rationale Substitution mit Blut- und Blutbestandteilkonserven

\section{Blutspende}

$1337 \mathrm{~km}$

"Look-back «-Studie der DRKBlutspendedienste

Universal-Spenderblut

Blutstillung; endoskopische

Endoskopische Therapie der Ösophagusvarizenblutung

\section{Bluttransfusionen}

(siche Hämotherapie)

\section{Blutung}

Neonatale Alloimmunthrombozytopenie

Blutung; gastrointestinale

Endoskopische intraoperative Diagnostik einer blutenden Angiodysplasie im Jejunum beim Heyde-Syndrom

Exulceratio simplex Dieulafoy Lipom mit zentraler Ulzeration und Blutung

Risikofaktoren für gastrointestinale Blutungen bei Patienten der Intensivstation

$1604 \mathrm{~km}$

\section{Blutungsneigung}

(siehe Diathese; hämorrhagi-

\section{5 fr sche)}

Blutzuckerselbstkontrolle

$1783 \mathrm{adt}$ Diabetikern (siehe Krisen; hypertonische)

1477 as

$1020 \mathrm{~km}$ Borrelia burgdorferi

Nachweis von Borrelia-burgdorferi-DNA in der Gelenkflüssigkeit bei Lyme-Arthri-

$1058 \quad \mathrm{lz}$

\section{Bromocriptin}

Bromocriptin-induzierte Pleuropneumopathie

\section{Bronchialkarzinom}

Asbest-induzierte Erkrankungen der Lunge und Pleura

1569 or Hyponatriämisches Koma

Pathologie der Pulmonalarterien bei Lungentumoren

\section{Bronchiektasen}

Zystische Fibrose

\section{Bronchiolitis Obliterans}

$1756 \quad \mathrm{lz}$ Organizing Pneumonia

»Bronchiolitis obliterans organizing pneumonia« mit akuter respiratorischer Insuffizienz

\section{Bronchitis; eosinophile}

965 pp Churg-Strauss-Syndrom oder chronische eosinophile Pneumonie?

1182 fr Bypass-Operation; aorto-

\section{koronare}

Akuter Koronargefäßverschluß nach elektiver perkutaner transluminaler Koronarangioplastie. Inzidenz und Therapie bei 5000 konsekutiven Patienten

$1019 \quad \mathrm{lz}$

1443 kom

\section{Calciumbilanz}

Vitamin D und Osteoporose. Pathogenese - Therapie

\section{Calciumstoffwechsel}

Einfluß einer niedrigdosierten Hydrochlorothiazidtherapie auf den Knochen-

1512 üb mineralgehalt des axialen und peripheren Skeletts

$1603 \mathrm{lz}$

\section{Carotiswandveränderun-} gen

Carotiswandveränderungen bei jungen Typ-I-Diabetikern. Ultraschalldiagnostik der frühen Arteriosklerose

$1699 \mathrm{mq}$

$1547 \mathrm{mq}$

$1337 \mathrm{~km}$

\section{CD4-Lymphozytopenie;} idiopathische

Idiopathische CD4-Lymphozytopenie mit letaler Salmonella-typhimurium-Sepsis

\section{Ceroidlipofuscidose}

Leere Vakuolen im Zytoplasma der Lymphozyten bei juveniler neuronaler Ceroidlipofuscinose (SpielAmbulante Versorgung von 1056 lz meyer-Vogt-Krankheit,
$1451 \mathrm{~km}$

1543 kas

$1603 \quad \mathrm{lz}$

$1139 \quad$ I7

1415 or

$1259 \quad \mathrm{lz}$

1312 kas

$1565 \quad \mathrm{lz}$

1023 or

\section{5 or}




\section{CFS}

(siehe Müdigkeitssyndrom; chronisches)

\section{C-13-Harnstoff-Atemtest}

Modifizierter ${ }^{13} \mathrm{C}$-Atemtest in der Diagnostik der Helicobacter-pylori-Besiedlung der gastralen Mucosa

\section{Cheiropathie}

Carotiswandveränderungen bei jungen Typ-I-Diabetikern. Ultraschalldiagnostik der frühen Arteriosklerose

\section{Chelatbildner}

Antioxidantien

\section{Chemotherapie}

Adjuvante Chemotherapie beim operierten Kolonkarzinom

Adjuvante Chemotherapie nach kurativer Gastrektomie bei Magenkarzinom

Adjuvante Therapie bei kolorektalen Karzinomen

Langzeitbeobachtung bei lymphoplasmozytoiden Immunozytomen

\section{Chinin}

Hohe Letalität von Tetanusinfektionen nach intramuskulärer Injektion von Chinin

Chirurgie; minimal-invasive

Derzeitiger Stellenwert der Laparoskopie in der onkologischen Chirurgie

Möglichkeiten der laparoskopischen Therapie innerer Hernien. Darstellung an drei Fällen

\section{Chirurgie; onkologische}

Derzeitiger Stellenwert der Laparoskopie in der onkologischen Chirurgie

\section{Chlamydien}

Enteropathogenität von Chlamydien

Isolierung von Chlamydia pneumoniae bei atypischer Pneumonie

\section{Cholangiokarzinom}

Diffus wachsendes Cholangiokarzinom

Cholangiopathie; HIV-assoziierte

HIV-assoziierte Cholangiopathie

Choledocholithiasis

(siehe Cholelithiasis)

\section{Cholelithiasis}

Kostenvergleich zwischen der laparoskopischen Cholezystektomie und der extrakorporalen Stoßwellenlithotripsie in der Behandlung von Gallenblasensteinen

\section{Cholesterin}

1225 or Cholesterin und koronare Herzkrankheit

Cholesterin-Normalwerte im Kindesalter

Einfluß spontan niedriger und diätetisch-medikamen-

1135 fr tös gesenkter Cholesterinspiegel auf nicht-kardiovaskuläre Todesursachen

1181 fr Fettarme Diät und körperliches Training bei koronarer Herzkrankheit

$1298 \mathrm{~km}$

\section{Cholesterinsteine}

(siehe Cholelithiasis)

1663 adt

$1487 \quad \mathrm{lz}$

Cholezystektomie; laparo-

\section{skopische}

Clip-Wanderung in den Ductus choledochus nach laparoskopischer Cholezystektomie

$1681 \mathrm{~km}$ Kostenvergleich zwischen der laparoskopischen Cholezystektomie und der extrakorporalen Stoßwellenlithotripsie in der Behandlung von Gallenblasensteinen

Laparoskopische Cholezystektomie nach Lebervoroperation

\section{Cholezystolithiasis}

(siehe Cholelithiasis)

Cholinesterase; im Serum

1518 kom Serum-Cholinesterase

Choriongonadotropin;

\section{humanes}

Indikation zur Amniozentese bei über 35jährigen Schwangeren aufgrund von Serummarkern

1462 kas

\section{Chromophore}

(siehe Therapie; photodynamische)

$1282 \mathrm{mq}$

\section{Chromosomenaberrationen}

Diagnose eines UllrichTurner-Syndroms im Rentengutachten

1004 adt bei über 35jährigen Schwangeren aufgrund von Serummarkern

Prader-Labhart-WilliSyndrom

Chromosomentransloka-

\section{2 or tionen}

Komplette Remission bei aku-

ter Promyelozytenleuk-

ämie. Vorteile von alltrans-Retinsäure im Vergleich mit konventioneller Chemotherapie

\section{Chronic Fatigue Syndrome}

1059 km (siehe Müdigkeitssyndrom; chronisches)

\section{1 fr Churg-Strauss-Syndrom}

1597 kom Churg-Strauss-Syndrom oder chronische eosinophile Pneumonie?

\section{Ciclosporin}

Kopfschmerzen unter Ciclosporin-Therapie

$1017 \quad \mathrm{lz}$

Rolle von Endothelin bei den Ciclosporin-Nebenwirkungen Nephrotoxizität und arterielle Hypertonie

\section{Ciguatera}

Ciguatera. Neue Fälle von Fischvergiftung bei deut-

$1506 \mathrm{mq}$ schen Karibik-Urlaubern

\section{Cimino-Shunt}

Generalisiertes IgG-LambdaPlasmozytom und Stenose eines Cimino-Shunts durch plasmazelluläre Infiltration

\section{Cisaprid}

Therapie der gastroösophagealen Refluxkrankheit

1184 lz Clearance; ösophageale

Diagnostik der gastroösophagealen Refluxkrankheit

\section{Clostridium tetani}

Hohe Letalität von Tetanusinfektionen nach intramus-

1016 fr kulärer Injektion von Chinin

\section{Clozapin}

$1413 \mathrm{~km}$

Therapie einer Clozapin-induzierten Agranulozytose mit granulozytenkolonie-stimulierendem Faktor

\section{Coarctatio aortae}

Postduktale Aortenisthmusstenose (Coarctatio aortae)

\section{Coeruloplasmin}

Hämolytische Krise mit Leberversagen als Erstmanifestation eines Morbus Wilson

$1413 \mathrm{~km}$

Colitis granulomatosa

(siehe Morbus Crohn)

\section{Rubrikenschlüssel \\ adt = Aktuelle Diagnostik und Therapie \\ ar $=$ Arztrecht \\ as $=$ Der Arzneistoff \\ epi $=$ Epikrise}

$\mathrm{fr} \quad=$ Fragen aus der Praxis
$\mathrm{gt}=$ Gedenktage
kas $=$ Kasuistiken
$\mathrm{km}=$ Kleine Mitteilungen
kom $=$ Kommentare

la = Leitartikel

$\mathrm{lz}=$ Leser-Zuschriften

$\mathrm{mg}=$ Medizingeschichte

$\mathrm{mq}=$ Mediquiz

$\mathrm{nk}=$ Nekrologe or $=$ Originalien
pp $=$ Prinzip \& Perspektive
stp $=$ Standpunkte
üb $=$ Übersichten 


\section{Colitis ulcerosa}

Endoskopische Diagnostik zur Prävention und Früherkennung des kolorektalen Karzinoms

Nicotinpflaster bei Colitis ulcerosa

\section{Corpus alienum}

(siehe Fremdkörper)

\section{Corpus callosum}

Agenesie des Corpus callosum (Balkenmangel)

\section{CPAP}

(siehe Überdruckbeatmung kontinuierliche nasale)

\section{Cromoglicinsäure}

Asthma bronchiale

\section{CSF}

(siehe Faktoren; koloniestimulierende)

\section{Cutter-Impfstoff}

Indikationen zur Pestimpfung und -chemoprophylaxe

\section{D}

\section{Darier-Zeichen}

Schock und Gerinruungsstörungen bei systemischer Mastozytose

\section{Darmperforation}

Maligne atrophische Papulose 1427 kas

Zeitintervall zwischen Koloskopie mit Biopsie und Kolonkontrasteinlauf

Dauerkatheter; intravasale

Infektionsprophylize bei Dauerverweilkaniilen

\section{Dauertherapie}

Regelmäßige Asthına-Therapie mit $B$-Sympathikornimetika

\section{Defibrillation}

(siehe Kardioversion; elektrische)

Degeneration; hepatolentikuläre

(siehe Morbus Wilson)

\section{Delta-Hepatitis}

Aktueller Stand der Behandlung chronischer Virus hepatitiden mit rekombi nantem Interfer on alpha

\section{Denver-Shunt}

Therapie des Aszites bei Lebererkrankurigen

\section{Depressionen}

Erfassung von Angst und Depressivität in der meclizinischen Routine versorgiung

\section{Dermatitis; atopi:sche}

(siehe Ekzem; erid ogene:s)

\section{Desinfektion}

Hautdesinfektion vor der E3lut- 1182 fr entnahme

\section{Desmosomen}

1001 adt Harnstoff in der Dermatologie

Detubularisation

Aktuelle Möglichkeiten des kontinenten Harnblasenersatzes

Diabetes mellitus

Ambulante Versorgung von Diabetikern

Angiotensin-Converting-

$1738 \mathrm{mq}$ Enzym-Hemmer bei der Behandlung der diabetischen Nephropathie

Insulinpflichtiger Diabetes mellitus nach 58 Jahren

Diabetes mellitus; Typ I

974 fr Carotiswandveränderungen bei jungen Typ-I-Diabetikern. Ultraschalldiagnostik der frühen Arteriosklerose

Intensivierte Behandlung des Diabetes mellitus Typ I und Entwicklung von Spätkomplikationen

Kombinierte Nieren- und Pankreastransplantation beim diabetischen Spätsyndrom

\section{Diagnostik; pränatale}

Diagnostik und Therapie der konnatalen Toxoplasmose

1231 käs Diathese; hämorrhagische

Komplette Remission bei akuterr Promyclozytenleukämie. Vorteile von alltrans-Retinsiiure im Vergeich mit konventioneller Chemotherapie

Neonatale Alloimmunthrombozytopenie

1017 fr Diät

Diärtherapie des Morbus Crohn

Fettarme Diät und körperliches Training bei koronarer Herzkrankheit

DiGeorge-Anomalie

Calcitriol-Gabe in der Sichwangerschaft bei partieller DiGeorge-Anomalie

Digitalisüberdosierung

Reversible Thrombozytope$n$ ie bei Digitoxinüberdosierung

\section{1 add Diphtherie}

Diphtherie-Auffrischimpfung bei Erwachsenen

Diskordanz: atrioventrikuläre

15.49 aid

Kongenital korrigierte Transposition der großen Arterien im Erwachsenenalter.

$12: 83$ aidt Wert nicht-invasiver Untersuchungsmethoden

Diskordanz; ventrikuloarterielle

Kongenital korrigierte Transp.osition der großen Arterien im Erwachsenenalter vert nicht-invasiver Untersuchungsrnethoden intima

Paradoxe zerebrale Embolie

$1183 \mathrm{lz}$

oder Dissektion der Arteria carotis interna?

\section{DNA-Amplifikation}

Klinische Bedeutung der Poly- 1625 adt merase-Kettenreaktion in

$1056 \mathrm{lz}$ der Infektiologie

1298 km DNS-Addukte

Sekundäre Neoplasien nach Immunsuppression

1747 üb

1450 lz Dokumentation; medizinische

ICD-Verschlüsselung und Pflege-Personalregelung

1225 or Doppelmembranfiltration (siehe LDL-Apherese)

\section{Dopplerechokardiographie}

976 km Dopplerechokardiographie bei chronischer rechtsventrikulärer Druckbelastung

1399 adt

\section{Doppler-Index}

Retrograde Katheter-Rekanalisation langstreckiger Verschlüsse der Arteria femoralis superficialis

\section{5 lz Dopplersonographie}

Dopplersonographie peripherer Arterien bei tiefe

1143 or Inspiration zur Überprüfung der sympathischen Gefäßinnervation

Dopplersonographie; farbkodierte

1512 üb Farbdopplersonographisch gesteuerte perkutane Alkoholinstillation zur Therapie der funktionellen

$1140 \mathrm{~km} \quad$ Schilddrüsenautonomie

\section{7 lz Dosisäquivalenz}

Problematik des Äquivalenzbegriffes bei der Therapie mit Glucocorticoiden. Ein Vergleich der klinischen

1776 kas Pharmakokinetik und Pharmakodynamik von Prednisolon und Methylprednisolon

\section{4 kas Down-Syndrom}

(siehe Trisomie 21)

\section{Drogenabusus}

1219 fr

Zerebrale Anfälle unter Doxepin während einer Substitution mit Dihydrocodein

Droopy-shoulder-Syndrom Neurologische Symptomatik, Diagnostik und Therapie des sogenannten $»$ thoracicoutlet-syndrome«

\section{Dual-Energy-X-Ray}

Absorptiometrie

Diagnostik des Osteoporoserisikos. Neue Entwicklungen
1061 or 
Einfluß einer niedrigdosierten Hydrochlorothiazidtherapie auf den Knochenmineralgehalt des axialen und peripheren Skeletts

Dual-Photonenabsorptiometrie

Diagnostik des Osteoporoserisikos. Neue Entwicklungen und »State of the Art« 1994

Duodenaldivertikel; juxtapapilläres

Juxtapapilläres Duodenaldivertikel

Duodenopankreatektomie

Pyloruserhaltung - »a never ending story«

Durchblutungsstörungen; arterielle

Akute Ischämie eines Armes als ungewöhnlicher Ausdruck eines Ergotismus

Maligne atrophische Papulose

Takavasu-Arteriitis

Dysfunktionen; postischämische myokardiale

Pathophysiologie der Myokarddurchblutung. Teil II: Postischämische kontraktile Dysfunktion (»stunned«-Myokard)

\section{Dyspnoe}

»Bronchiolitis obliterans organizing pneumonia« mit akuter respiratorischer Insuffizienz

\section{Dysraphiesyndrome}

Syringomyelie als seltene Ursache einer beatmungspflichtigen respiratorischen Insuffizienz

\section{Dysregulationen; neuro-} endokrinologische

Fibromyalgie-Syndrom

E

\section{Ebstein-Anomalie}

Ebstein-Anomalie

\section{Echokardiographie}

Echokardiographie bei Endokarditis

Spontaner Echokontrast im linken Ventrikel als Indikator für ein erhöhtes Thromboembolie-Risiko
1645 or Echokardiographie; transösophageale

Akute Aortendissektion. Diagnose durch transthorakale Echokardiographie

Akute Mitralinsuffizienz bei Osteogenesis imperfecta

1289 üb Echokardiographie bei Endokarditis

Klinische Bedeutung und echokardiographischer Nachweis von Aneurysmen des Vorhofseptums

$1661 \mathrm{mq}$ Kongenital korrigierte Transposition der großen Arterien im Erwachsenenalter.

1372 Wert nicht-invasiver Untersuchungsmethoden

Zerebraler ischämischer Insult. Wertigkeit der transösophagealen Echokardiographie in der Diagnostik kardialer Emboliequellen

Echokontrast; spontaner intrakardialer

Spontaner Echokontrast im linken Ventrikel als Indikator für ein erhöhtes Throm-

$1745 \mathrm{pp}$ boembolie-Risiko

\section{Eczema craquelé}

Eczema craquelé

Einschlußverbindungen

Harnstoff in der Dermatologie

1312 kas Eisenstoffwechsel

Eisenmangelanämie

Grundlagen des Eisenstoffwechsels

Hiatushernie

1771 kas

\section{Ekzem; endogenes}

Behandlung der Neurodermitis mit Liposomen?

Harnstoff in der Dermatologie

Ist die Neurodermitis eine Krankheit der höheren sozialen Schichten?

\section{$1639 \mathrm{lz}$ Elektrolythaushalt}

Therapie des Aszites bei Lebererkrankungen

Elektrostimulation; kardiale transösophageale

Therapie bradykarder und

$1782 \mathrm{mq}$

$1006 \ddot{u b}$

1317 kas tachykarder Rhythmusstörungen durch transösophageale Elektrostimulation des Herzens

\section{Eliminationsdiät}

Diättherapie des Morbus Crohn

\section{Embolie; kardiogene}

Klinische Bedeutung und echokardiographischer Nachweis von Aneurysmen des Vorhofseptums
Spontaner-Echokontrast im

1317 kas linken Ventrikel als Indika-

$1297 \mathrm{lz} \quad$ tor für ein erhöhtes Thromboembolie-Risiko

Zerebraler ischämischer

1101 lz Insult. Wertigkeit der transösophagealen Echokardio-

1006 üb graphie in der Diagnostik kardialer Emboliequellen

1205 adt Embolie; paradoxe

Paradoxe zerebrale Embolie oder Dissektion der Arteria carotis interna?

1156 kas

Embolie; pulmonale

(siehe Lungenembolie)

\section{Embryologie}

1585 adt

Kallmann-Syndrom. Pathophysiologie und Klinik

1436 üb

\section{Embryopathien}

Windpocken in der ersten Schwangerschaftshälfte

\section{Empfängnisverhütung}

Hodenkrebsrisiko nach

1317 kas Vasektomie

1585 adt

$1183 \mathrm{lz}$

\section{Enantiomere}

Sotalol

\section{Endokarditis}

$1203 \mathrm{mq}$

Echokardiographie bei Endokarditis

1126 üb

\section{Endotheldysfunktion}

Angina pectoris und normales Koronarangiogramm

1403 pp bei arterieller Hypertonie

1287 pp und linksventrikulärer Hypertrophie

$1398 \mathrm{mq}$ Gesteigerte vaskuläre Sensitivität auf Nitroglycerin bei Patienten mit Hypercholesterinämie und peripherer Endotheldysfunktion

1126 üb

$1757 \mathrm{~km}$

\section{Endothelfärbungen}

Tumorgefäßinvasion beim Mammakarzinom. Hämatoxylin-Eosin- versus immunhistochemische Färbung gegen Faktor-VIIIAntigen

\section{Endothelin}

Rolle von Endothelin bei den Ciclosporin-Nebenwirkungen Nephrotoxizität und arterielle Hypertonie

\section{Endothelinrezeptor-Ant-} agonisten

$1140 \mathrm{~km}$ Rolle von Endothelin bei den Ciclosporin-Nebenwirkungen Nephrotoxizität und arterielle Hypertonie
1477 as

$1527 \mathrm{~km}$

$1757 \mathrm{~km}$

1006 üb

1175 üb

1065 or

1491 or
1205 adt 
Endothelium-Derived-

Relaxing-Factor

Gesteigerte vaskuläre Sensiti vität auf Nitroglycerin bei Patienten mit Hypercholesterinämie und peripherer Endotheldysfunktion

Enteritis regionalis

(siehe Morbus Crohn)

Enteropathogenität

Enteropathogenität von Chlamydien

\section{Environtologie}

Fibromyalgie-Syndrom

Gerbstoffe und Krebsrisiko

Risiken der Sonnenexposition

\section{Enzephalitis}

Polyneuritis und Myositis bei Trypanosoma-gambienseInfektion

\section{Enzephalopathie}

Enzephalopathie nach Intoxikation mit einem Anticholinergikum

Therapie des Aszites bei Lebererkrankungen

\section{Eosinophilie}

Churg-Strauss-Syndrom oder chronische eosinophile Pneumonie?

Einseitige diffuse Lungenbeteiligung bei Vaskulitis mit Anti-Neutrophilen-Zytoplasma-Antikörpern sowie Antikörpern gegen glomeruläre Basalmembranen

Gnathostomiasis nach Aufenthalt in Thailand

\section{Epidemiologie}

Aktuelle Epidemiologie, Diagnostik und Therapie der Urogenitaltuberkulose

Epidemiologie und Klinik der chronischen Virushepatitis

Hepatitis-A-Impfung

HIV-Übertragung bei heterosexuellen Partnern

Ist die Neurodermitis eine Krankheit der höheren sozialen Schichten?

Operation bei Verdacht auf Appendizitis und Perforation

Schistosomiasis und Siegelringzellkarzinom der Ileozökalklappe

Tuberkuloseerkrankungen 1993

Übertragungsmodus von Helicobacter pylori

Epiphänomene; bei Krankheiten

Gamma-Schwerketten-Produktion als Epiphänomen bei Non-Hodgkin-Lymphom

Epithelkörperchenadenom

Neuropsychiatrische Symptomatik bei primärem Hyperparathyreoidismus
Eradikation

Ist die Ulcuskrankheit eine

1065 or Infektionskrankheit?
Ergotaminderivate

Bromocriptin-induzierte

Pleuropneumopathie

Ergotismus

Akute Ischämie eines Armes als ungewöhnlicher Ausdruck eines Ergotismus

\section{7 fr Ernährung}

Ciguatera. Neue Fälle von Fischvergiftung bei deut-

$\begin{array}{lll}1639 & \mathrm{lz} & \text { schen Karibik-Urlaubern } \\ 1411 & \mathrm{fr} & \text { Diättherapie des Morbus }\end{array}$ Crohn

Gerbstoffe und Krebsrisiko

1690 kas Erregerwandel

Nehmen Infektionen durch hämolysierende Streptokokken der Gruppe A zu?

$1803 \mathrm{lz}$ Erythromelalgie

Erythromelalgie (Erythrothermalgie)

1549 adt Erythrozytensubstitution

Rationale Substitution mit Blut- und Blutbestandteil-

$1565 \mathrm{lz}$ konserven

1071 kas

Estriol; unkonjugiertes

Indikation zur Amniozentese bei über 35jährigen Schwangeren aufgrund von Serummarkern

\section{ESWL}

(siehe Stoßwellenlithotripsie

1618 kas Extrakorporale)

Exulceratio simplex

Dieulafoy

1121 adt Exulceratio simplex Dieulafoy

1365 üb

1800 fr Facialisparese; periphere

$1805 \mathrm{~km}$ Intensivtherapie des GuillainBarré-Syndroms

1757 km Faktoren; koloniestimulierende

Schwere Panzytopenie im hohen Lebensalter nach zwölfmonatiger ACE-Hemmer-Therapie

1058 lz Faktor-VIII-Färbung

$1185 \mathrm{~km}$ toxylin-Eosin- versus immunhistochemische Färbung gegen Faktor-VIIIAntigen

Feinnadelpunktion; computertomographisch gesteuerte

Differentialdiagnose von Rundherden nach Lungentransplantation

1076 kas

Fernmetastasen

Tumorverkleinerung im Stadium M1?
$1699 \mathrm{mq}$

Fertilitätsstörungen

1488 km Kallmann-Syndrom. Pathophysiologie und Klinik

Prader-Labhart-WilliSyndrom

1543 kas Fettstoffwechselstörungen

Fischaugenkrankheit

1436 üb

974 fr

1393 kas

1501 kas Fibrinolyse

Thrombolyse bei akutem Herzinfarkt

Fibromyalgie-Syndrom

$975 \mathrm{lz}$ Fibromyalgie-Syndrom

Fieber

$1140 \mathrm{~km}$ »Bronchiolitis obliterans organizing pneumonia mit akuter respiratorischer Insuffizienz

\section{Fischaugenkrankheit}

Fischaugenkrankheit

Fischvergiftung

Ciguatera. Neue Fälle von Fischvergiftung bei deutschen Karibik-Urlaubern

Fistel; enterovesikale

Luft in der Blase durch Fistelverbindung zum Darm

Fistel; hepatobronchiale

Amöbenabszeß der Leber mit hepatobronchialer Fistel

Fistel; ösophago-mediastinale

Ösophago-mediastinale Fisteln als seltene Komplikation der Tuberkulose bei einem HIV-infizierten Patienten

\section{Flapping Tremor}

Medikamentös ausgelöste Asterixis

\section{Fluoridprophylaxe}

Akute Vergiftung durch fluoridiertes Trinkwasser

\section{8 üb}

Fluorouracil

Adjuvante Chemotherapie beim operierten Kolonkarzinom

1029 kas Adjuvante Therapie bei kolorektalen Karzinomen

Flußreserve; koronare

Angina pectoris und normales Koronarangiogramm

1491 or bei arterieller Hypertonie und linksventrikulärer Hypertrophie

\section{Folinsäure}

Adjuvante Chemotherapie beim operierten Kolonkarzinom

Adjuvante Therapie bei kolorektalen Karzinomen

1105 or Foramen ovale; offenes

Klinische Bedeutung und echokardiographischer Nachweis von Aneurysmen
$1220 \quad \mathrm{lz}$

$1639 \quad \mathrm{lz}$

1312 kas

1393 kas

$975 \quad \mathrm{lz}$

$1472 \mathrm{mq}$

1034 kas

1613 kas

$1221 \mathrm{lz}$

$1185 \mathrm{~km}$

1181 fr

1663 adt

1175 üb

1181 fr

$1663 \mathrm{adt}$

1205 adt 
Paradoxe zerebrale Embolie oder Dissektion der Arteria carotis interna?

\section{Forsa ovalis}

Klinische Bedeutung und echokardiographischer Nachweis von Aneurysmen des Vorhofseptums

\section{Frakturen; osteoporotische}

Einfluß einer niedrigdosierten Hydrochlorothiazidtherapie auf den Knochenmineralgehalt des axialen und peripheren Skeletts

Vitamin D und Osteoporose. Pathogenese - Therapie

\section{Fremdkörperingestion}

Präsakrale Phlegmone und Meningitis als Komplikationen eines Fremdkörpers im Rektosigmoid

\section{Frischblut}

Rationale Substitution mit Blut- und Blutbestandteilkonserven

Frischplasma; gefrorenes Rationale Substitution mit Blut- und Blutbestandteilkonserven

Früherkennung; von Malignomen

Tiefe Venenthrombose und okkulte, maligne Neoplasien

\section{Frühgeburtlichkeit}

Psychische Belastung in der Schwangerschaft und Frühgeburt

Fundusvarizen

Fundusvarizen

\section{G}

\section{Gallenblasenmotilitätsstö- rungen \\ Gallenblasen-Sludge und Ein-} nahme von Lipidsenkern

\section{Gambierdiscus toxicus}

Ciguatera. Neue Fälle von Fischvergiftung bei deutschen Karibik-Urlaubern

\section{Gamma-Glutamyltrans-} ferase

Die erhöhte Gamma-GT (Gamma-Glutamyltransferase). Ursachen und Interpretationen
1183 lz Gammopathie; monoklonale

Generalisiertes IgG-LambdaPlasmozytom und Stenose

1205 adt eines Cimino-Shunts durch plasmazelluläre Infiltration

Ganglien

Baker-Zyste

Hermann von Helmholtz

1645 or (1821-1894) - Militärarzt Sinnesphysiologe und »Reichskanzler der deutschen Physik«. Zum 100. Todestag des universalen

1479 üb Arztes und Naturforschers

\section{Gastrektomie}

Adjuvante Chemotherapie

990 kas nach kurativer Gastrektomie bei Magenkarzinom

\section{Gastritis}

Modifizierter ${ }^{13} \mathrm{C}$-Atemtest in der Diagnostik der Helicobacter-pylori-Besiedlung der gastralen Mucosa

\section{Gastropexie}

Behandlung eines intermittierenden Magenvolvulus durch Gastropexie mittels perkutaner endoskopischer Gastrostomie

\section{Gefäßtonus; Regulation}

$1719 \mathrm{~km}$

Gesteigerte vaskuläre Sensitivität auf Nitroglycerin bei Patienten mit Hypercholesterinämie und peripherer Endotheldysfunktion

$1141 \mathrm{~km}$ Gelenkluxationen

Larson-Syndrom

\section{Gentechnologie}

$959 \mathrm{mq}$ Klinische Bedeutung der Polymerase-Kettenreaktion in der Infektiologie

\section{Gerinnung}

Ist die »International Normalized Ratio (INR)« in der klinischen Praxis unentbehr-

1524 fr lich?

\section{Gerinnungsfaktoren}

Rationale Substitution mit

$975 \mathrm{lz} \quad$ Blut- und Blutbestandteilkonserven

\section{Gerinnungsstörungen}

Resistenz gegenüber aktiviertem Protein C

1041 adt rungen bei systemischer Mastozytose

\section{Geschäftsfähigkeit}

Geschäftsfähigkeit bei hohem Blutalkoholspiegel

Gesundheitsfürsorge

Placebo-kontrollierte Untersuchung zur Wirksamkeit der Influenza-Schutzimpfung?

Gesundheitsstrukturgesetz

ICD-Verschlüsselung und Pflege-Personalregelung

$1040 \mathrm{mq}$

$1215 \mathrm{mg}$

Gewebe-Plasminogenakti-

vator

(siehe Fibrinolyse)

Gilman, Alfred G.

Nobelpreis für Medizin 1994

\section{Glioblastom}

Glioblastom

$1298 \mathrm{~km}$

\section{Gliose}

Syringomyelie als seltene Ursache einer beatmungspflichtigen respiratorischen Insuffizienz

1569 or

1658 kas

\section{Glomerulonephritis}

Einseitige diffuse Lungenbeteiligung bei Vaskulitis mit Anti-Neutrophilen-Zytoplasma-Antikörpern sowie Antikörpern gegen glomeruläre Basalmembranen

\section{Gnathostomiasis}

Gnathostomiasis nach Aufent- 1618 kas halt in Thailand

1065 or

\section{Gonadendysgenesie}

Diagnose eines Ullrich-Turner-Syndroms im Rentengutachten

\section{Gonadorelin}

Kallmann-Syndrom. Pathophysiologie und Klinik

$1584 \mathrm{mq}$

1625 adt

Goodpasture-Syndrom

Einseitige diffuse Lungenbeteiligung bei Vaskulitis mit Anti-Neutrophilen-Zytoplasma-Antikörpern sowie Antikörpern gegen glome-

1529 la ruläre Basalmembranen

\section{G-Proteine}

Nobelpreis für Medizin 1994

Granulocyte-Colony-Stimulating-Factor

1555 üb Schwere Panzytopenie im hohen Lebensalter nach zwölfmonatiger ACE-Hemmer-Therapie

$1680 \mathrm{~km}$

Therapie einer Clozapin-induzierten Agranulozytose mit granulozytenkolonie-stimulierendem Faktor
1792 kom

$1057 \quad \mathrm{lz}$

$1412 \quad \mathrm{lz}$

1792 kom

$1000 \mathrm{mq}$

1771 kas

1071 kas

1115 kas

1436 üb

1071 kas

1029 kas

1467 kas

1602 fr

\footnotetext{
Rubrikenschlüssel

adt $=$ Aktuelle Diagnostik und Therapie

ar $=$ Arztrecht

as = Der Arzneistoff

epi $=$ Epikrise
}

\author{
fr $=$ Fragen aus der Praxis \\ gt $=$ Gedenktage \\ kas $=$ Kasuistiken \\ $\mathrm{km}=$ Kleine Mitteilungen \\ kom $=$ Kommentare
}

\author{
la = Leitartikel \\ $\mathrm{l}$ = Leser-Zuschriften \\ $\mathrm{mg}=$ Medizingeschichte \\ $\mathrm{mq}=$ Mediquiz \\ $\mathrm{nk}=$ Nekrologe
}

or $=$ Originalien

$p p=$ Prinzip \& Perspektive

stp $=$ Standpunkte

üb = Übersichten 
Granulocyte-MacrophageColony-Stimulating-Factor

Therapie einer Clozapin-induzierten Agranulozytose mit granulozytenkolonie-stimulierendem Faktor

\section{Granulome; eosinophile}

Churg-Strauss-Syndrom oder chronische eosinophile Pneumonie?

\section{Gravidität}

(siehe Schwangerschaft)

\section{Grenzstrangdurchtrennung}

Endoskopische transthora-

kale Sympathektomie bei

paraneoplastischem

Raynaud-Syndrom

\section{GSG}

(siehe Gesundheitsstrukturgesetz)

\section{Guillain-Barré-Syndrom}

Immunglobuline zur Therapie des Guillain-Barré-Syndroms im Kindesalter

Intensivtherapie des GuillainBarré-Syndroms

\section{H}

\section{HAD-Skala}

Erfassung von Angst und Depressivität in der medizinischen Routineversorgung

\section{Haffkin-Impfstoff}

Indikationen zur Pestimpfung und -chemoprophylaxe

\section{Halsrippe}

Neurologische Symptomatik, Diagnostik und Therapie des sogenannten $\gg$ thoracicoutlet-syndrome«

\section{Handtumoren}

Differentialdiagnose knotiger Tumoren an der Hand

\section{Harnblasenersatz}

Aktuelle Möglichkeiten des kontinenten Harnblasenersatzes

\section{Harnproduktion}

Glomeruläre Hyperperfusion und Niereninsuffizienz

\section{Harnsäure \\ Allopurinol \\ Harnstoff \\ Harnstoff in der Dermatologie Modifizierter ${ }^{13} \mathrm{C}$-Atemtest in der Diagnostik der Helico- bacter-pylori-Besiedlung der gastralen Mucosa}

\section{Harnstoffzyklus}

Harnstoff in der Dermatologie

\section{Hautdesinfektion}

Hautdesinfektion vor der Blut- 1182 fr entnahme

1283 adt

1714 fr

1087 üb

110

1327 üb

\section{$1136 \mathrm{fr}$}

\section{6 üb}

1569 or

üb

\section{Hauttumoren}

Differentialdiagnose knotiger

Tumoren an der Hand

Risiken der Sonnenexposition

\section{Hämodialyse}

Akute Hämolyse mit nachfolgender lebensbedrohlicher Pankreatitis bei Hämodialyse. Eine Komplikation, die von den derzeitigen Dialysegeräten nicht verhindert wird

Fortschritte der chronischen Dialyse-Behandlung in den neuen Bundesländern

Impfungen bei chronischer Niereninsuffizienz und nach Nierentransplantation

\section{Hämodynamik}

Gesteigerte vaskuläre Sensitivität auf Nitroglycerin bei Patienten mit Hypercholesterinämie und peripherer Endotheldysfunktion

Hämoglobin; glykosyliertes Ambulante Versorgung von Diabetikern

\section{Hämolyse; extravasale}

Akute Hämolyse mit nachfolgender lebensbedrohlicher Pankreatitis bei Hämodialyse. Eine Komplikation, die von den derzeitigen Dialysegeräten nicht verhindert wird

\section{Hämostase}

esistenz gegenüber aktiviertem Protein C

\section{Hämotherapie}

»Look-back«-Studie der DRK- 1643 km Blutspendedienste

Neonatale Alloimmunthrombozytopenie

Rationale Substitution mit Blut- und Blutbestandteilkonserven

Universal-Spenderblut

HCG

(siehe Choriongonadotropin; humanes)

\section{HDL-Cholesterin}

Fischaugenkrankheit

\section{Heiserkeit}

Heiserkeit bei Polymyalgia rheumatica

\section{Helicobacter pylori}

Ist die Ulcuskrankheit eine Infektionskrankheit?

Modifizierter ${ }^{13} \mathrm{C}$-Atemtest in der Diagnostik der Helicobacter-pylori-Besiedlung der gastralen Mucosa

Übertragungsmodus von Helicobacter pylori

$1261 \mathrm{~km}$

1323 adt

1065 or

$1056 \quad l$

1263 or

1512 üb

1555 üb

$1019 \quad \mathrm{lz}$

1393 kas

$1566 \quad \mathrm{lz}$

$1488 \mathrm{~km}$

1569 or

1719 km v. Helmholtz; Hermann

Hermann v. Helmholtz

(1821-1894) - Militärarzt,

Sinnerphysiologe und

»Reichskanzler der deutschen Physik«. Zum 100.

Todestag des universalen

Arztes und Naturforschers

\section{Heparin; niedermolekula-}

res

Einsatz von niedermolekularem Heparin zur Antikoagulation in der Schwangerschaft

\section{Hepatitis; chronische}

Epidemiologie und Klinik der chronischen Virushepatitis

\section{Hepatitis B}

Aktueller Stand der Behandlung chronischer Virushepatitiden mit rekombinantem Interferon alpha

Akzidentelle Nadelstichverletzung bei medizinischem Pflegepersonal

Epidemiologie und Klinik der chronischen Virushepatitis

Hepatitis-B-assoziierte Vaskulitis. Verlauf unter Therapie mit Glucocorticoiden und Alpha-Interferon

\section{Hepatitis $C$}

Aktueller Stand der Behandlung chronischer Virushepatitiden mit rekombinantem Interferon alpha

Akzidentelle Nadelstichverletzung bei medizinischem Pflegepersonal

Chronische Hepatitis $\mathrm{C}$ be Typ-II-Kryoglobulinämie und kutaner Vaskulitis

Epidemiologie und Klinik der chronischen Virushepatitis

1365 üb

$961 \mathrm{adt}$

$1563 \mathrm{fr}$

1365 üb

1388 kas

961 adt

$1563 \mathrm{fr}$

1365 üb

\section{Hepatitis D}

Epidemiologie und Klinik der chronischen Virushepatitis

\section{Hernien; innere}

Möglichkeiten der laparoskopischen Therapie innerer Hernien. Darstellung an drei Fällen

\section{Herpes zoster}

Wirksamkeit von Aciclovir und Glucocorticoiden in der Behandlung des Herpes zoster und postzosterischer Neuralgien

\section{Herpes-simplex-Virus-}

Infektionen

Chronische Müdigkeit und Herpes-Virus-Antikörper

\section{Herzinfarkt}

(siehe Myokardinfarkt)

\section{Herzinsuffizienz}

Beta-Rezeptorenblocker bei dilatativer Kardiomyopathie 


\section{Herzklappenfehler}

Akute Mitralinsuffizienz bei Osteogenesis imperfecta

Herzklappenprothesen

Echokardiographie bei Endokarditis

\section{Herzkrankheit; koronare}

Cholesterin und koronare Herzkrankheit

Einfluß spontan niedriger und diätetisch-medikamentös gesenkter Cholesterinspiegel auf nicht-kardiovaskuläre Todesursachen

Fettarme Diät und körperliches Training bei koronarer Herzkrankheit

Zentralnervöse Vermittlung der Angina pectoris

\section{Herzrhythmusstörungen}

Adenosintriphosphat (ATP) bei supraventrikulären Tachykardien im Neugeborenen- und Säuglingsalter

Akute Myokardischämie, ventrikuläre Tachyarrhythmien und plötzlicher Herztod

Idiopathisches QT-Syndrom (Romano-Ward-Syndrom)

Idioventrikulärer Rhythmus

Klinische Bedeutung des Ajmalin-Tests in der nichtinvasiven Diagnostik bei Wolff-Parkinson-WhiteSyndrom

Magnesium bei Herzinfarkt

Magnesium-Infusion bei akutem Herzinfarkt

Morbidität und Letalität bei Schlafapnoe und nächtlichen Bradyarrhythmien

Schrittmachertherapie beim Syndrom des kranken Sinusknotens. Senken vorhofbeteiligte Schrittmachersysteme die Häufigkeit von Vorhofflimmern und thromboembolischen Komplikationen sowie die Mortalität?

Therapie bradykarder und tachykarder Rhythmusstörungen durch transösophageale Elektrostimulation des Herzens

\section{Herzschrittmacher}

Schrittmachertherapie beim Syndrom des kranken Sinusknotens. Senken vorhofbeteiligte Schrittmachersysteme die Häufigkeit von Vorhofflimmern und thromboembolischen Komplikationen sowie die Mortalität?
1101 lz $\begin{aligned} & \text { Herztod; plötzlicher } \\ & \text { Akute Myokardischämie, ven- } 1786 \text { üb }\end{aligned} \quad \begin{aligned} & \text { Ösophago-mediastinale } \\ & \text { Fisteln als seltene Kompli- }\end{aligned}$ trikuläre Tachyarrhythmien und plötzlicher Herztod

\section{6 üb Herztransplantation}

Primär kutane Nocardia-farci- 1276 kas nica-Infektion nach Herztransplantation

$1059 \mathrm{~km}$

1597 kom

Primär kutane Nocardia-farci- 1568 nica-Infektion nach Herztransplantation (Berichtigung)

Herzvitien; angeborene

$1017 \mathrm{lz}$ Ebstein-Anomalie $1782 \mathrm{mq}$

Großer subaortaler Ventrikel- $1583 \mathrm{mq}$ septumdefekt

$1604 \mathrm{~km}$ Komplette Transposition der großen Arterien

Kongenital korrigierte Transposition der großen Arterien im Erwachsenenalter. Wert nicht-invasiver Untersuchungsmethoden

1786 üb Herzvitien; erworbene

Operationsindikation bei asymptomatischer hochgradiger Aortenklappenste-

$1204 \mathrm{mq}$ nose

$1432 \mathrm{mq}$ Heyde-Syndrom

985 or Endoskopische intraoperative Diagnostik einer blutenden Angiodysplasie im Jejunum beim Heyde-Syndrom

$1102 \mathrm{~km}$ Hiatushernie

1800 fr Hiatushernie

1187 or Hibernating-Myokard

Pathophysiologie der Myokarddurchblutung. Teil I: Adaptation an Myokard-

1683 or ischämie (»hibernating«Myokard)

Hiob-Syndrom

(siehe Hyper-IgE-Syndrom)

Hirninfarkt

(siehe Insult; zerebraler)

\section{5 üb Hirntumoren}

Glioblastom

HIV-Antikörper-Test

»Look-back«-Studie der DRK- 1643 km Blutspendedienste

1683 or

\section{HIV-Infektion}

Akzidentelle Nadelstichverlet- 1563 fr zung bei medizinischem Pflegepersonal

HIV-assoziierte Cholangiopathie

HIV-Übertragung bei heterosexuellen Partnern

»Look-back«-Studie der DRKBlutspendedienste merase-Kettenreaktion in
Ösophago-mediastinale

1613 kas kation der Tuberkulose be einem HIV-infizierten

Patienten

Sinusitis bei HIV-Infektion 1759 or

Sputumuntersuchung zur Dia- 1151 or gnostik der Pneumocystiscarinii-Pneumonie bei HIVInfizierten

Unverträglichkeit der Tuberkulosetherapie bei AIDS

Zidovudin bei asymptomatischen HIV-Patienten?

\section{HLA-Typisierung}

Aufbau der Deutschen Knochenmarkspenderdatei

$1662 \mathrm{mq}$ Hodenkrebs

1156 kas

Hodenkrebs

srisiko nach Vasektomie

Hormon; Antidiuretisches; Syndrom der inadäquaten

\section{Sekretion}

Hyponatriämisches Koma

1139

1630 üb Hornhauttrübung

Fischaugenkrankheit

$\mathbf{H}_{2}$-Rezeptor-Antagonisten

Therapie der gastroösophagealen Refluxkrankheit

$1603 \quad \mathrm{l}$

\section{Humanalbumin}

Rationale Substitution mit Blut- und Blutbestandteilkonserven

\section{Hybridisierung}

Klinische Bedeutung der Polyder Infektiologie

1589 pp Hydrocele testis

Eingeklemmte Leistenhernie Hydrocele testis

\section{Hydrochlorothiazid}

Einfluß einer niedrigdosierten Hydrochlorothiazidtherapie auf den Knochenmineralgehalt des axialen und peripheren Skeletts

\section{5-Hydroxy-Vitamin- $D_{3}$}

Vitamin D und Osteoporose. Pathogenese - Therapie

1728 kas

$1374 \mathrm{~km}$

$1359 \mathrm{ad}$

$1757 \mathrm{~km}$

\section{3 adt}

1555 üb

Hymenopterengift

Besteht bei einer InsektengiftAllergie immer die Indikation für eine Hyposensibilisierung?

\section{Hypakusis}

1004 adt

Diagnose eines Ullrich-Turner-Syndroms im Rentengutachten

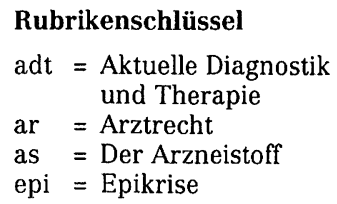

\author{
fr $\quad=$ Fragen aus der Praxis \\ gt $=$ Gedenktage \\ kas $=$ Kasuistiken \\ $\mathrm{km}=$ Kleine Mitteilungen \\ $\mathrm{kom}=$ Kommentare
}

\author{
la = Leitartikel \\ $\mathrm{l} \mathbf{z}=$ Leser-Zuschriften \\ $\mathrm{mg}=$ Medizingeschichte \\ $\mathrm{mq}=$ Mediquiz \\ $\mathrm{nk}=$ Nekrologe
}

or $=$ Originalien
pp $=$ Prinzip \& Perspektive
stp $=$ Standpunkte
üb $=$ Übersichten 


\section{Hypercalcämie}

Asymptomatischer primärer Hyperparathyreoidismus. Behandeln oder beobachten?

Neuropsychiatrische Symptomatik bei primärem Hyperparathyreoidismus

Hypercholesterinämie

Gallenblasen-Sludge und Einnahme von Lipidsenkern

Gesteigerte vaskuläre Sensitivität auf Nitroglycerin bei Patienten mit Hypercholesterinämie und peripherer Endotheldysfunktion

Hypercholesterinämie

\section{Hyperfiltration; glomeru-}

läre

Glomeruläre Hyperperfusion und Niereninsuffizienz

\section{Hyper-IgE-Syndrom \\ Hyper-IgE-Syndrom (Syn- onyma: Hiob-Syndrom, Buckley-Syndrom, »Job's syndrome $\ll)$}

\section{Hyperkapnie}

Ventilatorische Insuffizienz und hyperkapnische Kompensation infolge chronisch belasteter »Atempumpe«. Physiologie, Pathophysiologie und Therapie

\section{Hyperkeratosen}

Harnstoff in der Dermatologie

Hyperleukozytosesyndrorn

Komplette Remission bei akuter Promyelozytenleukämie. Vorteile von alltrans-Retinsäure im Vergleich mit konventioneller Chemotherapie

\section{Hyperlipidämie}

Cholesterin und koronare Herzkrankheit

Fettarme Diät und körperliches Training bei koronarer Herzkrankheit

Gallenblasen-Sludge und Einnahme von Lipidsenkern

\section{Hypermagnesiämie}

Magnesium

\section{Hyperparathyreoidismus; \\ primärer}

Asymptomatischer primärer Hyperparathyreoidismus. Behandeln oder beobachten?

Neuropsychiatrische Symptomatik bei primärem Hyper $r$ parathyreoidismus

Hyperperfusion; glomeruläre

Glomeruläre Hyperperfusiom und Niereninsuffizienz

\section{Hyperphagie}

Prader-Labhart-Willi-Syndrom
Hyperphosphatämie

967 üb Calcitriol-Gabe in der Schwangerschaft bei partieller DiGieorge-Anomalie

Hyperpigmentierung

Interdisziplinäre Aspekte der Notalgia paraesthetica

Farbdopplersonographisch gesteuerte perkutane Alkoholinstillation zur TheraSchilddrüsenautonomic

Jodinduzierte Hyperthyreose bei metastasiertem Schild-

drüsenkarzinom

Jodprophylaxe in der Schwangerschaft

Latente Hyperthyreose

$113.6 \quad$ fr $\quad$ Neonatale Hyperthyreose bei nicht diagnostiziertem Morbus Basedow der Mutter. Probleme der Diagnostik und Therapie anhand einer Kasuistik

Hypertonie; arterielle

Angina pectoris und normales Koronarangiogramm

$120^{\prime} 9$ üb bei arterieller Hypertonie und linksventrikulärer Hypertrophie

Angiotensin-Converting Enzym-Hemmer bei der Behandlung der diabetischen Nephropathie

Asymptomatischer primärer lyperparathyrenidismus Behandeln oder beobachten?

1143 or Kenin-Angiotensin-System und Blutdruckregulation

kolle von Endothelin bei den Ciclosporin-Nebenwirkungen Nephrotoxizität und arterielle Hypertonic

Symptomatik und endokrinologische Befunde bei katecholamin-sezernierenden Tumoren. Ergebnisse bei 106 konsekutiven Patienten

\section{Hypertonie; portale}

1.52.4 fr. Endoskopische Therapie der Ösophagusvarizenblutung

Lebervenenverschlußdruck-

166,9 as messung

Hypertonie; pulmonale

Dopplerechokardiographie

196,7 üb bei chronischer rechtsventrikulärer Druckbelastung

Hypertrophie; linksventrikuläre

1076 kas Angina pectoris und normales Koronarangiogramm bei arterieller Hypertonie und linksventrikulärer Hypertrophie

\section{6 fir Hyperurikämie} Allopurinol

\section{Hyperthyreose} pie der funktionellen
1776 kas Calcitriol-Gabe in der Schwangerschaft bei partieller DiGeorge-Anomalie pathie als Ursache einer schweren Linksherzinsuffizienz

Hypocalcämische Kardiomyopathie als Ursache einer schweren Linksherzinsuffizienz (Berichtigung)

1573 kas

Hypocholesterinämie

Hypocholesterinämie

Hypogonadismus; hypogonadotroper

1339 la

Kallmann-Syndrom. Pathophysiologie und Klinik

1334 fr

1346 kas

Hypokomplementämie

Chronische Hepatitis $\mathrm{C}$ bei Typ-II-Kryoglobulinämie und kutaner Vaskulitis

\section{Hyponatriämie}

Hyponatriämisches Koma

Hypoparathyreoidismus;

1175 üb idiopathischer

Calcitriol-Gabe in der Schwangerschaft bei partieller DiGeorge-Anomalie

1298 km Hyposensibilisierung

Besteht bei einer InsektengiftAllergie immer die Indikation für eine Hyposensibili-

967 üb sierung?

Hyposmie

Kallmann-Syndrom. Pathophysiologie und Klinik

965 pp Hypotriglyceridämie

1706 üb Hypocholesterinämie

Hypoxämie

Ventilatorische Insuffizienz und hyperkapnische Kom-

1721 or pensation infolge chronisch belasteter "Atempumpe«. Physiologie, Pathophysiologie und Therapie

1443 kom

1245 adt

ICD-Schlüssel

ICD-Verschlüsselung und Pflege-Personalregelung

1061 or $\mathbf{I g E}$

(siehe Immunglobulin E)

\section{Ileum-Pouch}

Aktuelle Möglichkeiten des kontinenten Harnblasen-

1175 üb ersatzes

lleus

Endoskopische Ballondilatation symptomatischer Strikturen bei Morbus Crohn

Möglichkeiten der laparoskopischen Therapie innerer Hernien. Darstellung an drei Fällen
Hypocalcämische Kardiomyo-
1776 kas

1270 kas

1677 fr

1239 kas

1776 kas

1093 la

1436 üb

$1412 \quad \mathrm{lz}$

1327 üb

1377 or

1199 kas 


\section{Imidazolpräparate}

Therapie kutaner und mukokutaner Leishmaniosen

\section{Immunadsorption}

(siehe LDL-Apherese)

\section{Immunchemotherapie}

Adjuvante Chemotherapie nach kurativer Gastrektomie bei Magenkarzinom

\section{Immundefektsyndrom;}

humanes erworbenes

Akzidentelle Nadelstichverletzung bei medizinischem Pflegepersonal

HIV-assoziierte Cholangiopathie

Idiopathische CD4-Lymphozytopenie mit letaler Salmonella-typhimurium-Sepsis

»Look-back«-Studie der DRK-Blutspendedienste

Ösophago-mediastinale Fisteln als seltene Komplikation der Tuberkulose bei einem HIV-infizierten Patienten

Sputumuntersuchung zur Diagnostik der Pneumocystiscarinii-Pneumonie bei HIVInfizierten

Unverträglichkeit der Tuberkulosetherapie bei AIDS

Zidovudin bei asymptomatischen HIV-Patienten?

\section{Immundefizienz}

Calcitriol-Gabe in der Schwangerschaft bei partieller DiGeorge-Anomalie

Idiopathische CD4-Lymphozytopenie mit letaler Salmonella-typhimurium-Sepsis

Impfungen bei chronischer Niereninsuffizienz und nach Nierentransplantation

Sekundäre Neoplasien nach Immunsuppression

\section{Immunglobulin E}

Hyper-IgE-Syndrom (Synonyma: Hiob-Syndrom, Buckley-Syndrom, »Job's syndrome«)

\section{Immunglobulintherapie}

Immunglobuline zur Therapie des Guillain-Barré-Syndroms im Kindesalter

Intensivtherapie des GuillainBarré-Syndroms

Rationale Substitution mit Blut- und Blutbestandteilkonserven

\section{Immunisierung \\ Diphtherie-Auffrischimpfung bei Erwachsenen}

Epidemiologie und Klinik der chronischen Virushepatitis

Hepatitis-A-Impfung

Impfungen bei chronischer Niereninsuffizienz und nach Nierentransplantation

Indikationen zur Pestimp-

$1298 \mathrm{~km}$ fung und -chemoprophylaxe

Placebo-kontrollierte Untersuchung zur Wirksamkeit der Influenza-Schutzimpfung?

1563 fr Immunkomplexkrankheiten

Hepatitis-B-assoziierte Vaskulitis. Verlauf unter Thera-

1004 adt

956 kas pie mit Glucocorticoiden und Alpha-Interferon

\section{litis. Verlauf unter Thera-} pie mit Glucocorticoiden und Alpha-Interferon

1613 kas

Immunglobuline zur Therapie des Guillain-Barré-Syndroms im Kindesalter

Impfungen bei chronischer Niereninsuffizienz und

1151 or nach Nierentransplantation

Therapie der multiplen Sklerose

$1728 \mathrm{kas}$

$1374 \mathrm{~km}$

Immunozytom

Gamma-Schwerketten-Produktion als Epiphänomen bei Non-Hodgkin-Lymphom

1776 kas

Immunozytom; lympho-

plasmozytoides

Langzeitbcobachtung bei lymphoplasmozytoiden

956 kas Immunozytomen

Immunsuppression

Differentialdiagnose von Rundherden nach Lungentransplantation

1323 adt

Idiopathische CD4-Lymphozytopenie mit letaler Salmonella-typhimurium-Sepsis

Primär kutane Nocardia-farci- 1276 kas

$1121 \mathrm{mq}$ nica-Infektion nach Herztransplantation

Primär kutane Nocardia-farcinica-Infektion nach Herztransplantation (Berichtigung)

1449 lz Psychosoziale Probleme bei Langzeitimmunsuppression nach Organtransplantation

1248 üb Sekundäre Neoplasien nach Immunsuppression

1555 üb Immunthrombozytopenie

Neonatale Alloimmunthrombozytopenie

1219 fr$$
\text { Impfschemata }
$$

$$
\begin{aligned}
& \text { Diphtherie-Auffrischimpfung } \\
& \text { bei Erwachsenen }
\end{aligned}
$$

1365 üb Infektionen; opportunisti-

sche

1800 fr Primär kutane Nocardia-farci- 1276 kas

1323 adt nica-Infektion nach Herztransplantation

1714 fr Primär kutane Nocardia-farcinica-Infektion nach Herztransplantation (Berichtigung)

1057 lz Sinusitis bei HIV-Infektion

Sputumuntersuchung zur Diagnostik der Pneumocystiscarinii-Pneumonie bei HIVInfizierten

1388 kas Unverträglichkeit der Tuberkulosetherapie bei AIDS

\section{Infektionsprophylaxe}

Infektionsprophylaxe bei Dauerverweilkanülen

1388 kas

Infiltrate; eosinophile pulmonale

1449 lz Churg-Strauss-Syndrom oder chronische eosinophile Pneumonie?

\section{3 adt Infiltrate; intrapulmonale}

Differentialdiagnose von Rundherden nach Lungen-

1371 fr transplantation

\section{Influenza}

Placebo-kontrollierte Untersuchung zur Wirksamkeit der Influenza-Schutzimpfung?

1235 kas

Inoue-Ballon

Notfallmäßige perkutane Mitralvalvuloplastie mit dem Inoue-Ballon bei hochgradiger Mitralstenose und kardiogenem Schock

INR

1105 or (siehe International Normalized Ratio)

\section{Insektengift-Allergie}

Besteht bei einer InsektengiftAllergie immer die Indikation für eine Hyposensibilisierung?

\section{Inselzelltransplantation}

1568

Kombinierte Nieren- und Pankreastransplantation beim diabetischen Spätsyndrom

\section{Insomnie}

$1678 \mathrm{lz}$ Ambulante Behandlung von Schlafstörungen im Alter

1759 or

1151 or

1728 kas

1017 fr

$1565 \quad \mathrm{lz}$

1105 or

$1057 \quad \mathrm{lz}$

1110 kas

\section{7 üb Instabilität; elektrische}

Akute Myokardischämie, ventrikuläre Tachyarrhythmien und plötzlicher Herztod

1512 üb

Insuffizienz; respiratorische

1219 fr
$1399 \mathrm{adt}$

1538 or

\footnotetext{
Rubrikenschlüssel

adt $=$ Aktuelle Diagnostik und Therapie

ar = Arztrecht

as $=$ Der Arzneistoff

epi $=$ Epikrise
}

$\mathrm{fr} \quad=$ Fragen aus der Praxis

gt $=$ Gedenktage

kas $=$ Kasuistiken

$\mathrm{km}=$ Kleine Mitteilungen

$\mathrm{kom}=$ Kommentare

\author{
la = Leitartikel \\ $\mathrm{l} \mathrm{z}=$ Leser-Zuschriften \\ $\mathrm{mg}=$ Medizingeschichte \\ $\mathrm{mq}=$ Mediquiz \\ $\mathrm{nk}=$ Nekrologe
}

$\begin{aligned} \text { or } & =\text { Originalien } \\ \text { pp } & =\text { Prinzip \& Perspektive } \\ \text { stp } & =\text { Standpunkte } \\ \text { üb } & =\text { Übersichten }\end{aligned}$ 


\section{Insulinbehandlung}

Insulinpflichtiger Diabetes mellitus nach 58 Jahren

Insulinbehandlung; intensivierte

Intensivierte Behandlung des Diabetes mellitus Typ I und Entwicklung von Spätkomplikationen

\section{Insult; zerebraler}

Paradoxe zerebrale Embolie oder Dissektion der Arteria carotis interna?

Zerebraler ischämischer Insult. Wertigkeit der trans ösophagealen Echokardiographie in der Diagnostik kardialer Emboliequellen

\section{Intensivmedizin}

Risikofaktoren für gastrointestinale Blutungen bei Patienten der Intensivstation

Therapie der akuten Pankreatitis

\section{Interaktionen; von Medika-} menten

Hohe Letalität von Tetanusinfektionen nach intramuskulärer Injektion von Chinin

Problematik des Äquivalenzbegriffes bei der Therapie mit Glucocorticoiden. Ein Vergleich der klinischen Pharmakokinetik und Pharmakodynamik von Prednisolon und Methylprednisolon

\section{Interferon alpha-2b}

Aktueller Stand der Behandlung chronischer Virushepatitiden mit rekombinantem Interferon alpha

Hepatitis-B-assoziierte Vaskulitis. Verlauf unter Therapie mit Glucocorticoiden und Alpha-Interferon

\section{Intermittent Positive}

Pressure Ventilation

Ventilatorische Insuffizienz und hyperkapnische Kompensation infolge chronisch belasteter »Atempumpe«. Physiologie, Pathophysiologie und Therapie

International Classification of Diseases

ICD-Verschlüsselung und Pflege-Personalregelung

\section{International Normalized}

\section{Ratio}

Ist die »International Normalized Ratio (INR) « in der klinischen Praxis unentbehrlich?

Intimadissektion

(siehe Dissektion; der Gefäßintima)
Intoxikationen

1450 lz Akute Vergiftung durch fluoridiertes Trinkwasser

Bleiintoxikation durch Mennige in Paprikapulver

$976 \mathrm{~km}$ Ciguatera. Neue Fälle von Fischvergiftung bei deutschen Karibik-Urlaubern

Enzephalopathie nach Intoxikation mit einem Anticholinergikum

1183 lz Serum-Cholinesterase

\section{Invagination}

Invagination bei PeutzJeghers-Syndrom

Ischämie; mesenteriale

Chronische mesenteriale Ischämie

Ischämie; zerebrale

1337 km Zerebraler ischämischer Insult. Wertigkeit der transösophagealen Echokardiographie in der Diagnostik kardialer Emboliequellen

1739 adt J

$1681 \mathrm{~km}$ Jodexposition

Jodinduzierte Hyperthyreose bei metastasiertem Schilddrüsenkarzinom

1671 üb Latente Hyperthyreose

Jod-123-Octreotid

(siehe Octreotid)

Jodsalzprophylaxe

Jodprophylaxe in der Schwangerschaft

\section{Juckreiz}

961 adt

(siehe Pruritus)

1388 kas

\section{Kaliumkanalblocker \\ Sotalol}

Kallmann-Syndrom

Kallmann-Syndrom. Pathophysiologie und Klinik

1209 üb Kardiomyopathie; dilatative

Beta-Rezeptorenblocker bei dilatativer Kardiomyopathie

\section{Kardiomyopathie; hypo-} calcämische

Hypocalcämische Kardiomyopathie als Ursache einer schweren Linksherzinsuffi-

$1412 \mathrm{lz}$ zienz

Hypocalcämische Kardiomyopathie als Ursache einer schweren Linksherzinsuffizienz (Berichtigung)

1529 la

Kardioversion; elektrische

Therapie bradykarder und tachykarder Rhythmusstörungen durch transösophageale Elektrostimulation des Herzens

Karpaltunnelsyndrom

Neurologische Symptomatik,

1087 üb Diagnostik und Therapie

$1756 \mathrm{lz}$ des sogenannten »thoracic-
outlet-syndrome«

975 lz Karyogramm

Diagnose eines Ullrich-Turner-Syndroms im Rentengutachten

\section{Karzinogenese}

1016 fr Asbest-induzierte Erkrankungen der Lunge und Pleura

$960 \mathrm{mq}$

Das extrapulmonale kleinzellige Karzinom - eine Rarität?

Gerbstoffe und Krebsrisiko

979 or Risiken der Sonnenexposition

Schistosomiasis und Siegelringzellkarzinom der Ileozökalklappe

1585 adt Sekundäre Neoplasien nach Immunsuppression

1115 kas

Karzinom; kleinzelliges extrapulmonales

Das extrapulmonale kleinzellige Karzinom - eine Rarität?

Karzinom; kolorektales

1573 kas

Adjuvante Therapie bei kolorektalen Karzinomen

Endoskopische Diagnostik zur Prävention und Früherkennung des kolorektalen Karzinoms

\section{Karzinomrisiko}

Hodenkrebsrisiko nach Vasektomie

\section{Katarakt}

Ambulante Kataraktoperationen

Katheter-Rekanalisation; retrograde

Retrograde Katheter-Rekanalisation langstreckiger Verschlüsse der Arteria femoralis superficialis

1477 as

1436 üb

$1604 \mathrm{~km}$

\section{Katheterverschluß; bei} Herzvitien

Nicht-operativer Verschluß des Vorhofseptumdefektes bei Erwachsenen. Erfahrungen mit dem Rashkindund dem Sideris-Okkluder

Kayser-Fleischer-Korneal-

ring

Hämolytische Krise mit Leberversagen als Erstmanifestation eines Morbus Wilson

\section{Keratinolyse}

Harnstoff in der Dermatologie

Keratoconjunctivitis sicca

Sicca-Symptomatik unter systemischer Therapie mit Beta-Rezeptorenblockern

\section{Keratosis solaris}

Solare Keratose und Sonnenschutzmittel
$1411 \mathrm{fr}$

1047 üb

$1058 \mathrm{lz}$

1747 üb

1591 üb

1663 adt

1001 adt

$1757 \mathrm{~km}$

$1486 \mathrm{fr}$ 


\section{Ketokonazol} Therapie kutaner und muko-
kutaner Leishmaniosen

\section{Kinderkardiologie}

Adenosintriphosphat (ATP) bei supraventrikulären Tachykardien im Neugeborenen- und Säuglingsalter

Kinderunfälle; im Straßenverkehr

Kindersitz im Personenwagen bewährt sich

\section{Klappenöffnungsfläche}

Operationsindikation bei asymptomatischer hochgradiger Aortenklappenstenose

Klassifikationen/Stadieneinteilungen

Adjuvante Therapie bei kolorektalen Karzinomen

Diagnostik und Therapie des Analkarzinoms

Sotalol

Therapie der akuten Pankreatitis

\section{Kniegelenkserguß; rezidi-}

\section{vierender}

Baker-Zyste bei osteoartikulärer Tuberkulose des Kniegelenks

Baker-Zyste bei osteoartikulärer Tuberkulose des Kniegelenks (Berichtigung)

\section{Knochenalter}

Differenzierung zwischen prämaturer Thelarche und Pubertas praecox anhand klinischer, hormoneller und radiologischer Befunde

\section{Knochendichte}

Diagnostik des Osteoporoserisikos. Neue Entwicklungen und »State of the Art« 1994

Einfluß einer niedrigdosierten Hydrochlorothiazid therapie auf den Knochenmineralgehalt des axialen und peripheren Skeletts

Osteoporose bei Männern. Pathogenese und klinische Einteilung bei 254 Fällen

\section{Knochenmarktransplanta-} tion

Aufbau der Deutschen Knochenmarkspenderdatei

\section{Knochenmasse}

Diagnostik des Osteoporoserisikos. Neue Entwicklungen und "State of the Art» 1994
Einfluß einer niedrigdosierten Hydrochlorothiazidtherapie auf den Knochenmineralgehalt des axialen und peripheren Skeletts

1351 kas Osteoporose bei Männern. Pathogenese und klinische Einteilung bei 254 Fällen

\section{Knochenmetastasen}

Jodinduzierte Hyperthyreose bei metastasiertem Schild-

$976 \mathrm{~km}$ drüsenkarzinom

\section{Knochenstoffwechsel}

1630 üb Asymptomatischer primärer Hyperparathyreoidismus. Behandeln oder beobachten?

Diagnostik des Osteoporoserisikos. Neue Entwicklungen und "State of the Art« 1994

1663 adt Einfluß einer niedrigdosierten Hydrochlorothiazidtherapie auf den Knochenmineralgehalt des axialen und peripheren Skeletts

1477 as

1739 adt

\section{Kognitionsstörungen}

Neuropsychiatrische Symptomatik bei primärem Hyperparathyreoidismus

1579 kas Kollagenosen

Diagnostik und Bedeutung von antinukleären Antikörpern

\section{Kolonbiopsie}

Zeitintervall zwischen Koloskopie mit Biopsie und

1301 or Kolonkontrasteinlauf

\section{Kolonkarzinom}

Adjuvante Chemotherapie beim operierten Kolonkarzinom

Adjuvante Therapie bei kolorektalen Karzinomen

\section{Kolonkontrasteinlauf}

1645 or Zeitintervall zwischen Koloskopie mit Biopsie und Kolonkontrasteinlauf

\section{Kolontuberkulose}

Endoskopische Diagnose

943 or einer Kolontuberkulose

\section{Koloskopie}

Zeitintervall zwischen Koloskopie mit Biopsie und Kolonkontrasteinlauf

1359 adt

Komplikationen; bei diagnostischen Eingriffen

Zeitintervall zwischen Koloskopie mit Biopsie und Kolonkontrasteinlauf
1645 or Komplikationen; bei operativen Eingriffen

Pyloruserhaltung - »a never ending story «

$1372 \quad \mathrm{lz}$

943 or Komplikationen; bei therapeutischen Eingriffen

Akute Hämolyse mit nachfolgender lebensbedrohlicher Pankreatitis bei Hämodia-

1573 kas lyse. Eine Komplikation, die von den derzeitigen Dialysegeräten nicht verhindert wird

967 üb Akuter Koronargefäßverschluß nach elektiver perkutaner transluminaler Koronarangioplastie. Inzidenz und Therapie bei

1289 üb 5000 konsekutiven Patienten

1645 or Farbdopplersonographisch gesteuerte perkutane Alkoholinstillation zur Therapie der funktionellen Schilddrüsenautonomie

Langzeitdilatation bei erfolgloser perkutaner transluminaler Koronarangioplastie

Schrittmachertherapie beim Syndrom des kranken Sinusknotens. Senken vor-

$1137 \quad \mathrm{lz} \quad$ hofbeteiligte Schrittmachersysteme die Häufigkeit von Vorhofflimmern und thromboembolischen Komplikationen sowie die Mortalität?

\section{3 fr Konsensuskonferenz}

Ist die Ulcuskrankheit eine Infektionskrankheit?

$1488 \mathrm{~km}$

\section{1 fr Kontaktekzem}

Eczema craquelé

$1203 \mathrm{mq}$

Kontrazeption; hormonelle

1663 adt Orale Kontrazeption bei 1100 fr Protein-C-Mangel

\section{Kopfschmerzen}

1333 fr Kopfschmerzen unter Ciclosporin-Therapie

1135 fr

\section{Koronarmorphologie}

Wiedereröffnung chronischer Koronararterienverschlüsse: Welche Faktoren beeinflussen den Erfolg?

\section{3 fr Koronarverschlüsse}

Akuter Koronargefäßverschluß nach elektiver perkutaner transluminaler Koronarangioplastie. Inzidenz und Therapie bei

1333 fr 5000 konsekutiven Patienten

\section{Rubrikenschlüssel}

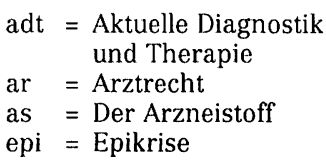

$\mathrm{fr} \quad=$ Fragen aus der Praxis
gt $=$ Gedenktage
kas $=$ Kasuistiken
km $=$ Kleine Mitteilungen
kom $=$ Kommentare
la = Leitartikel
$\mathrm{lz}=$ Leser-Zuschriften
$\mathrm{mg}=$ Medizingeschichte
$\mathrm{mq}=$ Mediquiz
$\mathrm{nk}=$ Nekrologe

\author{
or $=$ Originalien \\ $\mathrm{pp}=$ Prinzip \& Perspektive \\ stp = Standpunkte \\ üb $=$ Übersichten
}


Wiedereröffnung chronischer Koronararterienverschlüsse: Welche Faktoren beeinflussen den Erfolg?

Kostenentwicklung; im Gesundheitswesen

ICD-Verschlüsselung und Pflege-Personalregelung

Kostenvergleich zwischen der laparoskopischen Cholezystektomie und der extrakorporalen Stoßwellenlithotripsie in der Behandlung von Gallenblasensteinen

\section{Krampfanfälle}

Zerebrale Anfälle unter Doxepin während einer Substitution mit Dihydrocodein

Kreatinkinaseerhöhung

Akutes myoglobinurisches Nierenversagen als Folge von autoaggressivem Verhalten bei Oligophrenie

\section{Krebsrisiko}

Britische Atomwaffentests der fünfziger und sechziger Jahre

\section{Krisen; hypertonische}

Symptomatik und endokrinologische Befunde bei katecholamin-sezernierenden Tumoren. Ergebnisse bei 106 konsekutiven Patienten

Kryoglobulinämie; Typ II Chronische Hepatitis C bei Typ-II-Kryoglobulinämie und kutaner Vaskulitis

\section{Kryptorchismus}

Kallmann-Syndrom. Pathophysiologie und Klinik

\section{Kupferstoffwechsel}

Hämolytische Krise mit Leberversagen als Erstmanifestation eines Morbus Wilson

\section{Kyphoskoliose}

Ventilatorische Insuffizienz und hyperkapnische Kompensation infolge chronisch belasteter "Atempumpe«. Physiologie, Pathophysiologie und Therapie

\section{$\mathbf{L}$}

\section{Laboratoriumsmedizin}

Die erhöhte Gamma-GT (Gamma-Glutamyltransferase). Ursachen und Interpretationen

Klinische Bedeutung der Polymerase-Kettenreaktion in der Infektiologie

Persistierende Antistreptolysin-Titer

Sputumuntersuchung zur Diagnostik der Pneumocystiscarinii-Pneumonie bei HIV Infizierten
1766 or Langzeitdilatation; von

Koronarstenosen

Langzeitdilatation bei erfolgloser perkutaner transluminaler Koronarangioplastie

1412 lz phie

\section{Langzeit-Elektrokardiogra-}

Akute Myokardischämie, ventrikuläre Tachyarrhythmien und plötzlicher Herztod

Langzeit-pH-Manometrie

Diagnostik der gastroösophagealen Refluxkrankheit

\section{Lansoprazol}

1260 lz Therapie der gastroösophagealen Refluxkrankheit

\section{Laparoskopie}

Derzeitiger Stellenwert der

994 kas Laparoskopie in der onkologischen Chirurgie

Laparoskopische Cholezystektomie nach Lebervoroperation

$1413 \mathrm{~km}$ Larson-Syndrom

Larson-Syndrom

Larva migrans cutanea

Larva migrans cutanea

1721 or (»creeping eruption«)

Lavage; bronchoalveoläre

Sputumuntersuchung zur Diagnostik der Pneumocystiscarinii-Pneumonie bei HIVInfizierten

1239 kas LDL-Apherese

Intensivtherapie des GuillainBarré-Syndroms

gungen

Bleiintoxikation durch Mennige in Paprikapulver

1421 kas Lebertransplantation

Hämolytische Krise mit Leberversagen als Erstmanifestation eines Morbus Wilson

1209 üb Therapie des Aszites bei Lebererkrankungen

Lebervenenverschlußdruck

Lebervenenverschlußdruckmessung

Leberversagen; akutes

Hämolytische Krise mit Leberversagen als Erstmanifestation eines Morbus Wilson

1041 Leberzellkarzinom

Epidemiologie und Klinik der chronischen Virushepatitis

Lecithin-Cholesterin-Acyl-

1625 adt transferase

Fischaugenkrankheit

1099 fr Lehre; medizinische

Welches Menschenbild formt zukünftige Ärztinnen und Ärzte an der Universität?
Leiomyom; des Magens

Leiomyom des Magens

$1167 \mathrm{mq}$

1458 or Leishmaniosen; mukokutane

Therapie kutaner und mukokutaner Leishmaniosen

1169 adt

Leistenhernien

1786 üb Eingeklemmte Leistenhernie. Hydrocele testis

Leitungsbahnen; akzessorische

1433 adt

Klinische Bedeutung des Ajmalin-Tests in der nichtinvasiven Diagnostik bei Wolff-Parkinson-WhiteSyndrom

1473 adt

\section{Leukenzephalopathie}

Leukenzephalopathie nach intrathekaler Zytostatikagabe bei akuter lymphatischer Leukämie

1184 lz Levamisol

Adjuvante Chemotherapie beim operierten Kolonkarzinom

$1584 \mathrm{mq}$ Adjuvante Therapie bei kolorektalen Karzinomen

$1358 \mathrm{mq}$

985 or

$1637 \quad \mathrm{f}$

$1505 \mathrm{mq}$ LH-FSH-Quotient

Differenzierung zwischen prämaturer Thelarche und Pubertas praecox anhand klinischer, hormoneller und radiologischer Befunde

\section{LHRH-Test}

Differenzierung zwischen prämaturer Thelarche und Pubertas praecox anhand klinischer, hormoneller und radiologischer Befunde

\section{Lichtstrahlen}

1756 lz Risiken der Sonnenexposition

1047 üb

Linksherzinsuffizienz

1421 kas

Hypocalcämische Kardiomyo1270 kas pathie als Ursache einer schweren Linksherzinsuffizienz

1549 adt

Hypocalcämische Kardiomyopathie als Ursache einer schweren Linksherzinsuffizienz (Berichtigung)

\section{5 adt Lipidsenker}

Gallenblasen-Sludge und Einnahme von Lipidsenkern

1421 kas

Hypercholesterinämie

1524 fr

Lipom; intragastrales

Lipom mit zentraler Ulzeration und Blutung

\section{Liposomen}

1365 üb Behandlung der Neurodermitis mit Liposomen?

\section{Liquorzirkulationsstörun-}

gen

1393 kas

Syringomyelie als seltene Ursache einer beatmungspflichtigen respiratorischen Insuffizienz
$1099 \mathrm{fr}$

$1547 \mathrm{mq}$

1219 fr 
Lisinopril

GISSI III: Wirkung von Lisinopril und transdermaler Applikation von Nitroglycerin nach akutem Herzinfarkt

Litholyse; adjuvante orale

Kostenvergleich zwischen der laparoskopischen Cholezystektomie und der extrakorporalen Stoßwellenlithotripsie in der Behandlung von Gallenblasensteinen

\section{Lungenarterien}

Pathologie der Pulmonalarterien bei Lungentumoren

\section{Lungenembolie}

Direkter Embolusnachweis durch Spiral-Computertomographie bei akuter Lungenembolie

Einsatz von niedermolekularem Heparin zur Antikoagulation in der Schwangerschaft

\section{Lungentransplantation}

Differentialdiagnose von Rundherden nach Lungentransplantation

\section{Lungenverschattungen}

Bromocriptin-induzierte Pleuropneumopathie

Differentialdiagnose von Rundherden nach Lungentransplantation

Einseitige diffuse Lungenbeteiligung bei Vaskulitis mit Anti-NeutrophilenZytoplasma-Antikörpern sowie Antikörpern gegen glomeruläre Basalmembranen

\section{Lupus erythematodes}

Diagnostik und Bedeutung von antinukleären Antikörpern

\section{Lyme-Arthritis}

Nachweis von Borreliaburgdorferi-DNA in der Gelenkflüssigkeit bei LymeArthritis

\section{Lymphographie}

Kontrastmittelspeichernde Lymphknoten nach Lymphographie

\section{Lymphome; maligne}

Hochmalignes peripheres T-Zell-Lymphom vom großzelligen polymorphen Typ
$1804 \mathrm{~km}$

Lymphozytenkultur;

\section{gemischte}

Aufbau der Deutschen Knochenmarkspenderdatei

\section{Lynch-Syndrom}

Endoskopische Diagnostik zur Prävention und Früh-

1532 or erkennung des kolorektalen Karzinoms

\section{Lysetherapie}

(siehe Fibrinolyse)

\section{M}

\section{5 or Magenkarzinom}

Adjuvante Chemotherapie nach kurativer Gastrekto-

$1525 \mathrm{lz}$ mie bei Magenkarzinom Ist die Ulcuskrankheit eine Infektionskrankheit?

1497 kas

Magensäuresekretion Omeprazol

\section{Magenstumpfkarzinom}

Photodynamische Therapie eines Magenstumpfkarzi-

1105 or noms in kurativer Absicht. Erster Fallbericht einer klinischen Anwendung in Deutschland

\section{3 kas Magnesium}

Magnesium

1105 or Magnesium bei Herzinfarkt

Magnesium-Infusion bei akutem Herzinfarkt

1071 kas Makroglobulinurie

Langzeitbeobachtung bei lymphoplasmozytoiden Immunozytomen

\section{Malabsorption}

Zystische Fibrose

\section{MALT}

$1137 \mathrm{lz}$ (siehe Mucosa-Associated Lymphatic Tissue)

\section{Mamma-Augmentationspla-} stik

$1451 \mathrm{~km}$ Kernspintomographie bei Mammaprothesen. Aussagekraft im Vergleich mit Mammographie und Ultraschall

\section{$1700 \mathrm{mq}$ Mammakarzinom}

Autoimmunprozesse als para- 1194 kas neoplastische Manifestationen bei familiärem Mammakarzinom

$1321 \mathrm{mq}$ Kernspintomographie bei Mammaprothesen. Aussagekraft im Vergleich mit Mammographie und Ultraschall
Tumorgefäßinvasion beim

1491 or Mammakarzinom. Häma-

1359 adt toxylin-Eosin- versus immunhistochemische Färbung gegen Faktor-VIIIAntigen

1001 adt

\section{Mammaprothesen}

Kernspintomographie bei Mammaprothesen. Aussagekraft im Vergleich mit Mammographie und Ultraschall

\section{Manometrie; des Öso-}

phagus

Diagnostik der gastroösophagealen Refluxkrankheit

1298 km Marker; biochemische

Die klinische Bedeutung der Konzentrationsbestimmung

$1488 \cdot \mathrm{km}$ der Troponine

\section{Mastozytose}

Schock und Gerinnungsstörungen bei systemischer Mastozytose

Urticaria pigmentosa

951 kas

Mastzellenleukämie

Schock und Gerinnungsstörungen bei systemischer Mastozytose

\section{Mediawandverdickung}

Angina pectoris und normales Koronarangiogramm bei arterieller Hypertonie und linksventrikulärer Hypertrophie

1669 as

1800

\section{Medikamenteninteraktio-}

$1487 \quad \mathrm{lz}$

nen

(siehe Interaktionen; von Medikamenten)

\section{Medizingeschichte}

1259 lz Hermann von Helmholtz (1821-1894) - Militärarzt, Sinnesphysiologe und »Reichskanzler der deutschen Physik«. Zum 100. Todestag des universalen Arztes und Naturforschers

1453 or Welches Menschenbild formt zukünftige Ärztinnen und Ärzte an der Universität?

\section{Medizinphilosophie}

Welches Menschenbild formt zukünftige Ärztinnen und Ärzte an der Universität?

\section{Melanom; malignes}

Risiken der Sonnenexposition

1453 or

\section{Melarsoprol}

Polyneuritis und Myositis bei Trypanosoma-gambienseInfektion
1047

üb

1453 or

1433 adt

1231 kas

1053 fr

1231 kas

1175 üb

$1215 \mathrm{mg}$

1131 kom

1131 kom
Rubrikenschlüssel

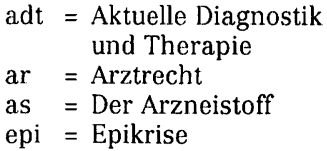

fr $\quad$ Fragen aus der Praxis

$\mathrm{gt}=$ Gedenktage

kas $=$ Kasuistiken

$\mathrm{km}=$ Kleine Mitteilungen

kom $=$ Kommentare

\author{
$\mathrm{a}=$ Leitartike \\ $\mathrm{l}$ = Leser-Zuschriften \\ $\mathrm{mg}=$ Medizingeschichte \\ $\mathrm{mq}=$ Mediquiz \\ $\mathrm{nk}=$ Nekrologe
}

or $=$ Originalien
pp $=$ Prinzip \& Perspektive
stp $=$ Standpunkte
üb $=$ Übersichten 
Meningitis

Präsakrale Phlegmone und Meningitis als Komplikationen eines Fremdkörpers im Rektosigmoid

\section{Mennige}

Bleiintoxikation durch Mennige in Paprikapulver

Mesenterialarterien-

\section{stenosen}

Chronische mesenteriale Ischämie

Metajodbenzylguanidinszintigraphie

Symptomatik und endokrinologische Befunde bei katecholamin-sezernierenden Tumoren. Ergebnisse bei 106 konsekutiven Patienten

\section{Metall-Clip}

Clip-Wanderung in den Ductus choledochus nach laparoskopischer Cholezystektomie

\section{Methotrexat}

Leukenzephalopathie nach intrathekaler Zytostatikagabe bei akuter lymphatischer Leukämie

\section{Methylprednisolon}

Problematik des Äquivalenzbegriffes bei der Therapie mit Glucocorticoiden. Ein Vergleich der klinischen Pharmakokinetik und Pharmakodynamik von Prednisolon und Methylprednisolon

\section{Microsporon canis}

Tinea capitis durch Microsporon canis

\section{Migräne}

Fibromyalgie-Syndrom

Mikroalbuminämie

Angiotensin-ConvertingEnzym-Hemmer bei der Behandlung der diabetischen Nephropathie

Mikrozirkulation; koronare

Angina pectoris und normales Koronarangiogramm bei arterieller Hypertonie und linksventrikulärer Hypertrophie

\section{Miktionsstörungen}

Aktuelle Epidemiologie, Diagnostik und Therapie der Urogenitaltuberkulose

\section{Minderwuchs}

Diagnose eines Ullrich-Turner-Syndroms im Rentengutachten

Minimal Invasive Surgery

(siehe Operationen; endoskopische)

\section{Minor Access Surgery}

(siehe Operationen; endoskopische)
Mischtumor; der Haut

990 kas Sogenannter Mischtumor der Haut (chondroides Syndrom)

Mitralinsuffizienz; akute

Akute Mitralinsuffizienz be Osteogenesis imperfecta

Notfallmäßige perkutane Mitralvalvuloplastie mit dem Inoue-Ballon bei hochgradiger Mitralstenose und kardiogenem Schock

979 or

Mitralklappenprolaps

Akute Mitralinsuffizienz bei Osteogenesis imperfecta

1721 or Zerebraler ischämischer Insult. Wertigkeit der transösophagealen Echokardiographic in der Diagnostik kardialer Emboliequellen

\section{$1506 \mathrm{mq}$}

Mitralstenose
Notfallmäßige perkutane Mitralvalvuloplastie mit dem Inoue-Ballon bei hochgradiger Mitralstenose und kardiogenem Schock

\section{7 fr Mitralvalvuloplastie}

Notfallmäßige perkutane Mitralvalvuloplastie mit dem Inoue-Ballon bei hochgradiger Mitralstenose und kar-

1671 üb diogenem Schock

Mißbildungen; konnatale

Kongenital korrigierte Transposition der großen Arterien im Erwachsenenalter. Wert nicht-invasiver Untersuchungsmethoden

Prader-Labhart-WilliSyndrom

$1357 \mathrm{mq}$ Molekulargenetik

Prader-Labhart-WilliSyndrom

\section{9 lz Morbus Basedow}

Jodprophylaxe in der

$1298 \mathrm{~km} \quad$ Schwangerschaft

Neonatale Hyperthyreose bei nicht diagnostiziertem Morbus Basedow der Mutter. Probleme der Diagnostik und Therapie anhand

1175 üb einer Kasuistik

\section{Morbus Crohn}

Diättherapie des Morbus Crohn

Endoskopische Ballondilatation symptomatischer Strikturen bei Morbus Crohn

Hochgradige Sigmastenose bei Rezidiv eines Morbus Crohn

1115 kas

Luft in der Blase durch Fistelverbindung zum Darm

\section{Morbus Down}

(siehe Trisomie 21)

\section{Morbus Fabry}

Angiokeratoma corporis diffusum

$1471 \mathrm{mq}$

Morbus haemolyticus neonatorum

Neonatale Alloimmunthrombozytopenie

1512 üb

Morbus Köhlmeier-Dégos

$1101 \mathrm{lz}$ Maligne atrophische Papulose 1427 kas

1110 kas Morbus Paget

Ostitis deformans (Morbus Paget)

Morbus Parkinson

Bromocriptin-induzierte Pleuropneumopathie

\section{$1101 \mathrm{lz}$ Morbus Waldenström}

Langzeitbeobachtung bei

1585 adt lymphoplasmozytoiden Immunozytomen

\section{Morbus Whipple}

Nachweis von Tropheryma whippelii mit der Polymerase-Kettenreaktion vor und nach Therapie eines Morbus Whipple

\section{Morbus Wilson}

Hämolytische Krise mit Leberversagen als Erstmanifestation eines Morbus

1110 kas Wilson

\section{Morphometrie}

Diagnostik des Osteoporoserisikos. Neue Entwicklungen und »State of the Art« 1994

1156 kas

Mucosa-Associated

Lymphatic Tissue

Ist die Ulcuskrankheit eine Infektionskrankheit?

974 fr

$974 \mathrm{fr}$

1339 la

1346 kas

Muir-Torre-Syndrom

Endoskopische Diagnostik zur Prävention und Früherkennung des kolorektalen Karzinoms

\section{Mukoviszidose}

Zystische Fibrose

Multiple Sklerose

Therapie der multiplen Sklerose

\section{Muskelatrophie}

Neurologische Symptomatik, Diagnostik und Therapie des sogenannten »thoracicoutlet-syndrome«
$1140 \mathrm{~km}$

1377 or

Muskelphysiologie

Hermann von Helmholtz (1821-1894) - Militärarzt, Sinnesphysiologe und »Reichskanzler der deutschen Physik «. Zum 100. Todestag des universalen Arztes und Naturforschers

\section{Muskelschmerzen}

(siehe Myalgien)

Müdigkeit

Müdigkeit und psychologischer Streß
$1122 \mathrm{mq}$

1543 kas

$1487 \quad \mathrm{lz}$

$1679 \quad \mathrm{lz}$

1421 kas

1289 üb

$1488 \mathrm{~km}$

1001 adt

$1259 \mathrm{lz}$

1371 fr

1087 üb

$1215 \mathrm{mg}$

$1281 \mathrm{mq}$
$1451 \mathrm{~km}$ 
Müdigkeitssyndrom; chronisches

Chronische Müdigkeit und Herpes-Virus-Antikörper Fibromyalgie-Syndrom

Myalgien

Fibromyalgie-Syndrom

Mycobacterium tuberculosis

Endoskopische Diagnose einer Kolontuberkulose

Ösophago-mediastinale Fisteln als seltene Komplikation der Tuberkulose bei einem HIV-infizierten

Patienten

\section{Myelopathie}

Syringomyelie als seltene Ursache einer beatmungspflichtigen respiratorischen Insuffizienz

\section{Myoepitheliom}

Myoepitheliom (myoepitheliales Adenom)

\section{Myoglobinurie}

Akutes myoglobinurisches Nierenversagen als Folge von autoaggressivem Verhalten bei Oligophrenie

\section{Myokarddurchblutung}

Pathophysiologie der Myokarddurchblutung. Teil I: Adaptation an Myokardischämie (»hibernating «Myokard)

Pathophysiologie der Myokarddurchblutung. Teil II: Postischämische kontraktile Dysfunktion (»stunned «-Myokard)

\section{Myokardinfarkt}

Angiotensin-ConvertingEnzym-Hemmer nach Herzinfarkt

Beta-Rezeptorenblocker als Notfallmaßnahme nach akutem Herzinfarkt?

Die klinische Bedeutung der Konzentrationsbestimmung der Troponine

GISSI III: Wirkung von Lisinopril und transdermaler Applikation von Nitroglycerin nach akutem Herzinfarkt

Magnesium bei Herzinfarkt

Magnesium-Infusion bei akutem Herzinfarkt

Thrombolyse bei akutem Herzinfarkt
Myokardischämie; akute

1296 fr trikuläre Tachyarrhythmien und plötzlicher Herz-

$1639 \mathrm{lz} \quad \begin{gathered}\text { tod } \\ \text { Zentralnervöse Vermittlung }\end{gathered}$ der Angina pectoris

1639 lz Myokarditis

Polyneuritis und Myositis bei Trypanosoma-gambienseInfektion

1653 kas

1613 kas Myositis

Polyneuritis und Myositis bei Trypanosoma-gambienseInfektion

\section{$\mathbf{N}$}

1771 kas

\section{Nabel-Pouch}

Aktuelle Möglichkeiten des kontinenten Harnblasenersatzes

$1091 \mathrm{mq}$ Nachsorge; nach Malignombehandlung

Diagnostik und Therapie des Analkarzinoms

994 kas

Nachtsehschwächen

Fischaugenkrankheit

Nadelstichverletzung

1589 pp zung bei medizinischem Pflegepersonal

Nahrungsmittelvergiftung

Ciguatera. Neue Fälle von Fischvergiftung bei deutschen Karibik-Urlaubern

\section{Nebennierenrindenhyper-}

plasie

Symptomatik und endokrinologische Befunde bei kate-

1448 fr cholamin-sezernierenden Tumoren. Ergebnisse bei 106 konsekutiven Patienten

1715 fr Nebenwirkungen; medikamentöse

Adjuvante Therapie bei kolorektalen Karzinomen

Akute Ischämie eines Armes als ungewöhnlicher Ausdruck eines Ergotismus

Angiotensin-ConvertingEnzym-Hemmer nach Herzinfarkt

Bromocriptin-induzierte Pleuropneumopathie

1800 fr Gallenblasen-Sludge und Einnahme von Lipidsenkern

1220 lz Hepatitis-A-Impfung

Hohe Letalität von Tetanusinfektionen nach intramuskulärer Injektion von Chinin
Immunglobuline zur Thera-

$1449 \quad \mathrm{lz}$ pie des Guillain-Barré-Syndroms im Kindesalter

Komplette Remission bei akuter Promyelozytenleukämie. Vorteile von alltrans-Retinsäure im Vergleich mit konventioneller Chemotherapie

1690 kas Kopfschmerzen unter Ciclosporin-Therapic

Leukenzephalopathie nach intrathekaler Zytostatikagabe bei akuter lymphatischer Leukämie

Magnesium

Medikament.ös ausgelöste Asterixis

Placebo-kontrollierte Untersuchung zur Wirksamkeit der Influenza-Schutzimpfung?

1327 üb Primär kutane Nocardia-farci- 1276 kas nica-Infektion nach Herztransplantation

Primär kutane Nocardia-farcinica-Infektion nach Herztransplantation (Berichtigung)

Psychosoziale Probleme bei Langzeitimmunsuppression nach Organtransplantation

Reversible Thrombozytopenie bei Digitoxinüberdosierung

Rolle von Endothelin bei den Ciclosporin-Nebenwirkungen Nephrotoxizität und

975 lz arterielle Hypertonie

Schwere Panzytopenie im hohen Lebensalter nach zwölfmonatiger ACE-Hemmer-Therapie

Sekundäre Neoplasien nach Immunsuppression

Sicca-Symptomatik unter systemischer Therapie mit Beta-Rezeptorenblockern

Sotalol

Therapie einer Clozapin-induzierten Agranulozytose mit granulozytenkolonie-stimulierendem Faktor

Unverträglichkeit der Tuberkulosetherapie bei AIDS

\section{Nematoden}

1448 fr Gnathostomiasis nach Aufenthalt in Thailand

1135 fr

1637 fr

1669 as

$1221 \mathrm{lz}$

$1057 \quad \mathrm{lz}$

1568

$1678 \quad \mathrm{lz}$

1734 kas

1706 üb

1029 kas

1747 üb

$1783 \mathrm{adt}$

1477 as

1467 kas

1728 kas

1543 kas Neonatologie

Adenosintriphosphat (ATP) bei supraventrikulären Tachykardien im Neugeborenen- und Säuglingsalter 1800 fr $\begin{gathered}\text { renen- und Sauglingsalter } \\ 1681 \mathrm{~km} \text { Neonatale Alloimmunthrom- }\end{gathered}$ bozytopenie
1618 kas

1351 kas

1512 üb

\footnotetext{
Rubrikenschlüssel

adt $=$ Aktuelle Diagnostik und Therapie

ar $=$ Arztrecht

as $=$ Der Arzneistoff

epi $=$ Epikrise
}

fr $=$ Fragen aus der Praxis

gt $=$ Gedenktage

kas $=$ Kasuistiken

$\mathrm{km}=$ Kleine Mitteilungen

kom $=$ Kommentare la = Leitartikel

$\mathrm{lz}=$ Leser-Zuschriften

$\mathrm{mg}=$ Medizingeschichte

$\mathrm{mq}=$ Mediquiz

$\mathrm{nk}=$ Nekrologe or $=$ Originalien

pp = Prinzip \& Perspektive

stp = Standpunkte

üb $=$ Übersichten 
Neoplasie; Multiple Endokrine; Typ II A

Interdisziplinäre Aspekte der Notalgia paraesthetica

Neoplasien; okkulte

Tiefe Venenthrombose und okkulte, maligne Neoplasien

Neoplasien; sekundäre nach Immunsuppression

Sekundäre Neoplasien nach Immunsuppression

Nephrocalcinose

Asymptomatischer primärer Hyperparathyreoidismus. Behandeln oder beobachten?

\section{Nephrolithiasis}

Asymptomatischer primärer Hyperparathyreoidismus. Behandeln oder beobachten?

Nephropathie; diabetische

Angiotensin-ConvertingEnzym-Hemmer bei der Behandlung der diabetischen Nephropathie

Intensivierte Behandlung des Diabetes mellitus Typ I und Entwicklung von Spätkomplikationen

\section{Nephrotoxizität}

Rolle von Endothelin bei den Ciclosporin-Nebenwirkungen Nephrotoxizität und arterielle Hypertonie

\section{Nervenkompressions-}

\section{syndrome}

Interdisziplinäre Aspekte der Notalgia paraesthetica

Neurologische Symptomatik Diagnostik und Therapie des sogenannten »thoracicoutlet-syndrome«

Nervenleitgeschwindigkeit Hermann von Helmholtz (1821-1894) - Militärarzt, Sinnesphysiologe und »Reichskanzler der deutschen Physik«. Zum 100. Todestag des universalen Arztes und Naturforschers

Neuralgie; postzosterische

Wirksamkeit von Aciclovir und Glucocorticoiden in der Behandlung des Herpes zoster und postzosterischer Neuralgien

\section{Neurodermitis}

(siehe Ekzem; endogenes)

\section{Neuroleptika}

Ambulante Behandlung von Schlafstörungen im Alter
Neurologie

Hermann von Helmholtz (1821-1894) - Militärarzt, Sinnesphysiologe und »Reichskanzler der deutschen Physik «. Zum 100. Todestag des universalen Arztes und Naturforschers

Neuropathie; sensible

Interdisziplinäre Aspekte der Notalgia paraesthetica

1747 üb Neurotoxizität

Kopfschmerzen unter Ciclosporin-Therapie

\section{7 üb Nicotinpflaster}

Nicotinpflaster bei Colitis ulcerosa

Niereninsuffizienz; akute

967 üb Akutes myoglobinurisches Nierenversagen als Folge von autoaggressivem Verhalten bei Oligophrenie

Einseitige diffuse Lungenbeteiligung bei Vaskulitis mit Anti-Neutrophilen-Zytoplasma-Antikörpern sowie Antikörpern gegen glomeruläre Basalmembranen

976 km Hämolytische Krise mit Leberversagen als Erstmanifestation eines Morbus Wilson

\section{Niereninsuffizienz; chroni-}

\section{6 üb sche}

Akute Hämolyse mit nachfolgender lebensbedrohlicher Pankreatitis bei Hämodialyse. Eine Komplikation, die von den derzeitigen Dia-

1307 kas lysegeräten nicht verhindert wird

1087 üb Glomeruläre Hyperperfusion und Niereninsuffizienz

Impfungen bei chronischer Niereninsuffizienz und nach Nierentransplantation

$1215 \mathrm{mg}$ Nierentransplantation

Impfungen bei chronischer Niereninsuffizienz und nach Nierentransplantation

Kombinierte Nieren- und Pankreastransplantation beim diabetischen Spätsyndrom

\section{Nierenzysten}

$1526 \mathrm{~km}$ Rupturgefahr bei Nierenzysten

Nitroglycerin; transdermal

GISSI III: Wirkung von Lisinopril und transdermaler Applikation von Nitroglycerin nach akutem Herzinfarkt

1538 or NO

(siehe Stickstoffmonoxid)

Nobelpreise für Medizin

Nobelpreis für Medizin 1994

\section{Nokardiose}

Primär kutane Nocardia-farci- 1276 kas nica-Infektion nach Herztransplantation
1792 kom

Primär kutane Nocardia-farci- 1568

$1215 \mathrm{mg}$ nica-Infektion nach Herztransplantation (Berichtigung)

Non-Hodgkin-Lymphome

Gamma-Schwerketten-Produktion als Epiphänomen bei Non-Hodgkin-Lymphom

Langzeitbeobachtung bei lymphoplasmozytoiden Immunozytomen

Non-Responder; nach akti-

1135 fr ver Immunisierung

Impfungen bei chronischer

Niereninsuffizienz und nach Nierentransplantation

$1261 \mathrm{~km}$

Normalwerte

Cholesterin-Normalwerte im Kindesalter

994 kas

Persistierende Antistreptolysin-Titer

Notalgia paraesthetica

1071 kas Interdisziplinäre Aspekte der Notalgia paraesthetica

\section{Notfallmedizin}

Beta-Rezeptorenblocker als Notfallmaßnahme bei akutem Herzinfarkt?

1235 kas

1421 kas

\section{0}

Oat Cell Karzinom

Das extrapulmonale klein-

1263 or zellige Karzinom - eine Rarität?

Octreotid

Therapie der akuten Pankrea- 1739 adt titis

\section{Okkluder}

1323 adt

des Vorhofseptumdef bei Erwachsenen. Erfahrungen mit dem Rashkindund dem Sideris-Okkluder

1323 adt

Omeprazol

Ist die Ulcuskrankheit eine Infektionskrankheit?

Omeprazol

1399 adt Therapie der gastroösophagealen Refluxkrankheit

Operationen; endoskopische

1486 fr Derzeitiger Stellenwert der Laparoskopie in der onkologischen Chirurgie $1804 \mathrm{~km} \quad \begin{array}{r}\text { Laparoskopische Cholezystek- } \\ \text { tomie nach Lebervoropera- }\end{array}$ tion

Methoden der interventionellen Pneumologie

Möglichkeiten der laparoskopischen Therapie innerer Hernien. Darstellung an drei Fällen

Operationen; laparoskopische

(siehe Operationen; endoskopische)
1591 üb

1323 adt

1371 fr

$1099 \mathrm{fr}$

1307 kas

1715 fr

1341 or

$1488 \mathrm{~km}$

1173 as

1473 adt

1518 kom

$1184 \quad \mathrm{lz}$

$1083 \mathrm{adt}$

1199 kas 
Operieren; ambulantes

Ambulante Kataraktoperationen

\section{Osteodensitometrie}

Diagnostik des Osteoporoserisikos. Neue Entwicklungen und »State of the Art« 1994

Einfluß einer niedrigdosierten Hydrochlorothiazid therapie auf den Knochenmineralgehalt des axialen und peripheren Skeletts

\section{Osteomyelitis}

Lumbale Spondylodiszitis durch Salmonella enteritidis

\section{Osteopathien}

Ostitis deformans (Morbus Paget)

\section{Osteoporose}

Diagnose eines UllrichTurner-Syndroms im Rentengutachten

Diagnostik des Osteoporoserisikos. Neue Entwicklungen und »State of the Art « 1994

Einfluß einer niedrigdosierten Hydrochlorothiazidtherapie auf den Knochenmineralgehalt des axialen und peripheren Skeletts

Osteoporose bei Männern Pathogenese und klinische Einteilung bei 254 Fällen

Vitamin D und Osteoporose. Pathogenese - Therapie

\section{Ovarialzysten}

Differenzierung zwischen prämaturer Thelarche und Pubertas praecox anhand klinischer, hormoneller und radiologischer Befunde

\section{Ozon}

Risiken der Sonnenexposition

Ösophagitis

Diagnostik der gastroösophagealen Refluxkrankheit

Therapie der gastroösophagealen Refluxkrankheit

Ösophagitis-Klassifikation Therapie der gastroösophagealen Refluxkrankheit

Ösophaguskarzinom

Ösophaguskarzinom

Ösophagusmanometrie

(siehe Manometrie; des Ösophagus)

\section{Ösophagusmotilität}

Diagnostik der gastroösophagealen Refluxkrankheit
Ösophagusvarizen

1486 fr Endoskopische Therapie der Ösophagusvarizenblutung

Fundusvarizen

1289 üb

1645 or PAl-1

(siehe Fibrinolyse)

Palliation

Derzeitiger Stellenwert der Laparoskopie in der onkologischen Chirurgie

1383 kas Endoskopische transthorakale Sympathektomie bei paraneoplastischem Raynaud-Syndrom

$1122 \mathrm{mq}$ Pankreasabszeß

Therapie der akuten Pankreatitis

1115 kas Pankreas-Duodenum-Nieren-Transplantation; simultane

1289 üb Kombinierte Nieren- und Pankreastransplantation beim diabetischen Spätsyndrom

\section{5 or Pankreasinsuffizienz}

Zystische Fibrose

Pankreaskarzinom

943 or Pankreaskopfkarzinom mit Stenosen der Ductus pancreaticus et choledochus

Pyloruserhaltung - "a never ending story «

Pankreaspseudozyste

ERCP bei bekannter

Pankreaspseudozyste

Therapie der akuten Pankreatitis

Pankreastransplantation

Kombinierte Nieren- und Pan- 1399 adt

kreastransplantation beim diabetischen Spätsyndrom

\section{Pankreatitis}

1433 adt

1473 adt

Akute Hämolyse mit nachfolgender lebensbedrohlicher Pankreatitis bei Hämodialyse. Eine Komplikation die von den derzeitigen Dia-

$1473 \mathrm{adt}$ ysegeräten nicht verhindert wird

Therapie der akuten Pankreatitis

$1781 \mathrm{mq}$

\section{Panzytopenie}

Schwere Panzytopenie im hohen Lebensalter nach zwölfmonatiger ACE-Hemmer-Therapie

\section{3 adt Paprikapulver}

Bleiintoxikation durch Mennige in Paprikapulver
1443 kom

$959 \mathrm{mq}$

1518 kom

1162 kas

Gnathostomiasis nach Aufenthalt in Thailand

Larva migrans cutanea (»creeping eruption«)

Paresen; schlaffe

Intensivtherapie des GuillainBarré-Syndroms

\section{PBM}

(siehe Peak-Bone-Mass)

1399 adt

\section{Peak-Bone-Mass}

Osteoporose bei Männern Pathogenese und klinische Einteilung bei 254 Fällen

$1259 \mathrm{lz}$

\section{Pentamidin}

Therapie kutaner und mukokutaner Leishmaniosen

$1168 \mathrm{mq}$

1372 lz Neuropsychiatrische Symptorungen matik bei primärem Hyperparathyreoidismus

\section{5 fr Pest}

1739 adt impfung und -chemoprophylaxe

Peutz-Jeghers-Syndrom

Endoskopische Diagnostik zur Prävention und Früherkennung des kolorektalen Karzinoms

Invagination bei Peutz-

1263 or Jeghers-Syndrom

Pflege-Personalregelung ICD-Verschlüsselung und Pflege-Personalregelung

\section{Pfortaderdruck}

Lebervenenverschlußdruckmessung

\section{Pharmakodynamik}

Problematik des Äquivalenzbegriffes bei der Therapie mit Glucocorticoiden. Ein Vergleich der klinischen Pharmakokinetik und Pharmakodynamik von Predni-

$1756 \quad \mathrm{l}$
1427 kas

1721 or

1618 kas

$1505 \mathrm{mq}$

1248 üb

943 or

1169 adt

1076 kas

$1714 \quad$ fr

1001 adt

$960 \mathrm{mq}$

$1412 \quad \mathrm{lz}$

1245 adt

\footnotetext{
Rubrikenschlüssel

adt $=$ Aktuelle Diagnostik und Therapie

ar $=$ Arztrecht

as $=$ Der Arzneistoff

epi $=$ Epikrise
}

fr $\quad=$ Fragen aus der Praxis

gt $=$ Gedenktage

kas $=$ Kasuistiken

$\mathrm{km}=$ Kleine Mitteilungen

kom $=$ Kommentare

\author{
la = Leitartikel \\ $\mathrm{lz}=$ Leser-Zuschriften \\ $\mathrm{mg}=$ Medizingeschichte \\ $\mathrm{mq}=$ Mediquiz \\ $\mathrm{nk}=$ Nekrologe
}

or $=$ Originalien

$\mathrm{pp}=$ Prinzip \& Perspektive

stp $=$ Standpunkte

üb = Übersichten 


\section{Pharmakokinetik}

Problematik des Äquivalenzbegriffes bei der Therapie mit Glucocorticoiden. Ein Vergleich der klinischen Pharmakokinetik und Pharmakodynamik von Prednisolon und Methylprednisolon

\section{Phlebothrombosen}

Einsatz von niedermolekularem Heparin zur Antikoagulation in der Schwangerschaft

Östrogenantagonisten und Thromboseprophylaxe

Tiefe Venenthrombose und okkulte, maligne Neoplasien

\section{Phlegmone; präsakrale}

Präsakrale Phlegmone und Meningitis als Komplikationen eines Fremdkörpers im Rektosigmoid

\section{Phosphatase; alkalische}

Hämolytische Krise mit Leberversagen als Erstmanifestation eines Morbus Wilson

\section{Phospholipase C}

Rolle von Endothelin bei den Ciclosporin-Nebenwirkungen Nephrotoxizität und arterielle Hypertonie

Phosphorsäureester

Serum-Cholinesterase

Photosensibilisierung

(siehe Therapie; photodynamische)

\section{Physiotherapie}

Zystische Fibrose

\section{Pigmentanomalie}

Interdisziplinäre Aspekte der Notalgia paraesthetica

\section{Plasmapherese}

(siehe Plasmaseparation)

\section{Plasmaseparation}

Intensivtherapie des GuillainBarré-Syndroms

\section{Plasminogenaktivator}

(siehe Fibrinolyse)

\section{Plasmozytom}

Generalisiertes IgG-LambdaPlasmozytom und Stenose eines Cimino-Shunts durch plasmazelluläre Infiltration

\section{Pleuraerguß}

Bromocriptin-induzierte Pleu- 1543 kas ropneumopathie

\section{Pleuramesotheliom;}

\section{malignes}

Asbest-induzierte Erkrankun- 1603 lz gen der Lunge und Pleura

\section{Pleuritis}

Bromocriptin-induzierte Pleuropneumopathie

1497 kas

1694 kas
Plexus brachialis 1671 üb Neurologische Symptomatik, des sogenannten "thoracicoutlet-syndrome"

\section{Pneumocystis-carinii-}

Pneumonie

Sputumuntersuchung zur Diagnostik der Pneumocystiscarinii-Pneumonie bei HIVInfizierten

Pneumologie; interventionelle

1182 fr Methoden der interventionellen Pneumologie

1719 km Pneumonie

»Bronchiolitis obliterans organizing pneumonia« mit akuter respiratorischer Insuffizienz

990 kas Churg-Strauss-Syndrom oder chronische eosinophile Pneumonie?

Isolierung von Chlamydia pneumoniae bei atypischer Pneumonie

Polyangiitis; mikroskopische

Einseitige diffuse Lungenbeteiligung bei Vaskulitis mit

1706 üb Anti-Neutrophilen-Zytoplasma-Antikörpern sowie Antikörpern gegen glomeruläre Basalmembranen

Polymerase-Kettenreaktion

1016 fr Klinische Bedeutung der Polymcrase-Kettenreaktion in der Infektiologie

Nachweis von Tropheryma whippelii mit der Polymerase-Kettenreaktion vor und nach Therapie eines Morbus Whipple

1307 kas Polymorphismus; genetischer

Neonatale Alloimmunthrombozytopenie

Polymyalgia rheumatica

Heiserkeit bei Polymyalgia rheumatica

\section{Polyneuritis}

Polyneuritis und Myositis bei Trypanosoma-gambienseInfektion

Polyneuropathie; neoplastische

Autoimmunprozesse als paraneoplastische Manifestationen bei familiärem Mammakarzinom

Polyposis; intestinalis

Endoskopische Diagnostik zur Prävention und Früherkennung des kolorektalen Karzinoms

Invagination bei PeutzJeghers-Syndrom

\section{Polyradikulitis}

Intensivtherapie des GuillainBarré-Syndroms
Polysaccharide; proteinge-

1087 üb bundene

Adjuvante Chemotherapie

$1298 \mathrm{~km}$ nach kurativer Gastrektomie bei Magenkarzinom

\section{Polysomnographie}

Morbidität und Letalität bei Schlafapnoe und nächtlichen Bradyarrhythmien

Posttransplant Lymphoproliferative Disorders

Differentialdiagnose von Rundherden nach Lungentransplantation

\section{Prader-Labhart-Willi- \\ Syndrom}

1312 kas Prader-Labhart-WilliSyndrom

\section{Präexzitationssyndrom}

1565 lz Klinische Bedeutung des Ajmalin-Tests in der nichtinvasiven Diagnostik bei

1462 kas Wolff-Parkinson-WhiteSyndrom

\section{Präkanzerosen}

Schistosomiasis und Siegelringzellkarzinom der Ileozökalklappe

1071 kas

\section{Prävention}

Akzidentelle Nadelstichverletzung bei medizinischem

Pflegepersonal

Antioxidantien

Cholesterin-Normalwerte im Kindesalter

1625 adt

Endoskopische Diagnostik zur Prävention und Früher-

$1679 \quad \mathrm{lz}$ kennung des kolorektalen Karzinoms

HIV-Übertragung bei heterosexuellen Partnern

Indikationen zur Pestimpfung und -chemoprophylaxe

Infektionsprophylaxe bei

1512 üb Dauerverweilkanülen

Ist die Neurodermitis eine Krankheit der höheren sozialen Schichten?

1566 lz Risiken der Sonnenexposition

Solare Keratose und Sonnenschutzmittel

1690 kas Vitamin D und Osteoporose. Pathogenese - Therapie

\section{Prednisolon}

Problematik des Äquivalenzbegriffes bei der Therapie mit Glucocorticoiden. Ein Vergleich der klinischen Pharmakokinetik und Pharmakodynamik von Prednisolon und Methylprednisolon

1001 adt

\section{Processus-transversus-}

\section{Anomalien}

Neurologische Symptomatik, Diagnostik und Therapie des sogenannten "thoracicoutlet-syndrome«
1187 or 


\section{Progesterondermatitis}

Autoirnmune Progesterondermatitis

\section{Prognosedeterminanten}

Adjuvante Therapie bei kolorektalen Karzinomen

Derzeitiger Stellenwert der Laparoskopie in der onkologischen Chirurgie

Rekanalisation langstreckiger Arteria-femoralis-Verschlüsse

Tumorgefäßinvasion beim Mammakarzinom. Hämatoxylin-Eosin- versus immunhistochemische Färbung gegen Faktor-VIIIAntigen

\section{Prokinetika}

Therapie der gastroösophagealen Refluxkrankheit

\section{Proktologie}

Diagnostik und Therapie des Analkarzinoms

\section{Promyelozytenleukämie;}

akute

Komplette Remission bei akuter Promyelozytenleukämie. Vorteile von alltrans-Retinsäure im Vergleich mit konventioneller Chemotherapie

\section{Prophylaxe}

Epidemiologie und Klinik der chronischen Virushepatitis

Indikationen zur Pestimpfung und -chemoprophylaxe

\section{Prostaglandinstoffwechsel}

Erythromelalgie (Erythrothermalgie)

\section{Prostatakarzinom}

Prostatakarzinom

\section{Prostatitis}

Aktuelle Epidemiologie, Diagnostik und Therapie der Urogenitaltuberkulose

\section{Protein C; aktiviertes}

Resistenz gegenüber aktiviertem Protein C

\section{Protein-C-Mangel}

Orale Kontrazeption bei Protein-C-Mangel

\section{Proteinkinase}

Rolle von Endothelin bei den Ciclosporin-Nebenwirkungen Nephrotoxizität und arterielle Hypertonie

\section{Proteinurie}

1258 fr Angiotensin-ConvertingEnzym-Hemmer bei der Behandlung der diabetischen Nephropathie

1663 adt

1518 kom

Prothesenhüllendefekt;

bei Mammaprothesen

Kernspintomographie bei Mammaprothesen. Aussa-

1802 lz gekraft im Vergleich mit Mammographie und Ultraschall

1491 or Prothrombinfragment $\boldsymbol{F}_{1+2}$

Orale Kontrazeption bei Protein-C-Mangel

Protonenpumpenhemmer Omeprazol

Thorapie der gastroösophagealen Refluxkrankheit

$1473 \mathrm{adt}$

\section{Pruritus}

Interdisziplinäre Aspekte der Notalgia paraesthetica

1701 adt

PSA

(siche Antigen; Prostataspezifisches)

1143 or Pseudoallergie

Unverträglichkeit der Tuberkulosetherapie bei AIDS

\section{Pseudohypoparathyreoi-}

\section{dismus}

Hypocalcämische Kardiomyopathie als Ursache einer

1365 üb schweren Linksherzinsuffizienz

1714 fr Hypocalcämische Kardiomyopathie als Ursache einer schweren Linksherzinsuffizienz (Berichtigung)

\section{$1039 \mathrm{mq}$ Psoriasis}

Harnstoff in der Dermatologie

\section{Psychosen}

1054 lz Neuropsychiatrische Symptomatik bei primärem Hyperparathyreoidismus

1121 adt

\section{Psychosomatik}

Erfassung von Angst und Depressivität in der medizinischen Routineversorgung

$1680 \mathrm{~km}$

Pubarche

Differenzierung zwischen prä- 1301 or

$1100 \mathrm{fr}$

1706 üb maturer Thelarche und Pubertas praecox anhand klinischer, hormoneller und radiologischer Befunde

1173 as

$1473 \mathrm{adt}$

1307 kas

$1298 \mathrm{~km}$

Pulmonalarteriendruck

Dopplerechokardiographie bei chronischer rechtsventrikulärer Druckbelastung

Pylorusstenose

Pylorusstenose

$1244 \mathrm{mq}$

1453 or

QT-Syndrom; idiopathi-

sches

Idiopathisches QT-Syndrom (Romano-Ward-Syndrom)

$1100 \mathrm{fr}$

\section{Qualitätskontrolle}

Ambulante Versorgung von Diabetikern

\section{Qualitätssicherung}

ICD-Verschlüsselung und Pflege-Personalregelung

Kostenvergleich zwischen der laparoskopischen Cholezystektomie und der extrakorporalen Stoßwellenlithotripsie in der Behandlung von Gallenblasensteinen

1728 kas

\section{Quick-Wert}

Ist die »International Normalized Ratio (INR)« in der klinischen Praxis unentbehrlich?

1270 kas

1126 üb

1076 kas

1283 adt

\section{Radikale; freie}

\section{Pubertas praecox}

Differenzierung zwischen prä- 1301 or maturer Thelarche und Pubertas praecox anhand klinischer, hormoneller und radiologischer Befunde
Antioxidantien

Pathophysiologie der Myokarddurchblutung. Teil II Postischämische kontraktile Dysfunktion (»stunned«-Myokard)

\section{Radiochemotherapie}

Adjuvante Therapie bei kolorektalen Karzinomen

Diagnostik und Therapie des Analkarzinoms

Radiotherapie; bei malignen Tumoren

Prostatakarzinom

Rashkind-Okkluder

Nicht-operativer Verschluß des Vorhofseptumdefektes bei Erwachsenen. Erfahrungen mit dem Rashkindund dem Sideris-Okkluder

1135 fr

$1745 \mathrm{pp}$

1663 adt

1701 adt 1341 or

Raynaud-Syndrom; sekundäres kale Sympathektomie bei paraneoplastischem Raynaud-Syndrom
Endoskopische transthora-

\section{Rubrikenschlüssel}

fr $\quad=$ Fragen aus der Praxis

gt = Gedenktage

kas $=$ Kasuistiken

$\mathrm{km}=$ Kleine Mitteilungen

kom $=$ Kommentare

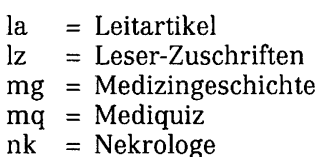

$\mathrm{nk}=$ Nekrologe

or $=$ Originalien

$\mathrm{pp}=$ Prinzip \& Perspektive

stp = Standpunkte

üb $=$ Übersichten

epi $=$ Epikrise 


\section{Rechtsherzbelastung}

Dopplerechokardiographie bei chronischer rechtsventrikulärer Druckbelastung

\section{Rechtsmedizin}

Geschäftsfähigkeit bei hohem Blutalkoholspiegel

\section{Recurrensparese}

Heiserkeit bei Polymyalgia rheumatica

\section{Refluxkrankheit}

Diagnostik der gastroösophagealen Refluxkrankheit

Therapie der gastroösophagealen Refluxkrankheit

\section{Rekanalisation; bei Koro-} narverschlüssen

Wiedereröffnung chronischer Koronararterienverschlüsse: Welche Faktoren beeinflussen den Erfolg?

Rekanalisation; peripherer Arterienverschlüsse

Rekanalisation langstreckiger Arteria-femoralis-Verschlüsse

\section{Rektumfremdkörper}

Präsakrale Phlegmone und Meningitis als Komplikationen eines Fremdkörpers im Rektosigmoid

Renin-Angiotensin-System

Renin-Angiotensin-System und Blutdruckregulation

\section{Re-Okklusion; von Koro-} narverschlüssen

Wiedereröffnung chronischer Koronararterienverschlüsse: Welche Faktoren beeinflussen den Erfolg?

\section{Reperfusion}

Pathophysiologie der Myokarddurchblutung. Teil II: Postischämische kontraktile Dysfunktion (»stunned «-Myokard)

\section{Restless legs}

Fibromyalgie-Syndrom

Retinopathie; diabetische

Ambulante Versorgung von Diabetikern

Intensivierte Behandlung des Diabetes mellitus Typ I und Entwicklung von Spätkomplikationen

\section{Revaskularisation}

Chronische mesenteriale Ischämie

\section{Rhabdomyolyse}

Akutes myoglobinurisches Nierenversagen als Folge von autoaggressivem Verhalten bei Oligophrenie

\section{Rhabdomyosarkom}

Pleomorphes Rhabdomyosarkom
Rhythmus; idioventri-

1061 or kulärer

Idioventrikulärer Rhythmus

\section{Risikofaktoren}

Akute Myokardischämie, ventrikuläre Tachyarrhythmien und plötzlicher Herztod

$1566 \mathrm{lz}$ Carotiswandveränderungen bei jungen Typ-I-Diabetikern. Ultraschalldiagnostik der frühen Arteriosklerose

1433 adt Cholesterin und koronare Herzkrankheit

1473 adt Einfluß spontan niedriger und diätetisch-medikamentös gesenkter Cholesterinspiegel auf nicht-kardiovaskuläre Todesursachen

1766 or Einsatz von niedermolekularem Heparin zur Antikoagulation in der Schwangerschaft

Epidemiologie und Klinik der chronischen Virushepatitis

$1802 \mathrm{lz}$ Fettarme Diät und körperliches Training bei koronarer Herzkrankheit

Fischaugenkrankheit

Gerbstoffe und Krebsrisiko

990 kas Hodenkrebsrisiko nach Vasektomie

Hohe Letalität von Tetanusinfektionen nach intramuskulärer Injektion von

\section{5 pp Chinin}

Hypocholesterinämie

Ist die Neurodermitis eine

Krankheit der höheren sozialen Schichten?

1766 or Morbidität und Letalität bei Schlafapnoe und nächtlichen Bradyarrhythmien

Orale Kontrazeption bei Protein-C-Mangel

1745 pp Osteoporose bei Männern. Pathogenese und klinische Einteilung bei 254 Fällen

Risikofaktoren für gastrointestinale Blutungen bei Patienten der Intensivstation

$1639 \mathrm{lz}$ Solare Keratose und Sonnenschutzmittel

1056 lz Tiefe Venenthrombose und okkulte, maligne Neoplasien

$976 \mathrm{~km}$

\section{Risikofaktoren; psycho-} soziale

Elterliche Vernachlässigung in der Kindheit und Adipo-

979 or sitas im frühen Erwachsenenalter

\section{Risikoindikatoren}

994 kas Fettarme Diät und körperliches Training bei koronarer Herzkrankheit

Rodbell, Martin

Nobelpreis für Medizin 1994

$1243 \mathrm{mq}$
Rundherde; pulmonale

Differentialdiagnose von Rundherden nach Lungentransplantation

Rückenschmerzen

Lumbale Spondylodiszitis

\section{durch Salmonella enteriti- dis \\ $1432 \mathrm{mq}$}

1786 üb

1225 or

\section{Salbutamol}

Regelmäßige Asthma-Therapie mit $\beta$-Sympathikomimetika

\section{$1059 \mathrm{~km}$ Salmonellosen}

Idiopathische CD4-Lymphozytopenie mit letaler Salmonella-typhimurium-Sepsis

Lumbale Spondylodiszitis durch Salmonella enteritidis

1497 kas

\section{Sarkoidose; der Leber}

Sarkoidose der Leber (Morbus Boeck)

\section{5 üb Schädelverletzungen} Kinder

\section{Schilddrüsenkarzinom}

1393 kas

1411 fr

$1757 \mathrm{~km}$

$1681 \mathrm{~km}$

Jodinduzierte Hyperthyreose bei metastasiertem Schilddrüsenkarzinom

Schilddrüsenkarzinom

\section{Schirmer-Test}

Sicca-Symptomatik unter systemischer Therapie mit Beta-Rezeptorenblockern

$1677 \mathrm{fr}$

$1757 \mathrm{~km}$

\section{Schistosomiasis}

Schistosomiasis und Siegelringzellkarzinom der Ileo-

1187 or zökalklappe

Schlafmedizin

1100 fr Ambulante Behandlung von Schlafstörungen im Alter

943 Morbidität und Letalität bei Schlafapnoe und nächtlichen Bradyarrhythmien

\section{7 km Schlaganfall}

(siehe Insult; zerebraler)

\section{Schmerztherapie}

$1223 \mathrm{~km}$

Endoskopische transthorakale Sympathektomie bei paraneoplastischem Raynaud-Syndrom

$1719 \mathrm{~km}$

Schmerzbehandlung bei ambulanten Patienten mit metastasierendem Karzinom

\section{$1103 \mathrm{~km}$ Schock}

Schock und Gerinnungsstörungen bei systemischer Mastozytose

\section{7 lz}

Schwangerschaft bei partieller DiGeorge-Anomalie 1792 kom rem Heparin zur Antikoagulation in der Schwangerschaft

1105 or Jodprophylaxe in der Schwangerschaft
1383 kas

$1020 \mathrm{~km}$ 956 kas

1383 kas

$1397 \mathrm{mq}$

$1021 \mathrm{~km}$

1573 kas

$1737 \mathrm{mq}$

$1783 \mathrm{adt}$

$1058 \quad \mathrm{lz}$

1538 or

1187 or

1162 kas

$1223 \mathrm{~km}$

1231 kas

1776 kas

1497 kas 
Neonatale Hyperthyreose bei nicht diagnostiziertem Morbus Basedow der Mutter. Probleme der Diagnostik und Therapie anhand einer Kasuistik

Psychische Belastung in der Schwangerschaft und Frühgeburt

\section{Schweißdrüsentumor}

Sogenannter Mischtumor der Haut (chondroides Syndrom)

\section{Schwerketten-Erkrankun-}

\section{gen}

Gamma-Schwerketten-Produktion als Epiphänomen bei Non-Hodgkin-Lymphom

\section{Screening; pränatales}

Diagnostik und Therapie der konnatalen Toxoplasmose

Indikation zur Amniozentese bei über 35jährigen Schwangeren aufgrund von Serummarkern

\section{Sehstörungen}

Fischaugenkrankheit

\section{Sekundärprävention}

Angiotensin-ConvertingEnzym-Hemmer nach Herzinfarkt

Fettarme Diät und körperliches Training bei koronarer Herzkrankheit

Selbstbeatmung; intermittierende

Ventilatorische Insuffizienz und hyperkapnische Kompensation infolge chronisch belasteter »Atempumpe«. Physiologie, Pathophysiologie und Therapie

\section{Selbstverstümmelung}

Akutes myoglobinurisches Nierenversagen als Folge von autoaggressivem Verhalten bei Oligophrenie

\section{Sensibilitätsstörungen}

Neurologische Symptomatik, Diagnostik und Therapie des sogenannten $»$ thoracicoutlet-syndrome«

\section{Sepsis-Erreger}

Nehmen Infektionen durch hämolysierende Streptokokken der Gruppe A zu?

\section{Serum-Ferritin}

Eisenmangelanämie
1346 kas

\section{Short-Term Hibernating-}

Myokard

Pathophysiologie der Myokarddurchblutung. Teil I Adaptation an Myokardischämie (»hibernating «Myokard)

$1141 \mathrm{~km}$

Shunt; transjugulärer intrahepatischer portosystemischer

$1471 \mathrm{mq}$ Therapie des Aszites bei Lebererkrankungen

Shunts; peritoneovenöse

Therapie des Aszites bei Lebererkrankungen

1235 kas Shunts; portosystemische

Endoskopische Therapie der Ösophagusvarizenblutung

Therapie des Aszites bei

$1335 \mathrm{lz} \quad$ Lebererkrankungen

$1413 \mathrm{~km}$ SIADH

(siehe Hormon; Antidiuretisches; Syndrom der inadäquaten Sekretion)

\section{Sicca-Symptomatik}

1393 kas Sicca-Symptomatik unter systemischer Therapie mit Beta-Rezeptorenblockern

\section{8 fr Sideris-Okkluder}

Nicht-operativer Verschluß

1017 lz des Vorhofseptumdefektes bei Erwachsenen. Erfahrungen mit dem Rashkindund dem Sideris-Okkluder

\section{Sigma-Rektum-Pouch}

1209 üb Aktuelle Möglichkeiten des kontinenten Harnblasenersatzes

\section{Signaltransduktion}

Nobelpreis für Medizin 1994

\section{Silikonimplantate}

Kernspintomographie bei Mammaprothesen. Aussa-

994 kas gekraft im Vergleich mit Mammographie und Ultraschall

Single-Photonenabsorptiometrie

1087 üb Diagnostik des Osteoporoserisikos. Neue Entwicklungen und »State of the Art« 1994

\section{Sinnesphysiologie}

1336 lz $\begin{aligned} & \text { Hermann von Helmholtz } \\ & (1821-1894) \text { - Militärarzt }\end{aligned}$ Sinnesphysiologe und »Reichskanzler der deutschen Physik«. Zum 100.

$1403 \mathrm{pp} \quad$ Todestag des universalen Arztes und Naturforschers

\section{Sinusitis}

Sinusitis bei HIV-Infektion

1759 or

1589 pp Sinusknotensyndrom

Schrittmachertherapie beim Syndrom des kranken Sinusknotens. Senken vorhofbeteiligte Schrittmachersysteme die Häufigkeit von Vorhofflimmern und thromboembolischen Komplika-

1549 adt tionen sowie die Mortalität?

\section{Sjögren-Syndrom}

Autoimmunprozesse als para1549 adt neoplastische Manifestationen bei familiärem Mammakarzinom

1443 kom

$1549 \mathrm{adt}$

Sklerosierungsbehandlung; von Ösophagusvari-

zen

Endoskopische Therapie der Ösophagusvarizenblutung

Sludge; in der Gallenblase

Gallenblasen-Sludge und Einnahme von Lipidsenkern

\section{Sodbrennen}

1783 adt Diagnostik der gastroösophagealen Refluxkrankheit

\section{Solvens-Detergens-Verfah-} ren

1341 or Rationale Substitution mit Blut- und Blutbestandteilkonserven

\section{Sonnenlicht}

Risiken der Sonnenexposition

\section{Sonnenschutzmittel}

1327 üb Solare Keratose und Sonnenschutzmittel

Sotalol

Sotalol

1792 kom

Spätsyndrom; diabetisches

Insulinpflichtiger Diabetes mellitus nach 58 Jahren

Kombinierte Nieren- und Pankreastransplantation beim diabetischen Spätsyndrom

Speicheldrüsentumoren

Kanalikuläres Adenom

1289 üb

Myoepitheliom (myoepitheliales Adenom)

Pleomorphes Rhabdomyosarkom

Spielmeyer-Vogt-Krankheit

$1215 \mathrm{mg}$ Leere Vakuolen im Zytoplasma der Lymphozyten bei juveniler neuronaler Ceroidlipofuscinose (Spielmeyer-Vogt-Krankheit, Batten-Krankheit)

\footnotetext{
Rubrikenschlüssel

adt $=$ Aktuelle Diagnostik und Therapie

ar = Arztrecht

as $=$ Der Arzneistoff

epi $=$ Epikrise
}

\author{
$\mathrm{fr} \quad=$ Fragen aus der Praxis \\ gt $=$ Gedenktage \\ kas $=$ Kasuistiken \\ $\mathrm{km}=$ Kleine Mitteilungen \\ kom $=$ Kommentare
}

\author{
la = Leitartikel \\ $\mathrm{l} z=$ Leser-Zuschriften \\ $\mathrm{mg}=$ Medizingeschichte \\ $\mathrm{mq}=$ Mediquiz \\ nk $=$ Nekrologe
}

$\begin{aligned} \text { or } & =\text { Originalien } \\ \text { pp } & =\text { Prinzip \& Perspektive } \\ \text { stp } & =\text { Standpunkte } \\ \ddot{\mathrm{ub}} & =\text { Übersichten }\end{aligned}$ 
Spiralcomputertomogra-

phie

Direkter Embolusnachweis durch Spiral-Computertomographie bei akuter Lungenembolie

\section{Spondylodiszitis}

Lumbale Spondylodiszitis durch Salmonella enteritidis

\section{Sputumdiagnostik}

Sputumuntersuchung zur Diagnostik der Pneumocystiscarinii-Pneumonie bei HIVInfizierten

Staging

(siehe Tumor-Staging)

Stammganglienverkalkun-

gen

Calcitriol-Gabe in der Schwangerschaft bei partieller DiGeorge-Anomalie

\section{Standby-Medikamente}

Indikationen zur Pestimpfung und -chemoprophylaxe

\section{Staroperation}

Ambulante Kataraktoperationen

Statistisches Bundesamt; Mitteilungen

Kindersitz im Personenwagen bewährt sich

Tuberkuloseerkrankungen 1993

\section{Stellatumblockade}

Endoskopische transthorakale Sympathektomie bei paraneoplastischem Raynaud-Syndrom

\section{Stickstoffmonoxid}

Gesteigerte vaskuläre Sensitivität auf Nitroglycerin bei Patienten mit Hypercholesterinämie und peripherer Endotheldysfunktion

\section{Stickstoffmonoxid-Syn-} thase

Induktion der Stickstoffmonoxid(NO)-Synthase

\section{Stoßwellenlithotripsie; Extrakorporale \\ Kostenvergleich zwischen der laparoskopischen Cholezystektomie und der extrakorporalen Stoßwel- lenlithotripsie in der Behandlung von Gallen- blasensteinen}

\section{Strahlenbelastung}

Britische Atomwaffentests der fünfziger und sechziger Jahre

\section{Streptokinase}

(siehe Fibrinolyse)
Streptokokken; hämolysierende

1525 lz Nehmen Infektionen durch hämolysierende Streptokokken der Gruppe A zu?

\section{Streptolysin O}

Persistierende Antistreptolysin-Titer

Streß; psychologischer

Müdigkeit und psychologischer Streß

\section{1 or Struma multinodosa}

Farbdopplersonographisch gesteuerte perkutane Alkoholinstillation zur Therapie der funktionellen Schilddrüsenautonomie

\section{Stunned Myokard}

Pathophysiologie der Myokarddurchblutung. Teil II: Postischämische kontraktile Dysfunktion (»stunned «-Myokard)

1714 fr Subarachnoidalblutungen Subarachnoidalblutung

Sulcus-ulnaris-Syndrom

Neurologische Symptomatik, Diagnostik und Therapie des sogenannten »thoracicoutlet-syndrome«

\section{Suramin}

$976 \mathrm{~km}$ Polyneuritis und Myositis bei Trypanosoma-gambienseInfektion

$1185 \mathrm{~km}$

\section{Sympathektomie}

Endoskopische transthora-

1162 kas kale Sympathektomie be paraneoplastischem Raynaud-Syndrom

Syndrom; hepatorenales

Therapie des Aszites bei Lebererkrankungen

Syndrom; paraneoplastisches

Autoimmunprozesse als paraneoplastische Manifestationen bei familiärem Mammakarzinom

$1413 \mathrm{~km}$ Das extrapulmonale kleinzellige Karzinom - eine Rarität?

Endoskopische transthorakale Sympathektomie bei

1532 or paraneoplastischem Raynaud-Syndrom

Hyponatriämisches Koma

Syndrome

Diagnose eines UllrichTurner-Syndroms im Rentengutachten

$1413 \mathrm{~km}$

Kallmann-Syndrom. Pathophysiologie und Klinik

Syndrome; neurokutane

Interdisziplinäre Aspekte der Notalgia paraesthetica

Synkinesien

Kallmann-Syndrom. Pathophysiologie und Klinik
Synoviadiagnostik

Nachweis von Borrelia-

$1336 \mathrm{lz}$ burgdorferi-DNA in der Gelenkflüssigkeit bei LymeArthritis

Syringom; chondroides

1099 fr Sogenannter Mischtumor der Haut (chondroides Syndrom)

$1451 \mathrm{~km} \quad$ Syringomyelie

Syringomyelie als seltene Ursache einer beatmungspflichtigen respiratori-

1607 or schen Insuffizienz

\section{$\mathbf{T}$}

Takayasu-Arteriitis

1745 pp Takayasu-Arteriitis

Tamoxifen

Östrogenantagonisten und

Thromboseprophylaxe

Tannine

Gerbstoffe und Krebsrisiko

$1322 \mathrm{mq}$

Tastkörperchen-Neurom

Digitales Tastkörperchen-

1087 üb Neurom

Teekonsum

Gerbstoffe und Krebsrisiko

Template-Technik

1690 kas

Diagnostik und Therapie des Analkarzinoms

\section{Teratogenität}

Wind pocken in der ersten Schwangerschaftshälfte

1162 kas

Tests; psychometrische

Erfassung von Angst und Depressivität in der medizinischen Routineversorgung

\section{9 adt Tetanus}

Hohe Letalität von Tetanusinfektionen nach intramuskulärer Injektion von Chinin

1194 kas Thelarche; prämature

Differenzierung zwischen prä- 1301 or maturer Thelarche und Pubertas praecox anhand klinischer, hormoneller und radiologischer Befunde

\section{2 kas Thenaratrophie}

Neurologische Symptomatik, Diagnostik und Therapie des sogenannten $»$ thoracic-

$1139 \mathrm{lz}$ outlet-syndrome«

\section{Therapie; photodynami-}

\section{5 kas sche}

Photodynamische Therapie eines Magenstumpfkarzi-

1436 üb noms in kurativer Absicht Erster Fallbericht einer klinischen Anwendung in Deutschland

1307 kas

\section{Thiazid}

Einfluß einer niedrigdosierten Hydrochlorothiazidtherapie auf den Knochenmineralgehalt des axialen und peripheren Skeletts
$1451 \mathrm{~km}$

$1471 \mathrm{mq}$

$1701 \mathrm{adt}$

$1527 \mathrm{~km}$

1283 adt

$1681 \mathrm{~km}$

1087 üb

951 kas 


\section{Thoracic-outlet-syndrome}

Neurologische Symptomatik, Diagnostik und Therapie des sogenannten »thoracicoutlet-syndrome«

\section{Thorakoskopie}

Methoden der interventionellen Pneumologie

Thoraxchirurgie; minimalinvasive

Methoden der interventionellen Pneumologie

\section{Thoraxschmerzen}

Akute Aortendissektion. Diagnose durch transthorakale Echokardiographie

Klinische und koronarangiographische Befunde bei Frauen mit Thoraxschmerzen

\section{Thromben; intrakardiale}

Spontaner Echokontrast im linken Ventrikel als Indikator für ein erhöhtes Thromboembolie-Risiko

\section{Thromboembolien}

Einsatz von niedermolekularem Heparin zur Antikoagulation in der Schwangerschaft

Schrittmachertherapie beim Syndrom des kranken Sinusknotens. Senken vorhofbeteiligte Schrittmachersysteme die Häufigkeit von Vorhofflimmern und thromboembolischen Komplikationen sowie die Mortalität?

Spontaner Echokontrast im linken Ventrikel als Indikator für ein erhöhtes Thromboembolie-Risiko

\section{Thrombolyse}

(siehe Fibrinolyse)

\section{Thrombophilie}

Orale Kontrazeption bei Protein-C-Mangel

\section{Thromboplastinzeit}

Ist die »International Normalized Ratio (INR) « in der klinischen Praxis unentbehrlich?

\section{Thrombosen; venöse}

Resistenz gegenüber aktiviertem Protein C

\section{Thromboseprophylaxe}

Östrogenantagonisten und Thromboseprophylaxe

\section{Thrombozytensubstitution}

Rationale Substitution mit Blut- und Blutbestandteilkonserven

\section{Thrombozytopenie}

1087 üb Neonatale Alloimmunthrombozytopenie

Reversible Thrombozytopenie bei Digitoxinüberdosierung

1083 adt Thymushypoplasie

Calcitriol-Gabe in der Schwangerschaft bei partieller DiGeorge-Anomalie

1083 adt Thyreotoxikose

(siche Hyperthyreose)

\section{Thyreotropin}

1297 lz Latente Hyperthyreose

Neonatale Hyperthyreose bei nicht diagnostiziertem Mor-

$1337 \mathrm{~km}$ bus Basedow der Mutter. Probleme der Diagnostik und Therapie anhand ciner Kasuistik

\section{Tinea capitis}

1317 kas Tinea capitis durch Microsporon canis

\section{Tiotropiumbromid}

Enzephalopathie nach Intoxikation mit einem

1497 kas Anticholinergikum

\section{TIPS}

(siche Shunt; transjugulärer intrahepatischer porto-

1683 or systemischer)

\section{Todesursachen}

Einfluß spontan niedriger und diätetisch-medikamentïs gesenkter Cholesterinspiegel auf nicht-kardiovaskuläre Todesursachen

\section{7 kas Torsade de pointes}

Sotalol

\section{Touristikmedizin}

Gnathostomiasis nach Aufenthalt in Thailand

Larva migrans cutanea (»creeping eruption «)

1100 fr Polyneuritis und Myositis bei Trypanosoma-gambienseInfektion

1529 la Therapie kutaner und muko kutaner Leishmaniosen

Toxoplasmose; konnatale Diagnostik und Therapie der konnatalen Toxoplasmose

$1680 \mathrm{~km}$ Tracheobronchitis; akute

Isolierung von Chlamydia pneumoniae bei atypischer Pneumonie

\section{2 fr \\ Training; körperliches}

Fettarme Diät und körperliches Training bei koronarer Herzkrankheit

1555 üb
Tranquilizer

1512 üb Ambulante Behandlung von Schlafstörungen im Alter

1734 kas Transcortin

Problematik des Äquivalenzbegriffes bei der Therapie mit Glucocorticoiden. Ein

1776 kas Vergleich der klinischen Pharmakokinetik und Pharmakodynamik von Prednisolon und Methylprednisolon

\section{Transferrin}

1334 fr

1346 kas

Eisenmangelanämie

\section{Transfusion}

(siehe Hämotherapie)

Transkriptase; reverse

Klinische Bedeutung der Polymerase-Kettenreaktion in der Infektiologie

$1357 \mathrm{mq}$

\section{Transplantation}

Aufbau der Deutschen Knochenmarkspenderdatei

Kombinierte Nieren- und Pan- 1399 adt

$1803 \mathrm{lz}$ kreastransplantation beim diabetischen Spätsyndrom

Psychosoziale Probleme bei Langzeitimmunsuppression nach Organtransplantation

Sekundäre Neoplasien nach Immunsuppression

1538 or

1671 üb

$1403 \mathrm{pp}$

$1625 \mathrm{adt}$

Transposition; kardialer Arterien

1597 kom Kongenital korrigierte Transposition der großen Arterien im Erwachsenenalter. Wert nicht-invasiver Untersuchungsmethoden

\section{Tränensekretion}

1477 as Sicca-Symptomatik unter systemischer Therapie mit

1618 kas

$1505 \mathrm{mq}$ Beta-Rezeptorenblockern

\section{Treitz-Hernie}

1690 kas

Möglichkeiten der laparoskopischen Therapie innerer Hernien. Darstellung an drei Fällen

\section{9 adt Tretinoin}

Komplette Remission bei akuter Promyelozytenleuk-

$1335 \mathrm{lz} \quad$ ämie. Vorteile von alltrans-Retinsäure im Vergleich mit konventioneller Chemotherapie

1462 kas Trinkwasserfluoridierung

Akute Vergiftung durch fluori- $1185 \mathrm{~km}$ diertes Trinkwasser

\section{7 lz Tripel-Therapie}
Ist die Ulcuskrankheit eine Infektionskrankheit?

1783 adt

1199 kas

1143 or

$1488 \mathrm{~km}$

\footnotetext{
Rubrikenschlüssel

adt $=$ Aktuelle Diagnostik und Therapie

ar $=$ Arztrecht

as $=$ Der Arzneistoff

epi $=$ Epikrise
}

\author{
fr $\quad=$ Fragen aus der Praxis \\ gt $=$ Gedenktage \\ kas $=$ Kasuistiken \\ $\mathrm{km}=$ Kleine Mitteilungen \\ $\mathrm{kom}=$ Kommentare
}

\author{
la = Leitartikel \\ $\mathrm{lz}=$ Leser-Zuschriften \\ $\mathrm{mg}=$ Medizingeschichte \\ $\mathrm{mq}=$ Mediquiz \\ $\mathrm{nk}=$ Nekrologe
}

$\begin{aligned} \text { or } & =\text { Originalien } \\ \text { pp } & =\text { Prinzip \& Perspektive } \\ \text { stp } & =\text { Standpunkte } \\ \text { üb } & =\text { Übersichten }\end{aligned}$ 


\section{Trisomie 21}

Indikation zur Amniozentese bei über 35jährigen

Schwangeren aufgrund

von Serummarkern

\section{Tropenkrankheiten}

Schistosomiasis und Siegelringzellkarzinom der Ileozökalklappe

\section{Tropheryma whippelii}

Nachweis von Tropheryma whippelii mit der Polymerase-Kettenreaktion vor und nach Therapie eines

Morbus Whipple

\section{Troponin}

Die klinische Bedeutung der Konzentrationsbestimmung der Troponine

\section{Trypanosomiasis}

Polyneuritis und Myositis be Trypanosoma-gambienseInfektion

\section{TSH}

(siehe Thyreotropin)

\section{TSH-Rezeptor-Autoantikör-}

per

Neonatale Hyperthyreose bei nicht diagnostiziertem Morbus Basedow der Mutter. Probleme der Diagnostik und Therapie anhand einer Kasuistik

\section{Tuberkulin-Hauttests}

Aktuelle Epidemiologie, Diagnostik und Therapie der Urogenitaltuberkulose

\section{Tuberkulose}

Tuberkuloseerkrankungen 1993

Unverträglichkeit der Tuberkulosetherapie bei AIDS

\section{Tuberkulose; extrapulmo-} nale

Aktuelle Epidemiologie, Diagnostik und Therapie der Urogenitaltuberkulose

Baker-Zyste bei osteoartikulärer Tuberkulose des Kniegelenks

Baker-Zyste bei osteoartikulärer Tuberkulose des Kniegelenks (Berichtigung)

Endoskopische Diagnose einer Kolontuberkulose

Ösophago-mediastinale Fisteln als seltene Komplikation der Tuberkulose bei einem HIV-infizierten Patienten

Tuberkulostatika

(siehe Antituberkulotika)

\section{Tumorantigene}

Das extrapulmonale kleinzellige Karzinom - eine Rarität?

\section{Tumorchirurgie}

Tumorverkleinerung im Stadium M1?
Tumoren; an der Hand

$1413 \mathrm{~km}$ Differentialdiagnose knotiger Tumoren an der Hand

Tumor-Gefäß-Interaktion

Pathologie der Pulmonalarterien bei Lungentumoren

\section{8 lz Tumorgefäßinvasion}

Tumorgefäßinvasion beim Mammakarzinom. Hämatoxylin-Eosin- versus

$1679 \mathrm{lz}$ immunhistochemische Färbung gegen Faktor-VIIIAntigen

\section{Tumorschmerzen}

Schmerzbehandlung bei ambulanten Patienten mit

1013 la metastasierendem Karzinom

\section{Tumor-Staging}

Derzeitiger Stellenwert der

1690 kas Laparoskopie in der onkologischen Chirurgie

Tumorverkleinerung

Tumorverkleinerung im Stadium M1?

Turner-Syndrom

Diagnose eines UllrichTurner-Syndroms im Rentengutachten

T-Zell-Lymphom; pleomorphes

Hochmalignes peripheres T-Zell-Lymphom vom großzelligen polymorphen Typ

1121 adt

\section{U}

\section{5 km Ulcuskrankheit}

Ist die Ulcuskrankheit eine Infektionskrankheit?

Modifizierter ${ }^{13} \mathrm{C}$-Atemtest in der Diagnostik der Helicobacter-pylori-Besiedlung der gastralen Mucosa

1121 adt Omeprazol

\section{Ullrich-Turner-Syndrom}

1579 kas Diagnose eines UllrichTurner-Syndroms im Rentengutachten

\section{6 \\ Ultraviolettstrahlung}

1653 kas

1613 kas

Risiken der Sonnenexposition

Umweltschadstoffe

(siehe Environtologie)

Unfallverhütung

Kindersitz im Personenwagen bewährt sich

Schutzhelme für radfahrende Kinder

\section{Universal-Spenderblut}

Universal-Spenderblut

1591 üb

\section{Urease-Test}

Modifizierter ${ }^{13} \mathrm{C}$-Atemtest in der Diagnostik der Helicobacter-pylori-Besiedlung der gastralen Mucosa

Urikostatikum

Allopurinol

1045 as

Urogenitaltuberkulose

Aktuelle Epidemiologie, Dia-

1415 or gnostik und Therapie der Urogenitaltuberkulose

Überdruckbeatmung; konti-

1491 or nuierliche nasale

Morbidität und Letalität bei Schlafapnoe und nächtlichen Bradyarrhythmien

\section{Übergewicht}

(siehe Adipositas)

$1223 \mathrm{~km}$

\section{V}

\section{Varizella-Zoster-Virus}

Windpocken in der ersten Schwangerschaftshälfte

1518 kom Wirksamkeit von Aciclovir und Glucocorticoiden in der Behandlung des Herpes zoster und postzosteri-

1564 fr scher Neuralgien

Varizellen-Syndrom; kongenitales

1115 kas Windpocken in der ersten Schwangerschaftshälfte

\section{Vasektomie}

Hodenkrebsrisiko nach Vasektomie

\section{$1321 \mathrm{mq}$ Vaskulitis}

Churg-Strauss-Syndrom oder chronische eosinophile Pneumonie?

Hepatitis-B-assoziierte Vaskulitis. Verlauf unter Therapie mit Glucocorticoiden und Alpha-Interferon

$1488 \mathrm{~km}$

1569 or

Maligne atrophische Papulose

\section{Vaskulitis; ANCA-assozi-}

\section{ierte}

Einseitige diffuse Lungenbeteiligung bei Vaskulitis mit Anti-Neutrophilen-Zyto-

1173 as

1115 kas Antikörpern gegen glomeruläre Basalmembranen

\section{Vasodilatation}

Gesteigerte vaskuläre Sensitivität auf Nitroglycerin bei Patienten mit Hypercholesterinämie und peripherer Endotheldysfunktion

Vasokonstriktion; postinspiratorische

$976 \mathrm{~km}$

$1021 \mathrm{~km}$

Dopplersonographie peripherer Arterien bei tiefer Inspiration zur Überprüfung der sympathischen Gefäßinnervation

\section{9 lz Vasomotion}

Angina pectoris und norma-

1569 or bei arterieller Hypertonie und linksventrikulärer Hypertrophie
$1527 \mathrm{~km}$

$1526 \mathrm{~km}$

$1527 \mathrm{~km}$

$1757 \mathrm{~km}$

$1565 \quad \mathrm{lz}$

1388 kas

1427 kas

1071 kas

1065

$1567 \mathrm{~km}$ 


\section{Vasospastik}

Akute Ischämie eines Armes als ungewöhnlicher Ausdruck eines Ergotismus

Endoskopische transthorakale Sympathektomie bei paraneoplastischem Raynaud-Syndrom

\section{Vater-Pacini-Tastkörper-}

chen

Digitales TastkörperchenNeurom

\section{Venenkatheter}

Hautdesinfektion vor der Blutentnahme

Infektionsprophylaxe bei Dauerverweilkanülen

\section{Ventrikelseptumdefekt}

Großer subaortaler Ventrikelseptumdefekt

Verletzungen; bei Radfahrern

Schutzhelme für radfahrende Kinder

\section{Verschreibungspraxis}

Ambulante Behandlung von Schlafstörungen im Alter

\section{Versorgung; ambulante}

ärztliche

Ambulante Versorgung von Diabetikern

\section{Verweilkanülen}

Infektionsprophylaxe bei Dauerverweilkanülen

\section{Virostatika}

Zidovudin bei asymptomatischen HIV-Patienten?

Virusinaktivierungsverfahren

Rationale Substitution mit Blut- und Blutbestandteilkonserven

\section{Vitamin-A-Derivate}

Komplette Remission bei akuter Promyelozytenleukämie. Vorteile von all-transRetinsäure im Vergleich mit konventioneller Chemotherapie

\section{Vitamin C}

Antioxidantien

\section{Vitamin-D-Substitution}

Hypocalcämische Kardiomyopathie als Ursache einer schweren Linksherzinsuffizienz

Hypocalcämische Kardiomyopathie als Ursache einer schweren Linksherzinsuffizienz (Berichtigung)
Vitamin D und Osteoporose. Pathogenese - Therapie

1501 kas

\section{Vitamin E}

1162 kas

Antioxidantien

\section{Volvulus; des Magens}

Behandlung eines intermittierenden Magenvolvulus durch Gastropexie mittels perkutaner endoskopi-

$999 \mathrm{mq}$ scher Gastrostomie

\section{Vorhofseptumaneurysma}

(siehe Aneurysma; des Vorhofseptums)

\section{2 fr \\ Vorhofseptumdefekt}

1017 fr

Nicht-operativer Verschluß des Vorhofseptumdefektes bei Erwachsenen. Erfahrungen mit dem Rashkindund dem Sideris-Okkluder

\section{W}

$1021 \mathrm{~km}$ zierten Agranulozytose mit

1538 or granulozytenkolonie-stimulierendem Faktor

\section{Wasserhaushalt}

Glomeruläre Hyperperfusion

1056 lz $\begin{gathered}\text { und Niereninsuffizienz } \\ \text { Therapie des Aszites bei }\end{gathered}$ Lebererkrankungen

1017 fr Wärmebehandlung

Therapie kutaner und mukokutaner Leishmaniosen

$1374 \mathrm{~km}$ Whipple-Operation

Pyloruserhaltung - »a never ending story «

\section{Wirbelkörperfrakturen}

1555 üb Asymptomatischer primärer Hyperparathyreoidismus. Behandeln oder beobachten?

Osteoporose bei Männern Pathogenese und klinische Einteilung bei 254 Fällen

\section{Wolff-Parkinson-White-} Syndrom

Adenosintriphosphat (ATP) bei supraventrikulären Tachykardien im Neugebo1135 fr renen- und Säuglingsalter Klinische Bedeutung des Ajmalin-Tests in der nichtinvasiven Diagnostik bei Wolff-Parkinson-WhiteSyndrom
1479 üb

1135

Xanthinoxidase-Inhibitor

\section{Allopurinol}

1045 as

1658 kas Sicca-Symptomatik unter systemischer Therapie mit Beta-Rezeptorenblockern

1783 adt

\section{$\mathbf{Y}$}

\section{Yersinia pestis}

Indikationen zur Pestimpfung und -chemo-

1341 or prophylaxe

\section{$\mathbf{Z}$}

\section{Zidovudin}

Akzidentelle Nadelstichverlet- 1563 fr zung bei medizinischem Pflegepersonal

Zidovudin bei asymptomatischen HIV-Patienten?

$1374 \mathrm{~km}$

1467 kas

Zollinger-Ellison-Syndrom Omeprazol

1173 as

Zystendrainage; bei Pan-

\section{6 fr kreaspseudozysten}

ERCP bei bekannter Pan-

1549 adt kreaspseudozyste

\section{Zystenruptur}

Rupturgefahr bei Nieren-

$1169 \mathrm{adt}$ zysten

Zystitis

Aktuelle Epidemiologie, Dia-

$1372 \quad \mathrm{l} \quad$ gnostik und Therapie der Urogenitaltuberkulose

\section{Zytokine}

967 üb Aktueller Stand der Behandlung chronischer Virushepatitiden mit rekombinantem Interferon alpha

943 or Induktion der Stickstoffmonoxid(NO)-Synthase

\section{Zytostatika}

Sekundäre Neoplasien nach Immunsuppression

1747 üb

\section{1 kas Zytostatikaresistenz}

Pathologie der Pulmonalarterien bei Lungentumoren

\section{Rubrikenschlüssel \\ adt = Aktuelle Diagnostik und Therapie \\ ar $=$ Arztrecht \\ as $=$ Der Arzneistoff \\ epi $=$ Epikrise}

\author{
$\mathrm{fr} \quad=$ Fragen aus der Praxis \\ gt $=$ Gedenktage \\ kas $=$ Kasuistiken \\ $\mathrm{km}=$ Kleine Mitteilungen \\ kom $=$ Kommentare
}

\author{
la = Leitartikel \\ $\mathrm{l} \mathrm{z}=$ Leser-Zuschriften \\ $\mathrm{mg}=$ Medizingeschichte \\ $\mathrm{mq}=$ Mediquiz \\ $\mathrm{nk}=$ Nekrologe
}

$\begin{aligned} \text { or } & =\text { Originalien } \\ \text { pp } & =\text { Prinzip \& Perspektive } \\ \text { stp } & =\text { Standpunkte } \\ \ddot{\mathrm{u} b} & =\text { Übersichten }\end{aligned}$ 


\section{A}

Alfke, $\mathrm{H}$.

Altenwerth, F. J.

Altermatt, J.

Andersch-

Borchert, I.

Andrassy, $\mathrm{K}$.

Anelli-Monti,

Brigitte

Antoni, D.

Arns, W.

Aumiller, J.

Aygen, S.

B

Baldt, M.

Baron, R

Barth, J.

Bauermeister, G.

Becker, W.

Behre, H. M.

Beischer,W.

Benninger, J.

Berg, P. A.

Berg, T.

Berger, $M$.

Beuckelmann, D.

Beyer, J.

Beyer, $\mathrm{T}$.

v. Birgelen, C.

Blank, W.

Blomhard, G.

Blum, H. E

Blum, J.

Boden, $\mathrm{H}$.

Bodenseh, Anne

Böckenförde, J. B.

Böhner, $\mathrm{H}$.

Bojanovski, D.

Bokemeyer, D.

Bong, J.

Bordel, $\mathrm{H}$.

Brambs, H. J.

Braun, B.

Bräuninger, $W$.

v. Breska, B.

Bruch, C.

Bruch, $\mathrm{T}$.

Brühl, P.

Bruhn, H. D.

Brune, S.

Brunner, H. R.

Büchler, M. W.

Bünte, S.

Burg, S.

Buss, U.

Busse, 0.
Adamek, R. J.

Burkardt, $\mathrm{H}$.

$\begin{array}{rr}1569 & \text { or } \\ 1653 & \text { kas } \\ 1802 & \text { lz } \\ 1658 & \text { kas } \\ 1194 & \text { kas } \\ 975 & \text { lz } \\ & \\ 994 & \text { kas } \\ 1061 & \text { or } \\ & \\ 1029 & \text { kas } \\ 1135 & \text { fr } \\ 1427 & \text { kas } \\ 1569 & \text { or }\end{array}$

(1)

1312 kas

1453 or

1162 kas

1671 üb

1783 adt

1199 kas

1346 kas

1436 üb

1225 or

1532 or

$1639 \mathrm{lz}$

$961 \mathrm{adt}$
$1298 \mathrm{~km}$

$1800 \mathrm{fr}$

$976 \mathrm{~km}$

1477 as

1034 kas

1607 or

1421 kas

1792 kom

1169 adt

1405 üb

$1565 \mathrm{lz}$

1645 or

979 or

1706 üb

1579 kas

$1167 \mathrm{mq}$

1333 fr

1607 or

1219 fr

1317 kas

1317 kas

$1526 \mathrm{~km}$

1121 adt

$1100 \mathrm{fr}$

$1183 \mathrm{lz}$

1065 or

1739 adt

1555 üb

956 kas

1690 kas

1283 adt

$1183 \mathrm{lz}$

\section{C}

Calderoni, A.

Carlsson, J.

Cidlinsky, $\mathrm{K}$.

Classen, $\mathrm{M}$.

Costabel, U.

Czarnetzki,

Beate M.

Czerwenka, K.

1194 kas $1183 \mathrm{lz}$

990 kas

1755 fr

1565 lz

$1053 \mathrm{fr}$
D

Dalhoff, K.

Damian, M. S.

Daul, A. E.

de Leon, F.

Degenhardt, S.

Dekan, G.

Delius, $W$.

Derendorf, $\mathrm{H}$.

Dertinger, S.

Diekstall, F. F.

Diener, H. C.

Diesfeld, H. J.

Dingerkus, $\mathrm{H}$.

Ditton, H. J.

Dißmann, R.

Dobos, G. J.

Dörner, Renate

Dörr, H. G.

Dohmen, A.

Dohrmann, P.

Doniec, J. M.

Dorfmüller, P.

Dorndorf, W.

Dorsch, W.

Dorst, A. J.

Dralle, $\mathrm{H}$.

Drexler, $\mathrm{H}$.

Drochner, U.

Dumoulin, F. L.

1462 kas

1690 kas

1263 or

$1431 \mathrm{mq}$

1421 kas

1105 or

1029 kas

1671 üb

990 kas

1393 kas

$1639 \mathrm{lz}$

$975 \mathrm{lz}$

1585 adt

1679 lz

1585 adt

1071 kas

$1019 \mathrm{lz}$

1346 kas

1776 kas

$1639 \mathrm{lz}$

1701 adt

1701 adt

1307 kas

1690 kas

974 fr

943 or

1721 or

1065 or

$1448 \mathrm{fr}$

$1000 \mathrm{mq}$

$1322 \mathrm{mq}$

$1398 \mathrm{mq}$

Dumoulin, F. L. 1239 kas

Ebel, $\mathrm{H}$.

Eberli, F.

Ebert, A.

Eckersberger, F.

Ehlenz, K.

Ehninger, G.

Eisele, R.

Elbert, Gabriele

Ell, C.

End, Adelheid

Engeroff, B.

Ensslen, R.

Erbel, R.

Erdmann, E.

Everlien, M.

Evers, J.

Ewig, S.

E

1399 adt

1543 kas

1359 adt

1312 kas

1573 kas

1359 adt

1683 or

$1643 \mathrm{~km}$

951 kas

990 kas

1532 or

1105 or

1721 or

1341 or

1458 or

$1101 \mathrm{lz}$

1630 üb

1110 kas

$\begin{array}{rr}1281 & \mathrm{mq} \\ 1296 & \text { fr }\end{array}$

Faber, T.

Fabry, W.

Fallen, $\mathrm{H}$.

Faßbender, D.

Federmann, G.

Federmann, M.

Fehm, H. L.

v. Ferber, L.

Feussner, $\mathrm{H}$.

Fischer, H. P.

Fischer, M.

Fisseler-Eckhoff, 1415

Annette

Flachskampf, F. A. 1006 üb

Flepp, M. $\quad 1374 \mathrm{~km}$

Föh, K. P.

Frank, U.

Franke, S.

Freissmuth, M.

1270 kas

1017 fr

1006 üb

Freudenberg. J. 1569 or

Frost D.

$\begin{array}{ll}1335 & \mathrm{lz} \\ 1225 & \text { or }\end{array}$

G

Genée, $\mathrm{P}$

Geppert, R.

Gerbes, A. L.

Gessler, P

Giokoglu, K.

Girndt, M.

Gleichmann, U. $\quad 1110$ kas

Glück, Dorothee $1643 \mathrm{~km}$

Glück, T.

Glüer, C. C.

Görge, G.

Golder, W.

Goldschmidt, $\mathrm{H}$.

Gondolf, K. B.

1771 kas

1156 kas

1509 adt

1549 adt

1351 kas

1766 or

1323 adt

1388 kas

1645 or

1501 kas

1287 pp

$1403 \mathrm{pp}$

1071 kas

Gossner, L. $\quad 951$ kas

Grabensee, B. 1421 kas

Grabenwöger, M. 1105 or

Grassot, Annegret 1728 kas

Greger, B.

Greiwe, $M$.

Greminger, P.

1399 adt

1115 kas

1543 kas

1613 kas 
J

Jacki, S

Jaedicke, W.

Jakob, Helga

Janitschke, K.

Jansen, W.

Jaspersen, D.

Jelinek, $\mathrm{T}$.

Jenss, $\mathrm{H}$.

Jergas, M.

Jilg, W.

Joachim, H.

Job, F. P.

Jockenhövel, F.

Joseph, K.

Joseph, Urte

Jung, M.

Junge, $\mathrm{U}$.

Junghanss, $T$.

Just, H.

\section{K}

Kändler, C.

Kaider, Alexandra

Kaiser, $\mathrm{H}$.

Kalkum, M.

Kann, P.

Karnik, R.

Kaserer, K.

Kasper. H.

Kauczor, H.-U.

Kaufmann, T.

Kelbel, C.

v. Keller, J.

Kellner, M.

Kelm, M.

Kiefel, V.

Kiefer, J.

Kirch, W.

Kirschner, T.

Kleimann, F.

Klein, $\mathrm{P}$.

Klein, Reinhild

Klepetko, W.

Klink, K.

Klöpper, J. W.

Klose, K.-J.

$1567 \mathrm{~km}$

Kniemeyer, H. W. $\quad 979$ or

Knobloch, J.

Knolle, J.

Koch, K.-M.

Koehler, U.

Köhler, D.

Köhler, H.

Koelfen, W.

König, A.

König, St. A.

König, V.

Körholz, N. P.

Körner, T.

Köster, Ingrid

Köster, 0 .

1169 adt

1786 üb

1383 kas
Kohl, F.

Konietzko, J.

1694 kas

$1412 \mathrm{lz}$

985 or

$1335 \mathrm{lz}$

1156 kas

$1661 \mathrm{mq}$

1618 kas

1333 fr

1645 or

1625 adt

1800 fr

1602 fr

967 üb

1573 kas

1573 kas

1443 kom

1377 or

1065 or

1776 kas

1491 or

$1566 \mathrm{lz}$

$1082 \mathrm{mq}$

1479 üb

1771 kas

1591 üb

1411 fr

$1525 \mathrm{lz}$

$1624 \mathrm{mq}$

1497 kas

1359 adt

1076 kas

1175 üb

1512 üb

1538 or

1734 kas

1783 adt

1524 fr

1603 lz

1239 kas

$1639 \mathrm{lz}$

1105 or

$1101 \mathrm{lz}$

1766 or

1231 kas

1187 or

1209 üb

1323 adt

1449 lz

1412 lz

1351 kas

961 adt

1023 or

$1547 \mathrm{mq}$

$1056 \mathrm{lz}$

1645 or

Korn, Maria Heike

Krakamp, B.

Krause, G.

Brigitte

Krech, R.

Kreft, B.

Krieg, J.-C.

Kroll, $\mathrm{H}$.

Kruse, $\mathrm{K}$.

Krüger, C.

Kubanek, B.

Kücherer, C.

Küther, S.

Kuhle, R.

Kuhn, A.

Kurz, S.

Kuster, $\mathrm{H}$.

Kutzner, $\mathrm{H}$

Lamminger,

Claudia

Lange, $\mathrm{H}$.

Layer, $\mathrm{P}$.

Lechner, $\mathrm{K}$.

Leidig, $\mathrm{P}$.

Leitner, C.

Leitner, $\mathrm{H}$.

Leiß, 0 . dorf, Anja

Leppek, L.

Leppek, R.

Leschke, M.

Liehr, R.-M.

Lipp, T.
Korting, H. C.

Kosow, Andrea

Kostenis, Evi

Kozuschek, W.

$1215 \mathrm{mg}$

Kraemer-Hansen, 1678

Krahwinkel, W. $1101 \quad \mathrm{lz}$

Kramer, H. J.

Krappweis, Jutta

Kraus-Huonder,

Krawzak, H.-W.

Kretzschmar, W 1335 ,

Kreuzer, H.

Kreuzpaintner, G

Kurz, Christine

1421 kas

$\mathbf{L}$

Labenz, J.

Lamberts, Regina $1259 \quad$ lz

Landthaler, M.

1399 kadt

Lanzendörfer, C. $1017 \quad \mathrm{lz}$

$\begin{array}{lll}\text { Layer, P. } & 1034 & \mathrm{kas} \\ \text { Lechner, Gabriele } & 1168 \mathrm{mq}\end{array}$

Leinweber, B.

Lengfelder, Eva

Eva 1143 or

Lindemann, W.

Lingen, Renate
$1016 \mathrm{fr}$

1105 or

1307 kas

1645 or

1173 as

$1699 \mathrm{mq}$

1706 üb

1734 kas

$975 \mathrm{lz}$

$1091 \mathrm{mq}$

$1243 \mathrm{mq}$

1579 kas

$1167 \mathrm{mq}$

1115 kas

$1283 \mathrm{adt}$

1317. kas

1076 kas

1512 üb

1776 kas

1346 kas

$1643 \mathrm{~km}$

956 kas

$961 \mathrm{adt}$

$1282 \mathrm{mq}$

$1183 \mathrm{lz}$

1491 or

1065 or

1151 or

1427 kas

1569 or

$1039 \mathrm{mq}$

$1203 \mathrm{mq}$

$1357 \mathrm{mq}$

$1505 \mathrm{mq}$

1307 kas

1312 kas

$1699 \mathrm{mq}$

1690 kas

1312 kas

1771 kas

Lippert, H.-D.

Lippert, J.

Lobeck, H.

Lode, $\mathrm{H}$.

Löhnert, $M$.

Löscher, $\mathrm{T}$.

Loew, $\mathrm{H}$.

Lohmöller, G.

Lohri, A.

Loose, R.

Ludwig, W.-D.

Lüderitz, B.

Lüthy, R.

1099 fr

ohr, L

Motz, W.

Moyses, K.

$1567 \mathrm{~km}$

1573 kas

1023 or

1433 adt

1473 adt

1421 kas

1283 adt

1029 kas

Maaß, Andrea

Maaß, M.

Maier, Birgit

Maier, C.

Maiwald, $M$.

Malfertheiner, $\mathrm{P}$.

Mann, J.

Manns, M. P.

Mares, $\mathrm{P}$.

artin, $M$.

artin, W.-R.

Mast, $H$.

Mathas, B.

Mauch, $\mathrm{H}$

Meier-Willersen,

H. J.

Meinertz, T.

Menges, $M$.

Merle, $\mathrm{H}$.

Merz, D.

Meschede, D.

Mezger, J.

Mikmann,

Milde, $\mathrm{H}$.

Mildenberger, $\mathrm{P}$.

inami, $\mathrm{K}$.

itterbauer

Gerlinde

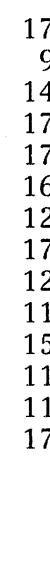

Meyer-Lehnert, $\mathrm{H}$.

Möllmann, H. W. 1671 üb 
$\mathbf{R}$

Rabast, U.

$1781 \mathrm{mq}$

Raffenberg, M.

1728 kas

Rambach, W.

Rees, W.

Reifart, N

Reinwein, D.

Reischl, U.

Renner, E.

Reuss-Borst,

Monika A.

Richter, G.

Riecken, E. 0.

Riederer, J.

Rieger, H.-J.

$\begin{array}{lrr} & 1255 & \text { ar } \\ & 1522 & \text { ar } \\ & 1561 & \text { ar } \\ \text { Riemann, J. F. } & 1712 & \text { ar } \\ \text { Riess, G. } & 1181 & \text { fr } \\ \text { Ringe, J. D. } & 1029 & \text { kas } \\ & 943 & \text { or } \\ \text { Rintelen, C. } & 1289 & \text { üb } \\ \text { Rister, M. } & 1312 & \text { kas } \\ \text { Rittmannsberger, } & 1431 & \mathrm{mq} \\ \text { H. } & 1221 & \text { lz } \\ \text { Ritz, E. } & & \\ & 994 & \text { kas } \\ \text { Ritzkowsky, A. } & 1136 & \text { fr } \\ \text { Rockstroh, J. K. } & 1563 & \text { fr } \\ \text { Rodert, A. } & 1004 & \text { adt } \\ \text { Röggla, M. } & 1359 & \text { adt } \\ \text { Rohr, H. } & 1312 & \text { kas } \\ \text { Rohrbach, R. } & 1449 & \text { lz } \\ \text { Roth, S. } & 1071 & \text { kas } \\ \text { Rothmund, M. } & 1327 & \text { üb } \\ & 1372 & \text { lz } \\ & 1399 & \text { adt } \\ \text { Ruef, C. } & 1573 & \text { kas } \\ \text { Rueff, Franziska } & 1759 & \text { or } \\ \text { Rühl, G. H. } & 1093 & \text { la } \\ \text { Rüther, E. } & 1569 & \text { or } \\ \text { Rupprecht, E. } & 1538 & \text { or } \\ & 1040 & \mathrm{mq} \\ \text { Russi, E. W. } & 1244 & \mathrm{mq} \\ \text { Rutsch, W. } & 1358 & \mathrm{mq} \\ \text { Rutt, C. M. A. } & 11572 & \mathrm{mq} \\ \text { Ruzicka, T. } & 1359 & \text { or } \\ & 1526 & \mathrm{adt} \\ \mathrm{km}\end{array}$

\section{$\mathbf{S}$}

Saeger, W.

Sandholzer, $\mathrm{H}$.

Sandmann, $W$.

Sauer, R.

Sauerbruch, T.

Sawicki, T.

Schaberg, $T$.

Schachenmayr, W. 1690 kas

Schaefer, H. E. $\quad 1467$ kas

Schäfer, $\mathrm{H}$.

Schäfers, R. F.

Scharf, R. E.

Scharrer, A.

Schaumann, D.

Schaumann, R.

Scheele, Ch

Scheithauer, W.

Schenk, T.

$1397 \mathrm{mq}$

1276 kas

1766 or

1625 adt

$1281 \mathrm{mq}$

1694 kas

1131 kom

1433 adt

1473 adt

$1639 \mathrm{lz}$

1096 ar

$1680 \mathrm{~km}$

1486 fr

1383 kas

$1336 \mathrm{lz}$

$1184 \mathrm{lz}$

1591 üb

1591 üb
Schentke, K. U.

Scherer, D.

Schnaith, E.

Schneider, A.

Schneider, B.

Schneider, Sabine

Schnur, S.

Schölmerich, J.

Schömig, A.

Schönberger, W.

v. Schönfeld, J.

Schönhofer, B.

Schollmeyer, P.

Schramm, J.

Schratzlseer, G.

Schreiber, M.

Schreiber, W.

Schröder, D.

Schröder, K.

Schröder, R.

Schuchlenz, $\mathrm{H}$.

Schüler, A.

Schüler, S.

Schürmeyer, T.H 1721 or

Schuler, M. $\quad 1747$ üb

Schuler, U. $\quad 1359$ adt

Schulte, H. D. 1023 or

Schulte, H. M. $\quad 1270$ kas

Schultheiß, H. P. 1023 or

Schulz, R. $\quad 1317$ kas

1589 pp

$1745 \mathrm{pp}$

Schulze, R.

1458 or

Schwartzkopff, B. 1175 üb

Schwarz, F. $\quad 1766$ or

Scriba, P. C. $\quad 1334$ fr

1339 la

1412 lz

Sechtem, U. $\quad 1630$ üb

Seefried, Waltraud $1335 \mathrm{lz}$

Seggewi $\beta, H . \quad 1110$ kas

Sevelda, P. $\quad 1491$ or

Shah, P. M.

Sibrowski, W.

Siepmann, M.

Sievert, $H$.

$1336 \mathrm{lz}$

$1019 \quad \mathrm{lz}$

1783 adt

948 or

1341 or

1458 or

$1802 \quad \mathrm{lz}$

Siewert, J. R.

1518 kom

1564 fr

Sigel, $\mathrm{H}$.

Simon, $M$.

Simon, R.

Singer, I.

1683 or

Slany, J.

1270 kas

1690 kas

1771 kas

Smaczny,Christina $1259 \quad \mathrm{lz}$

Sonnenberg, A. 1532 or

Speich, R.

Spengel, F.

Spengler, U.

Spies, $\mathrm{H}$.

Spies, H. F.

Spittler, S.

Spitzczok v. Bri-

sinski, I.

Sprecher, W.

Sprott, H.

Sroka, R.

Staedt, J.

Staudinger, $\mathrm{T}$.

Steinmetz, U.

Stellwaag, M.

Stift, A.

Störger, H.

Stolz, W.

Stoppe, Gabriela

Strasser, Ruth H.

Strauer, B. E.

Stremmel, W.

Strick, S.

Strnad, V.

Strohmeyer, G.

Stuck, M.

Stüfe, A.

Sultan, N.

Suter, T.

Sültz, J.
1543 kas
Tauchert, M.

el, $M$

Thelen, M.

Thieler, $\mathrm{H}$.

ilsner, $\mathrm{V}$.

Trauner, A.
Waleczek, $\mathrm{H}$

$1372 \quad \mathrm{kz}$

1184 lz

1199 kas

1694 kas

1121 adt

1524 fr

$1122 \mathrm{mq}$

1388 kas

1151 or

956 kas

1235 kas

1653 kas

1653 kas

1156 kas

1061 or

1497 kas

$1054 \mathrm{lz}$

$1139 \mathrm{lz}$

1105 or

$1259 \mathrm{lz}$

1301 or

1263 or

1317 kas

1187 or

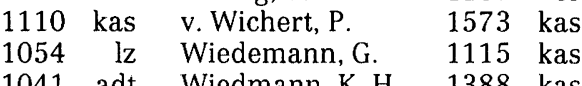

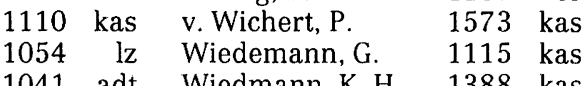

1041 adt Wiedmann, K. H. 1388 kas

1759 or Wiesbauer, P. 1453 or

$1058 \mathrm{lz}$ Wiese, R. 1231 kas

948 or Wiesmann, U. 1371 fr

1543 kas Wildt, L. 1776 kas

1716 lz Windeck, R. 1263 or

Windler, E.

Winkler, W.-B. 1771 kas

Winter, Silke $\quad 1538$ or

Whotzke U.

1156 kas

Wolf, F.

$1183 \mathrm{lz}$

$1565 \mathrm{lz}$

1312 kas

1351 kas

1501 kas

$1525 \mathrm{lz}$

$1450 \mathrm{lz}$

$1261 \mathrm{~km}$

1467 kas

1182 fr

1613 kas

Wolf, G.

Wolner, E.

Wüllenweber,

1529 la

1307 kas

1346 kas

1453 or

1105 or

tho Pesch, S

Y
Youssefzadeh, $\quad 1453$ or Soraya
U

Uffmann, $\mathrm{M}$

Uhl, W.

Uhlig, T.

Ulmer, A.

Ulram, A.

Utech, A.

Valentin, A.

Vester, E.

Völler, $\mathrm{H}$

Volkmann, $\mathrm{H}$

$\begin{array}{lr}1427 & \mathrm{kas} \\ 1405 & \text { üb }\end{array}$

Wagner, H.-J.

Wagner, $\mathrm{T}$.

Wagner, T. A.

Wagner, T. O. F.

Wahner, H. W.
1645 or

1739 adt

$1737 \mathrm{mq}$

$1260 \mathrm{lz}$

1771 kas

1458 or

1771 kas

1023 or

1023 or
Zehender, M.

1786 üb

$1716 \mathrm{lz}$

1065 or

$1584 \mathrm{mq}$

$1738 \mathrm{mq}$

1728 kas

1618 kas

$1716 \mathrm{lz}$

Ziegler, M.

Zöller, L.

Zuber, Margit

Züchner, $\mathrm{H}$.

Zwettler, U.

1137 lz

994 kas 


\title{
Therapie des Aszites bei Lebererkrankungen*
}

\author{
A. L. Gerbes und G. Paumgartner \\ Medizinische Klinik II, Klinikum Großhadern der Universität München
}

Die besonderen Probleme der Aszitestherapie bei Leberzirrhose werden durch die Kenntnis wichtiger pathophysiologischer Faktoren besser verständlich $(7,19,29,32)$. Aus der Vielzahl von Faktoren, die an der Aszitesbildung beteiligt sein können, sind einige allgemein als wesentlich erachtete pathophysiologische Veränderungen in $\mathbf{A b b} \mathbf{1}$ dargestellt.

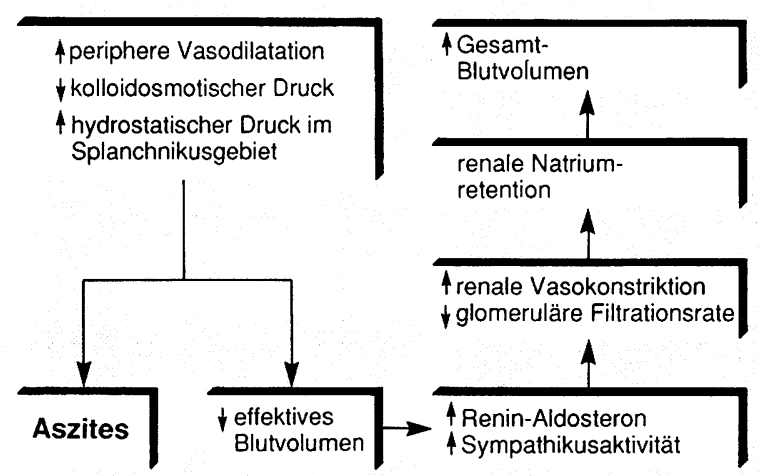

Abb. 1 Wichtige pathophysiologische Faktoren der Aszitesbildung bei Leberzirrhose.

Durch periphere arterielle Vasodilatation (32), Verminderung des kolloidosmotischen und Erhöhung des hydrostatischen Drucks im Splanchnikusgebiet kommt es zu einer Verschiebung der Starling-Kräfte im Splanchnikusgebiet mit Extravasation in die Bauchhöhle. Das zentral effektive Blutvolumen, das heißt das Blutvolumen im Bereich der Druck- und Volumenrezeptoren des zentralen Kreislaufs, nimmt ab. Im Sinne einer Gegenregulation steigen dann die Plasmakonzentrationen von Renin, Aldosteron, Noradrenalin und Vasopressin und bewirken eine renale Vasokonstriktion mit Retention von Salz und Wasser. Mit zunehmendem Schweregrad der Zirrhose nehmen auch die periphere Vasodilatation und die portale Hypertonie zu, das effektive Blutvolumen sinkt weiter, so daß schließlich selbst eine ausgeprägte Aktivierung der natrium- und volu-

Dtsch. med. Wschr. 119 (1994), 1549-1554

(C) Georg Thieme Verlag Stuttgart · New York menretinierenden Hormonsysteme nicht mehr eine Wiederauffüllung des verminderten effektiven Blutvolumens erreichen kann. Wenn unter dem Einfluß der portalen Hypertonie die Bildung von Lymphe zunimmt und die Kapazität der Lymphgefäße überschritten wird, kommt es zu Aszites. Das pathophysiologische Geschehen ist also durch zwei scheinbar widersprüchliche Veränderungen gekennzeichnet:

1. renale Vasokonstriktion bei peripherer Vasodilatation und

2. Verminderung des zentral effektiven Blutvolumens trotz Erhöhung des Gesamtblutvolumens. Therapeutische Bemühungen sollten diese Veränderungen berücksichtigen oder sie zumindest nicht verschlimmern.

\section{Medikamentöse Therapie}

Vor Beginn der Therapie sollte durch eine diagnostische Aszitespunktion eine maligne Grunderkrankung oder Infektion des Aszites ausgeschlossen werden.

Die Palette therapeutischer Maßnahmen reicht von diätetischer Natriumrestriktion bis hin zur Lebertransplantation (Tab. 1). Am besten hat sich das konventionelle Stufenschema bewährt (Abb. 2): Zunächst sind Bettruhe und Natriumrestriktion angezeigt (2, 6 , 14, 23). Eine Beschränkung der täglichen Kochsalzzufuhr auf $3 \mathrm{~g}$ (etwa $50 \mathrm{mmol}$ ) scheint praktikabel, auch im Hinblick auf die Compliance, und erleichtert das Erzie-

Tab. 1 Therapeutische Möglichkeiten bei hepatischem Aszites

Bettruhe

diätetische Natriumrestriktion

diuretische Medikamente

therapeutische Parazentese

peritoneovenöser Shunt (PVS)

portosystemische Shunts (TIPS)

Lebertransplantation

* Der Beitrag »Diagnostik des Aszites« ist im vorhergehenden Heft (Nr. 44) erschienen. 


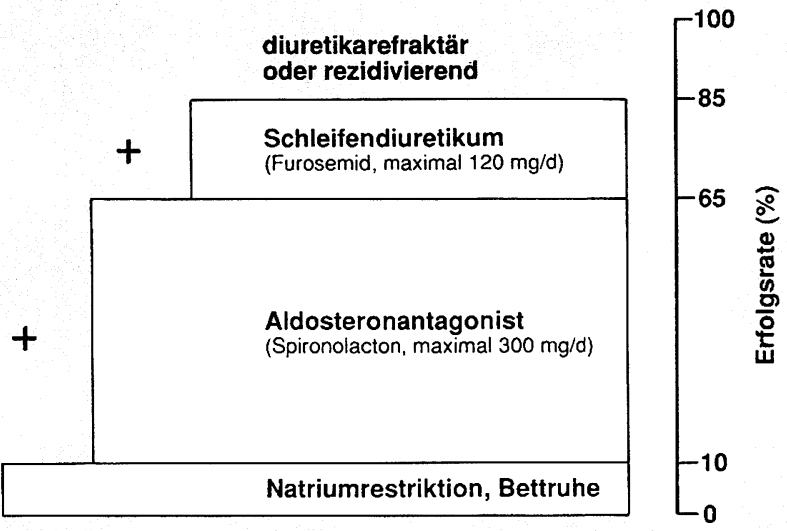

Abb. 2 Konventionelles Stufenschema der Aszitestherapie bei Leberzirrhose.

len einer negativen Natriumbilanz. Bettruhe führt zu einer Erhöhung des zentral effektiven Blutvolumens und verstärkt damit die Natriumausscheidung. Bei ungenügendem Ansprechen oder oft auch zugleich wird ein Aldosteronantagonist (im allgemeinen Spironolacton) und gegebenfalls zusätzlich ein Schleifendiuretikum (meist Furosemid) verabreicht $(8,20,28,30,31)$. Wenn über einige Tage weniger als durchschnittlich $200-300 \mathrm{~g}$ Aszites täglich mobilisiert werden kann, sollte die Diuretikadosis erhöht werden. Die Anfangsdosis von Spironolacton beträgt 50-100 mg täglich und kann alle 5 Tage um $50-100 \mathrm{mg}$ gesteigert werden (bis maximal $300 \mathrm{mg} / \mathrm{d}$ ), wenn die Natriumausscheidung nicht deutlich ansteigt. Die initiale Dosis von 20-40 mg Furosemid kann in Abständen von 1-2 Tagen um 20-40 mg erhöht werden (bis maximal $120 \mathrm{mg} / \mathrm{d}$ ); dabei ist eine über den Tag verteilte Dosierung zu empfehlen, um eine brüske Natriurese mit nachfolgendem »rebound «-Effekt und Abnahme der Natriumausscheidung nach hoher Einzeldosis $\mathrm{zu}$ vermeiden. Hierdurch kann bei etwa $85-90 \%$ der Patienten der Aszites ausgeschwemmt werden. Möglicherweise kann das neue Schleifendiuretikum Torasemid, das eine längere Halbwertszeit hat als Furosemid, die Ansprechrate erhöhen (3). So ist gezeigt worden, daß Torasemid bei Patienten mit schlechtem Ansprechen auf Furosemid noch eine deutliche Natriurese bewirken kann und auch bei Kombination mit einem Aldosteronantagonisten eine höhere Wirksamkeit als Furosemid aufweist $(9,15)$. Therapiestudien mit ausreichend langer Beobachtungszeit stehen jedoch für Torasemid noch aus. Der Wirkmechanismus des zur Aszitestherapie gelegentlich empfohlenen Diuretikums Xipamid ist nicht vollständig geklärt $(29,30)$; auch liegen zu wenige Daten über die Pharmakodynamik vor, um das Medikament für die Standardbehandlung des Aszites zu empfehlen. Amilorid scheint Aldosteronantagonisten unterlegen, insbesondere bei gesteigerter Aktivität des Renin-Aldosteron-Systems (1).

Von besonderer Bedeutung für die Durchführung der diuretischen Behandlung ist es, Kontraindikationen zu beachten und die Therapie sorgfältig zu überwachen; dies um so mehr, als bei dieser nicht kausalen Behandlung Nebenwirkungen unbedingt vermieden werden sollten. Als Kontraindikationen sind zu beachten:
- Elektrolytstörungen. - Bei ausgeprägter Hyponatriämie $(<125 \mathrm{mmol} / \mathrm{l})$ ist eine diuretische Behandlung im allgemeinen ungeeignet, da sich die Hyponatriämie dadurch verschlimmern kann. Häufig liegt eine Verdünnungshyponatriämie vor, die durch Einschränkung der Flüssigkeitszufuhr und nicht mit $\mathrm{NaCl}-S u b s t i t u t i o n$ behandelt werden sollte. Eine Hyperkaliämie wird oftmals durch ein Schleifendiuretikum gebessert, während einer Hypokaliämie mit Aldosteronantagonisten und Kaliumsubstitution begegnet werden kann.

- Eingeschränkte Nierenfunktion. - Bei deutlich eingeschränkter Nierenfunktion (Serum-Kreatinin $>2$ $\mathrm{mg} / \mathrm{dl}$ oder Serum-Harnstoff $>80 \mathrm{mg} / \mathrm{dl}$ oder Kreatinin-Clearance $<40 \mathrm{ml} / \mathrm{min}$ ) und Ausschluß einer organischen Nierenerkrankung handelt es sich im allgemeinen um eine prärenal bedingte Störung. Sie kann durch Gabe von Diuretika und Verminderung des Plasmavolumens verschlimmert werden. Außerdem kann es zu einer deutlichen Verlängerung der Halbwertszeit und damit schlechter Steuerbarkeit von Diuretika kommen (30). Der Versuch, bei schon reduzierter Nierenfunktion durch massive Erhöhung der Diuretikadosis eine Steigerung der Natriurese zu erzwingen, kann ein hepatorenales Syndrom auslösen. Vor dieser immer wieder zu beobachtenden iatrogenen Komplikation muß ausdrücklich gewarnt werden. Bei Patienten mit hepatorenalem Syndrom scheint eine temporäre Reduktion des renalen und Erhöhung des systemischen Gefäßwiderstands durch das Vasopressinanalogon Ornipressin (16) mit nachfolgender Verbesserung der Nierenfunktion möglich.

- Enzephalopathie. - Eine Enzephalopathie wird durch die diuretikainduzierte Abnahme des Plasmavolumens häufig verschlimmert und daher gemeinhin als relative Kontraindikation für eine diuretische Therapie betrachtet.

\section{Kontrolle der Therapie}

Bei der Überwachung der Therapie sind Parameter des therapeutischen Ansprechens und mögliche Nebenwirkungen zu beachten. $\mathrm{Zu}$ empfehlen ist die regelmäßige (zunächst mindestens jeden zweiten Tag) Messung von Körpergewicht und 24-Stunden-Urin (Natrium, Kalium, Kreatin-Clearance). Eine deutliche Zunahme der Natriumausscheidung im Urin ohne begleitende Abnahme des Körpergewichtes nach Beginn der diuretischen Therapie weist auf eine unzureichende diätetische Compliance des Patienten hin. Bestehen periphere Ödeme, können 1-2l Flüssigkeit täglich diuretisch mobilisiert werden, ohne daß es zu einer Beeinträchtigung des effektiven Blutvolumens kommt (22). Fehlen periphere Ödeme oder sind sie unter diuretischer Behandlung verschwunden, sollte eine tägliche $\mathrm{Ge}$ wichtsabnahme von $300-500 \mathrm{~g}$ angestrebt, von 500$700 \mathrm{~g}$ nicht überschritten werden. Mögliche Nebenwirkungen sind Tachykardie, Enzephalopathie oder Verminderung der Kreatinin-Clearance als Zeichen des zunehmenden Volumenmangels, ferner Elektrolytstörungen $(4,13,28)$. Zu ungenügendem Ansprechen auf diuretische Behandlung können neben der Noncompliance vor allem eine spontane bakterielle Peritonitis, eine gastrointestinale Blutung als Ursache eines Volumenman- 
gels und schließlich auch die iatrogene Zufuhr von Natrium (Antibiotika, Antacida) oder nicht-steroidalen Antiphlogistika (Verschlechterung der Nierenfunktion) führen.

Besondere therapeutische Schwierigkeiten bieten vor allem der ausgeprägte Aszites und der diuretikarefraktäre oder häufig rezidivierende Aszites.

\section{Ausgeprägter Aszites}

Die therapeutische Aszitespunktion (Parazentese) hat in den letzten Jahren zur Behandlung des ausgeprägten Aszites eine Renaissance erlebt. Nach der Entwicklung moderner Diuretika in den sechziger Jahren war man von der Parazentese abgekommen aus Furcht vor Nebenwirkungen wie Infektion, Niereninsuffizienz und Enzephalopathie (als Folge des durch Punktion induzierten Volumenmangels). Vor wenigen Jahren hatte jedoch eine Arbeitsgruppe aus Barcelona zeigen können, daß bei einer täglichen Punktion von 4-6l Aszites den Nebenwirkungen eines Volumenmangels durch die intravenöse Substitution von 40-60g Albumin vorgebeugt werden kann (12). Daraufhin wurden die therapeutischen Aszitespunktionen von 4-6l pro Sitzung bis zur Aszitesfreiheit bei gleichzeitiger Albuminsubstitution mit dem konventionellen diuretischen Vorgehen verglichen $(10,26)$. Beide Verfahren führten bei etwa $90 \%$ der Patienten zum Erfolg bei ähnlicher Nebenwirkungsrate. Allerdings wurden die Patienten nach Punktion deutlich schneller frei von Aszites (4-6 Tage) als unter Diuretikatherapie (19-25 Tage). Anschließend mußten natürlich auch die durch Parazentese behandelten $\mathrm{Pa}$ tienten wegen der Reakkumulation von Aszites auf $\mathrm{Di}$ uretika eingestellt werden. Spätere Untersuchungen der spanischen Arbeitsgruppe (35) ergaben, daß die totale Parazentese, das heißt das Ablassen der gesamten Aszitesflüssigkeit mit Albuminsubstitution nicht mehr Nebenwirkungen hatte als die wiederholte Punktion von nur 4-6l. Für das praktische Vorgehen können heute bei Fehlen von Kontraindikationen (Serum-Bilirubin $>10 \mathrm{mg} / \mathrm{dl}$, Prothrombinzeit $<40 \%$, Thrombozyten $<40000 / \mu l$, Serum-Kreatinin $>3 \mathrm{mg} / 100 \mathrm{ml}$, deutliche Enzephalopathie) tägliche Punktionen von bis zu 6 Litern Aszites mit Albuminsubstitution (8-10 g/l Aszites) zur Erzielung einer raschen Aszitesfreiheit empfohlen werden.

Verschiedene Untersuchungen widmeten sich der Frage, ob kostengünstigere Plasmaexpander anstelle von Albumin zur Volumensubstitution verwendet werden können $(21,27)$. Albumin ist etwa zehnmal teurer als äquivalente Mengen von Dextran oder einem Gelatinepräparat. Es zeigte sich, daß die PlasmaReninaktivität als Ausdruck des verminderten effektiven Blutvolumens bei Verwendung von Dextran, nicht aber von Albumin, bereits wenige Tage nach Punktion und Substitution deutlich angestiegen war. Dennoch ergaben sich keine Unterschiede in der Häufigkeit der Komplikationen, der Rehospitalisierung wegen eines ausgeprägten Aszites, der Rate der Niereninsuffizienz oder der Überlebenswahrscheinlichkeit. Die besten Ergebnisse in diesem Zusammenhang wurden jedoch bisher mit Albumin als Plasmaexpander erzielt.

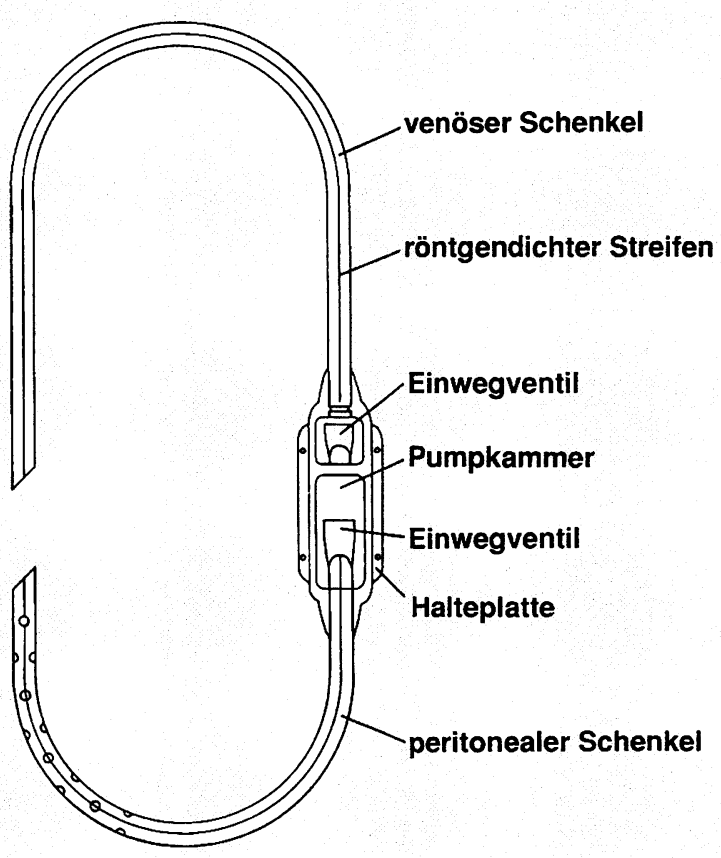

Abb. 3 Schematische Darstellung eines peritoneo-venösen Shunts (hier: Denver-Shunt mit Pumpkammer).

\section{Diuretikarefraktärer oder rezidivierender Aszites}

Eine allgemein anerkannte Definition des diuretikarefraktären oder rezidivierenden Aszites gibt es nicht. Meist spricht man von einem diuretikarefraktären Aszites, wenn trotz maximaler Diuretikadosis keine ausreichende Mobilisierung des Aszites erzielt werden kann oder wenn die Diuretika wegen Nebenwirkungen abgesetzt oder reduziert werden müssen und der Aszites dann wieder zunimmt. Wenn Patienten nach zunächst erfolgreicher Therapie sich immer wieder mit ausgeprägtem Aszites vorstellen (zum Beispiel mindestens dreimal innerhalb eines Jahres; 11), handelt es sich um einen rezidivierenden Aszites.

\section{Peritoneovenöser Shunt}

Zur Behandlung von Patienten mit diuretikarefraktärem Aszites war in den siebziger Jahren von Le Veen und Mitarbeitern (36) das Konzept des peritoneovenösen Shunts (PVS) entwickelt worden. Hierbei handelt es sich um ein subkutan zu implantierendes Silikonschlauchsystem, dessen peritonealer Schenkel im Aszites zu liegen kommt (Abb. 3). Durch eine am Rippenbogen $\mathrm{zu}$ befestigende Kammer mit Einwegventilen (beim Denver-Shunt durch manuelle Kompression pumpbar) ist der unidirektionale Fluß des Aszites sichergestellt. Der venöse Schenkel wird in die Vena jugularis eingebunden, so daß seine Spitze in der Vena cava superior vor dem Vorhof liegt. Aufgrund des Druckgradienten wird kontinuierlich Aszites in den zentralvenösen Kreislauf infundiert. Die Aszitesflüssigkeit dient somit zur Wiederauffüllung des verminderten zentral effektiven Blutvolumens. Verschiedene Untersuchungen ha- 


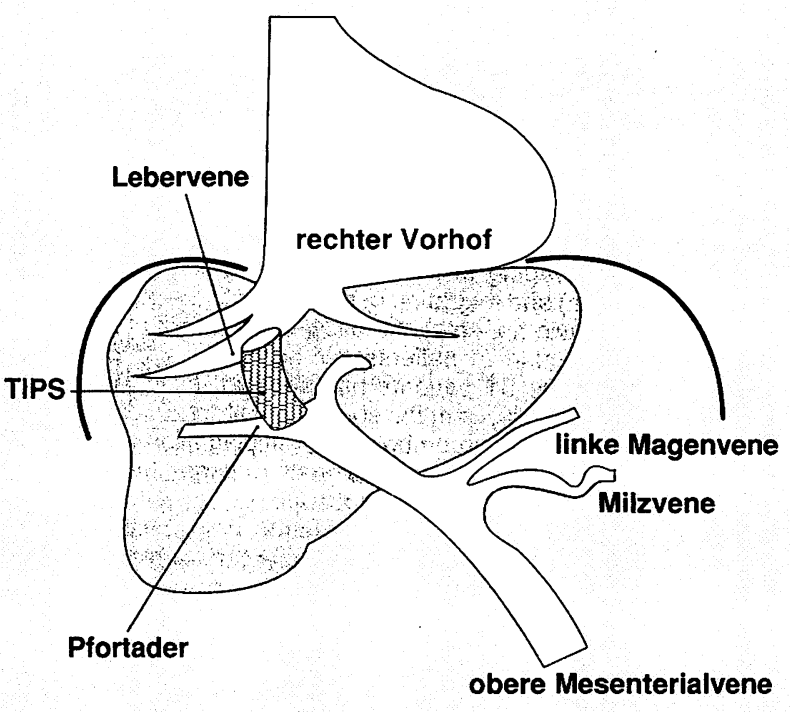

Abb. 4 Schematische Darstellung der Lage eines TIPS (transjugulärer intrahepatischer portosystemischer Shunt).

ben gezeigt, daß es in der Tat zu den erwünschten hämodynamischen und neurohumoralen Veränderungen mit Reduktion der Aktivierung des Renin-Aldosteron- und sympathikoadrenergen Systems und zu einer verstärkten Diurese und Natriuese kommt. Leider werden die günstigen Wirkungen des PVS von Komplikationen wie Gerinnungsstörung, Infektion, Sepsis und Thrombosierung des venösen Schenkels begleitet $(8,33)$. Vor allem das häufige Shunt-Versagen durch Verstopfen der Ventilkammer führte dazu, daß der initiale Enthusiasmus über dieses therapeutische Konzept verebbte.

Nach den ermutigenden Ergebnissen mit Parazentese und Albuminsubstitution bei ausgeprägtem Aszites lag es nahe, dieses Verfahren bei diuretikarefraktärem oder rezidivierendem Aszites mit der Implantation eines PVS zu vergleichen $(11,34)$. In einer prospektiven randomisierten Untersuchung (11) bei jeweils über 40 Patienten konnte der Aszites mit beiden Verfahren bei nahezu $90 \%$ der Patienten mobilisiert werden; in etwa je einem Viertel der Fälle traten Nebenwirkungen auf. Die 1-Jahres-Überlebensrate betrug bei beiden Verfahren etwa $50 \%$. Als wesentlicher Unterschied zeigte sich, daß in der Parazentesegruppe jeder Patient durchschnittlich dreimal pro Jahr wegen erneuten Auftretens von ausgeprägtem Aszites zur Behandlung aufgenommen werden mußte und daß die Patienten einen höheren Diuretikaverbrauch aufwiesen als in der PVSGruppe. In der Gruppe mit peritoneovenösem Shunt mußte sich jeder Patient nur einmal pro Jahr wegen Wiederauftretens von Aszites in der Klinik vorstellen; allerdings war bei nahezu der Hälfte dieser Patienten der Shunt verschlossen, was meistens eine Re-Intervention erforderte. Nach den Ergebnissen dieser Untersuchung kann die therapeutische Aszitespunktion mit Albuminsubstitution der Implantation eines peritoneovenösen Shunts zumindest als ebenbürtig erachtet werden. Allerdings ermöglichen beide Verfahren keineswegs eine zufriedenstellende Behandlung dieser Patienten.

\section{Portosystemische Shunts}

Bei der Anlage von portosystemischen Shunts kommt es zur Erniedrigung des portalvenösen Druckgradienten $(18 \mathrm{a}, 37)$; dabei handelt es sich eher um eine kausale Behandlungsmöglichkeit des Aszites als bei der Gabe von Diuretika. In der Tat wurde nach operativer Anlage von portosystemischen Anastomosen eine leichtere Therapierbarkeit des Aszites beobachtet. Eine beträchtliche perioperative Letalität, Verschlechterung der Leberfunktion, hohe Inzidenz einer ausgeprägten hepatischen Enzephalopathie und schließlich Erschwerung einer späteren Lebertransplantation haben aber zu einem starken Rückgang dieser Operationen geführt.

Durch einen transjugulären intrahepatischen portosystemischen Shunt (TIPS) kann ein portosystemischer Shunt ohne die Risiken einer Operation, ohne Nachteile für eine spätere Transplantation durch operative Veränderungen der Abdominalgefäße und mit dem Vorteil einer graduierbaren Drucksenkung erzielt werden $(5,24)$. Zur Technik der TIPS-Anlage (Abb. 4) sei auf den unlängst in dieser Wochenschrift erschienen Artikel von Rössle und Mitarbeitern (25) verwiesen. Durch individuelle Aufweitung des Shunt-Durchmessers (im allgemeinen 8 bis $12 \mathrm{~mm}$ ) kann der angestrebte Druckgradient erzielt und eventuell dem erhöhten Enzephalopathierisiko einzelner Patienten Rechnung getragen werden. Der von der Freiburger Gruppe mittlerweile über $300 \mathrm{mal}$ vorgenommene Eingriff wurde vor allem zur Prophylaxe von Rezidivblutungen aus gastroösophagealen Varizen eingesetzt. Dabei wurde zugleich häufig ein deutlicher Rückgang des Aszites bemerkt. Ochs und Mitarbeiter (18) haben deswegen bei 50 Patienten mit diuretikarefraktärem Aszites eine TIPS-Inplantation vorgenommen. Sie erzielten in $66 \%$ der Fälle eine totale Mobilisation und in $26 \%$ eine partielle Mobilisation des Aszites, nur in $8 \%$ stellte sich kein Erfolg ein. Die 1-JahresÜberlebensrate von $50 \%$ kann angesichts der Schwere des Krankheitsbildes dieser Patienten als günstig bezeichnet werden. Der Wert des TIPS im Vergleich zur Parazentese bei Patienten mit diuretikarefraktärem oder rezidivierendem Aszites kann augenblicklich noch nicht beurteilt werden und wird in prospektiven randomisierten Studien untersucht.

\section{Lebertransplantation}

Therapierefraktärer Aszites als alleinige Indikation zur Lebertransplantation wird im allgemeinen eine Ausnahme sein. Häufig befinden sich Patienten mit diuretikarefraktärem Aszites in einem weit fortgeschrittenen Stadium der Lebererkrankung (Child C) und damit in einem für eine Transplantation zu schlechten Allgemein- und Ernährungszustand. Bei Child-B-Patienten könnte das Auftreten von diuretikarefraktärem Aszites allerdings den Ausschlag zur Indikation einer Lebertransplantation geben. Der postoperative Erfolg nach Transplantation von Patienten mit ausgeprägtem Aszites unterscheidet sich nicht von dem bei Patienten mit geringem Aszites (17). 


\section{Schlußfolgerung}

Patienten mit »unkompliziertem« Aszites (keine Enzephalopathie, Elektrolytstörung oder deutlich eingeschränkte Nierenfunktion) können gut nach dem herkömmlichen Stufenschema aus diätetischer Natriumrestriktion, Aldosteronantagonisten und Schleifendiuretika behandelt werden. Eine anfänglich engmaschige Überwachung ist besonders wichtig, um Nebenwirkungen zu vermeiden. Bei ausgeprägtem Aszites empfiehlt sich zur initialen Behandlung die therapeutische Aszitespunktion von 4-6l täglich mit intravenöser Albuminsubstitution von 40-60 g und anschließender Einstellung auf Diuretika. Zur Behandlung des diuretikarefraktären oder rezidivierenden Aszites hat sich die therapeutische Aszitespunktion mit Albuminsubstitution der Implantation eines peritoneovenösen Shunts (PVS) als zumindest ebenbürtig erwiesen. Der transjuguläre intrahepatische portosystemische Shunt (TIPS) ist eine vielversprechende Neuentwicklung, deren therapeutischer Wert bei diuretikarefraktärem oder rezidivierendem Aszites in vergleichenden Studien untersucht werden muß. Die Lebertransplantation ist die kausale Behandlung des refraktären Aszites und sollte bei entsprechender Schwere der Lebererkrankung erwogen werden.

Für langjährige anregende Zusammenarbeit auf diesem Gebiet danken wir Prof. Dr. J. Schölmerich und Prof. Dr. D. Jüngst. Herrn Prof. Dr. T. Sauerbruch danken wir für seine kritische und anregende Durchsicht des Manuskriptes und H. Stippel für die Sekretariatsarbeiten. Die Untersuchungen der Autoren wurden durch die Deutsche Forschungsgemeinschaft unterstützt.

\section{Literatur}

1 Angeli, P., M. D. Pria, E. D. Bei, G. Albino, L. Caregaro, C. Merkel, G. Ceolotto, A. Gatta: Randomized clinical study of the efficacy of amiloride and potassium canrenoate in nonazotemic cirrhotic patients with ascites. Hepatology 19 (1994), 72-79.

2 Bernardi, M., C. Santini, F. Trevisani, M. Baraldini, A. Ligabue, G. Gasbarrini: Renal function impairment induced by change in posture in patients with cirrhosis and ascites. Gut 26 (1985), 629-635.

3 Broekhuysen, J., F. Deger, J. Douchamps, H. Ducarne, A. Herchuelz: Torasemide, a new potent diuretic. Double-blind comparison with furosemide. Europ. J. Pharmacol. 31, Suppl. (1986), 29-34.

4 Conn, H. O.: Diuresis of ascites. Fraught with or free from hazard. Gastroenterology 73 (1977), 619-621.

5 Conn, H. O.: Transjugular intrahepatic portal-systemic shunts. The state of the art. Hepatology 17 (1993), 148-158.

6 Fogel, M. R., V. K. Sawhney, E. A. Neal, R. G. Miller, C. M. Knauer, P. B. Gregory: Diuresis in the ascites patient. A randomized controlled trial of three regimens. J. clin. Gastroenterol. 3, Suppl. 1 (1981), 73-80.

7 Gerbes, A. L.: Pathophysiology of ascites formation. Hepatogastroenterology 38 (1991), 360-364.

8 Gerbes, A. L.: Medical treatment of ascites and hepatorenal syndrome in cirrhosis. In Rodes, J., V. Arroyo (Ed.): Therapy in Liver Disease (Ediciones Doyma: Barcelona 1992), 143-148.

9 Gerbes, A. L., U. Bertheau-Reith, C. Falkner, D. Jüngst, G. Paumgartner: Advantages of the new loop diuretic torasemide over furosemide in patients with cirrhosis with and without ascites. J. Hepatol. 17 (1993), 353-358.

10 Gines, P., V. Arroyo, E. Quintero, R. Planas, F. Bary, J. Cabrera, A. Rimola, J. Viver, J. Camps, W. Jimenez, R. Mastai, J. Gaya, J. Rodes: Comparison between paracentesis and diuretics in the treatment of cirrhotics with tense ascites. Results of a randomized study. Gastroenterology 93 (1987), 234-241.

11 Gines, P., V. Arroyo, V. Vargas, R. Planas, F. Casafont, J. Panes, M. Hoyos, L. Viladomiu, A. Rimola, R. Morillas, J. M. Salmeron, A. Gines, R. Estaban, J. Rodes: Paracentesis with intravenous infusion of albumin as compared with peritoneovenous shunting in cirrhosis with refractory ascites. New Engl. J. Med. 325 (1991), 829-835.

12 Gines, P., L. Tito, V. Arroyo, R. Planas, J. Panes, J. Viver, M. Torres, P. Humbert, A. Rimola, J. Llach, S. Badalamenti, W. Jimenez, J. Gaya, J. Rodes: Randomized comparative study of therapeutic paracentesis with and without albumin in cirrhosis. Gastroenterology 94 (1988), $1493-1502$.

13 Gregory, P. B., P. H. Broekelschen, M. D. Hill, A. B. Lipton, C. M. Knauer, M. Egger, R. Miller: Complications of diuresis in the alcoholic patient with ascites. A controlled trial. Gastroenterology 73 (1977), 534-538.

14 Karnad, D. R., P. Tembulkar, P. Abraham, N. K. Desai: Headdown tilt as a physiological diuretic in normal controls and in patients with fluid-retaining states. Lancet 1987/II, 525-527.

15 Laffi, G., F. Marra, G. Buzzelli, G. Azzena, E. Meacci, M. L. De Feo, G. La Villa, P. Gentilini: Comparison of the effects of torasemide and furosemide in nonazotemic cirrhotic patients with ascites. A randomized, double-blind study. Hepatology 13 (1991), 1101-1105.

16 Lenz, K., H. Hörtnagl, W. Druml, H. Reither, R. Schmid, B. Schneeweiss, A. Laggner, G. Grimm, A. L. Gerbes: Ornipressin in the treatment of functional renal failure in compensated liver cirrhosis. Effects on renal hemodynamics and atrial natriuretic factor. Gastroenterology 101 (1991), 1060-1067.

17 Neuhaus, P., W. O. Bechstein: Aszites und Lebertransplantation. Chirurg 64 (1993), 16-20.

18 Ochs, A., K. Haag, M. Sellinger, M. Langer, W. Gerok, M. Rössle: TIPS: Efficacy and survival in 49 patients with refractory and »untreatable« aszites. Hepatology 18 (1993), 292 (Abstract).

18a Paquet, K. J., J. Schölmerich: Pfortaderhochdruck (Karger: Basel-Freiburg 1994).

19 Paumgartner, G., A. L. Gerbes: Differentialdiagnose und pathophysiologische Grundlagen des Aszites. Chirurg 64 (1993), 1-6. 
20 Perez-Ayuso, R. M., V. Arroyo, R. Planas, J. Gaya, F. Bory, A. Rimola, F. Rivera, J. Rodes: Randomized comparative study of efficacy of furosemide versus spironolactone in nonazotemic cirrhosis with ascites. Gastroenterology 84 (1983), 961-968.

21 Planas, R., P. Gines, V. Arroyo, J. Llach, J. Panes, V. Vargas, J. M. Salmeron, A. Gines, C. Toledo, A. Rimola, W. Jimenez, M. Asbert, M. A. Gassull, J. Rodes: Dextran-70 versus albumin as plasma expanders in cirrhotic patients with tense ascites treated with total paracentesis. Results of a randomized study. Gastroenterology 99 (1990), 1736-1744.

22 Pockros, P. J., T. B. Reynolds: Rapid diuresis in patients with ascites from chronic liver disease. The importance of peripheral edema. Gastroenterology 90 (1986), 1827-1833.

23 Ring-Larsen, H., J. H. Henriksen, C. Wilken, J. Clausen, H. Pals, N. J. Christensen: Diuretic treatment in decompensated cirrhosis and congestive heart failure. Effect of posture. Brit. med. J. 292 (1986), $1351-1353$.

24 Rössle, M., K. Haag, A. Ochs, M. Sellinger, G. Nöldge, J. M. Perarnau, E. Berger, U. Blum, A. Gabelmann, K. Hauenstein, M. Langer, W. Gerok: The transjugular intrahepatic portosystemic stent-shunt procedure for variceal bleeding. New Engl. J. Med. 330 (1994), 165-171.

25 Rössle, M., K. Haag, A. Ochs, M. Sellinger, K. H. Hauenstein, M. Langer, W. Gerok: Transjugulärer intrahepatischer portosystemischer Stent-Shunt. Dtsch. med. Wschr. 119 (1994), 31-35.

26 Salerno, F., S. Badalamenti, P. Incerti, S. Tempini, B. Restelli, S. Bruno, G. Bellati, L. Roffi: Repeated paracentesis and iv albumin infusion to treat »tense « ascites in cirrhotic patients. A safe alternative therapy. J. Hepatol. 5 (1987), 102-108.

27 Salerno, F., S. Badalamenti, E. Lorenzano, P. Moser, P. Incerti: Randomized comparative study of hemaccel vs. albumin infusion after total paracentesis in cirrhotic patients with refractory ascites. Hepatology 13 (1991), 707-713.

28 Sherlock, S., S. Shaldon: The aetiology and management of ascites in patients with hepatic cirrhosis. A review. Gut 4 (1963), 95-105.

29 Schölmerich, J.: Aszites (Springer: Berlin 1991).

30 Schölmerich, J.: Strategies in the treatment of ascites. Hepatogastroenterology 38 (1991), 365-370.

31 Schölmerich, J., W. Gerok: Diuretikatherapie bei Leberzirrhose mit Aszites. Therapiewoche 35 (1985), 2185-2198.

32 Schrier, R. W., V. Arroyo, M. Bernardi, M. Epstein, J. H. Hendriksen, J. Rodes: Peripheral arterial vasodilation hypothesis. A proposal for the initiation of renal sodium and water retention in cirrhosis. Hepatology 8 (1988), 1151-1157.

33 Schumpelick, V., K.-P. Riesener: Peritoneo-venöser Shunt. Indikation, Grenzen, Ergebnisse. Chirurg 64 (1993), 11-15.

34 Stanley, M. M., S. Ochi, K. K. Lee, B. A. Nemchausky, H. B. Greenlee, J. I. Allen, M. J. Allen, R. A. Baum, T. R. Gadacz, D. S. Camara, J. A. Caruana, E. R. Schiff, A. S. Livingstone, A. K. Samanta, A. Z. Najem, M. E. Glick, G. L. Juler, N. Adham, J. D. Baker, G. D. Cain, P. H. Jordan, D. C. Wolf, J. T. Fulenwider, K. E. James: Peritoneovenous shunting as compared with medical treatment in patients with alcoholic cirrhosis and massive ascites. New Engl. J. Med. 321 (1989), 1632-1638.

35 Tito, L., P. Gines, V. Arroyo, R. Planas, J. Panes, A. Rimola, J. Llach, P. Humbert, S. Badalamenti, W. Jimenez, J. Rodes: Total paracentesis associated with intravenous albumin management of patients with cirrhosis and ascites. Gastroenterology 98 (1990), 146-151.

36 Le Veen, H. H., G. Christoudias, I. P. Moon, R. Luft, G. Falk, S. Grosberg: Peritoneovenous shunting for ascites. Ann. Surg. 180 (1974), 580-591

37 Warren, W. D.: Control of variceal bleeding. Reassessment of rationale. Amer. J. Surg. 145 (1983), 8-16.
Privatdozent Dr. A. L. Gerbes, Prof. Dr. G. Paumgartner Medizinische Klinik II der Universität

Marchioninistr. 15

81366 München 